\title{
EFFECTS OF FNA PRETREATMENT ON MUNICIPAL SOLID WASTE ACIDIFICATION FOR VOLATILE FATTY ACID PRODUCTION
}

\author{
by
}

Ama Dufie Kankam,

BSc Civil Engineering, Kwame Nkrumah University of Science and Technology, Kumasi, Ghana 2013

\author{
An MRP \\ presented to Ryerson University \\ in partial fulfillment of the \\ requirements for the degree of \\ Master of Engineering \\ in the program of Civil Engineering
}

Toronto, Ontario, Canada, 2018

(C) Ama Kankam, 2018 


\section{AUTHOR'S DECLARATION FOR ELECTRONIC SUBMISSION OF A MRP}

I hereby declare that I am the sole author of this MRP. This is a true copy of the MRP, including any required final revisions. I authorize Ryerson University to lend this MRP to other institutions or individuals for the purpose of scholarly research. I further authorize Ryerson University to reproduce this MRP by photocopying or by other means, in total or in part, at the request of other institutions or individuals for the purpose of scholarly research. I understand that my MRP may be made electronically available to the public. 
Effects of FNA pretreatment on municipal solid waste acidification for volatile fatty acid production

Master of Engineering, 2018

Ama Dufie Kankam, Civil Engineering, Ryerson University

\begin{abstract}
The current waste management processes only treat the waste to meet environmental regulations and neglects the potential benefits that can be obtained. There is a potential of viewing waste as feedstock for the production of value-added chemicals, which in turn reduces the quantities of waste. Anaerobic fermentation was carried out on TWAS under concentrations between 0 and 2.8 mg N/L FNA at a contact temperature of $25^{\circ} \mathrm{C}$ and $\mathrm{pH}$ of $5.5 \pm 0.2$ for contact time of 24 hours under Standard Retention Times of 1 day and 2 days. The FNA doses were; 0.35, 0.7, 1.4 and 2.8 mg N/L. A raw sample of TWAS without any pre- treatment, i.e. no FNA addition nor $\mathrm{pH}$ adjustment and a control sample (FNA $=0 \mathrm{mg} \mathrm{N} / \mathrm{L}$ and the $\mathrm{pH}$ was adjusted to 5.5 and kept at a constant temperature of $25^{\circ} \mathrm{C}$ for $24 \mathrm{hrs}$ without any FNA additions) was also included.
\end{abstract}




\section{Acknowledgements}

I would like to express my sincere gratitude and appreciation to my supervisor Dr. Elsayed Elbeshbishy whose endless support and guidance helped tremendously during this study. His initiative and guidance throughout this period were invaluable and made this process more fulfilling

I would also like to thank members of my research group Ana Rabii and Frances Okoye, whose invaluable experience, knowledge, direction and help is the reason I was able to complete this project. Their assistance in the laboratory portion of this research was priceless and our conversations helped during the long hours in the laboratory.

To my partner Tolulope Oludemi, who covered for me when I was unavailable, I say thank you. Going through this experience with you was wonderful. Our continuous "girl talk" and listening sessions to, from and during our laboratory sessions helped me more than you think.

Finally, to my family, I am grateful. My Auntie Gladys Osei who made sure I had a warm meal every time I got home at ungodly hours, my Auntie Grace Sereboe whose phone calls of encouragement helped me more than she knows, my sister Michelle Jubin who offered her home to me when commuting was a struggle, along with my other sisters Abena Kankam and Afua Kankam who were there for me and helped me when things were becoming overwhelming. I am also grateful to my parents, Mr. and Mrs. Kankam whose frequent long-distance calls of encouragement helped a whole lot. I truly appreciate you all. 


\section{Contents}

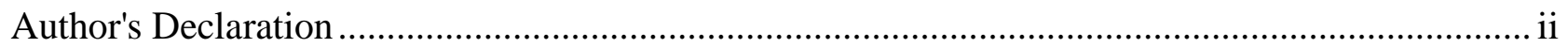

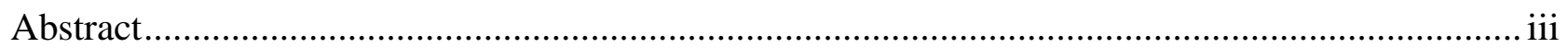

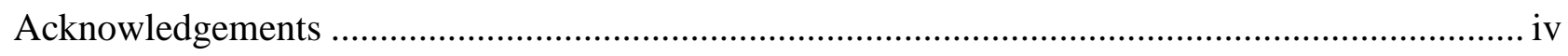

List of Tables .................................................................................................................... vii

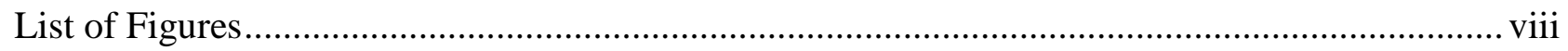

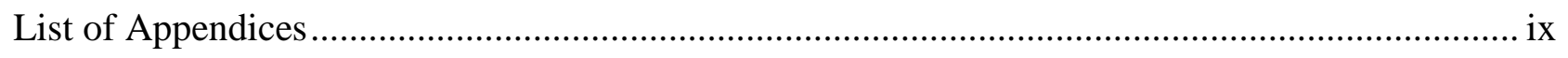

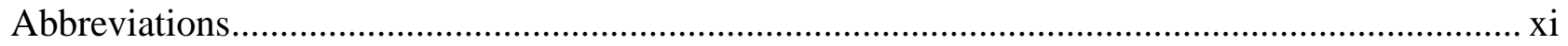

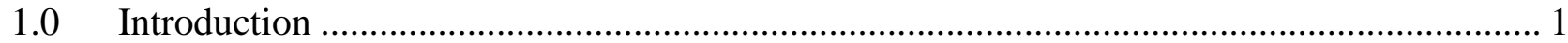

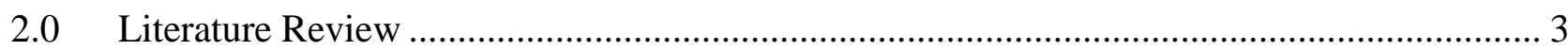

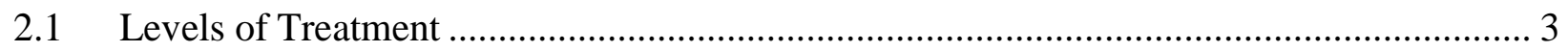

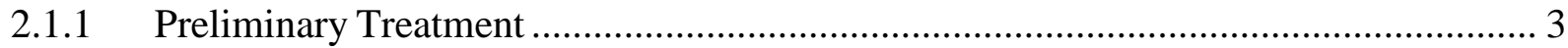

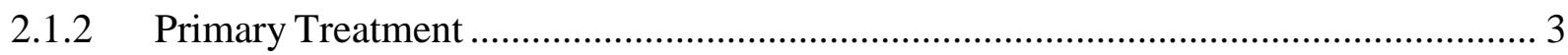

2.1.3 Secondary Treatment ………………………................................................ 3

2.1.4 Tertiary/Advanced Treatment ................................................................................. 4

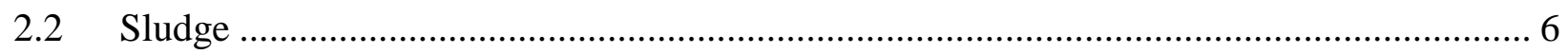

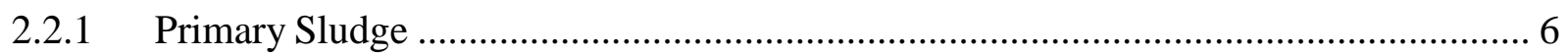

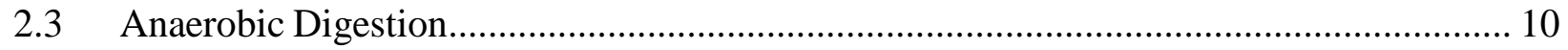

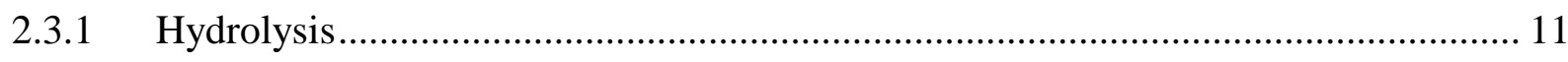

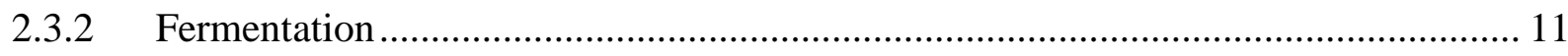

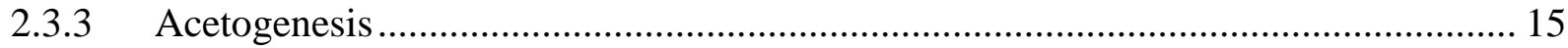

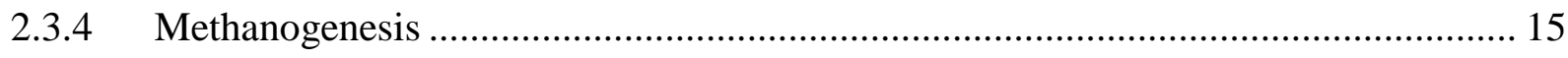

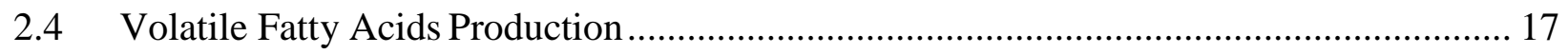

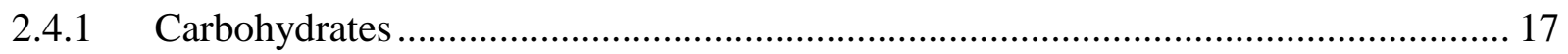

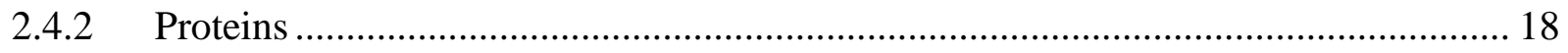

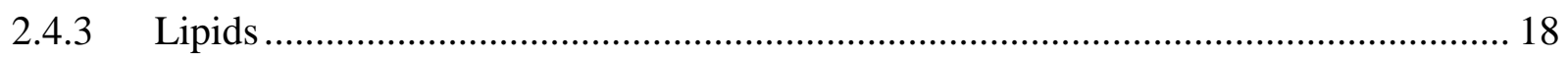

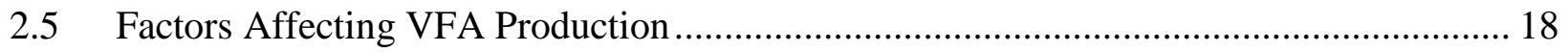

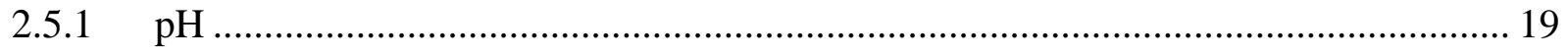

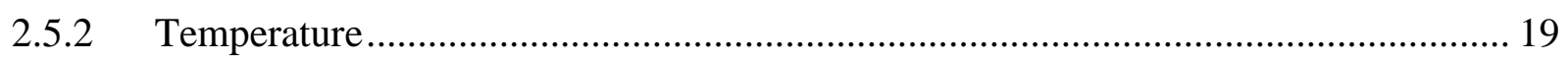

2.5.3 Retention Time ………………………………............................................. 19

2.5.4 Organic Loading Time....................................................................................... 19

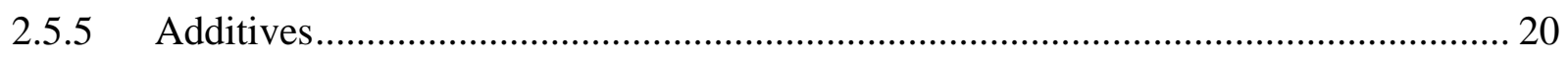

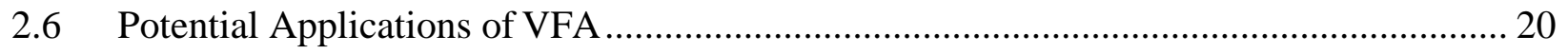




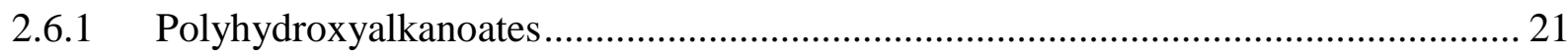

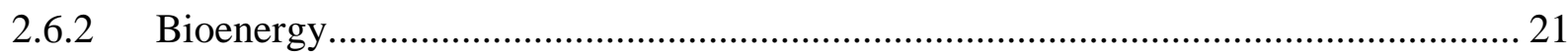

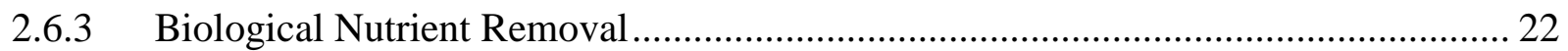

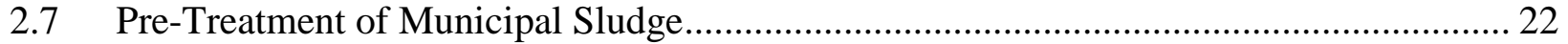

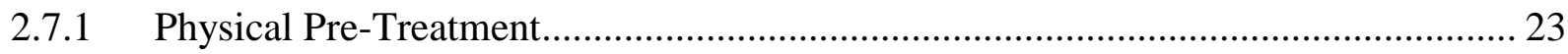

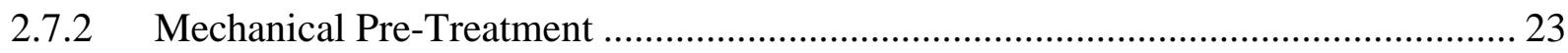

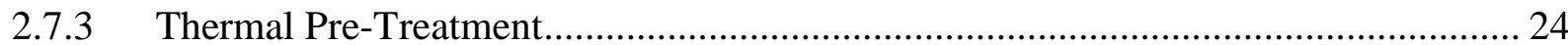

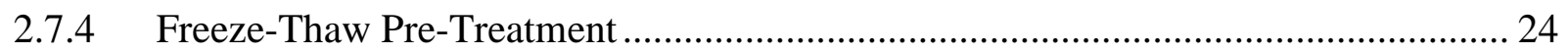

2.7.5 Biological Pre-Treatment .................................................................................... 24

2.7.6 Chemical Pre-Treatment .................................................................................. 24

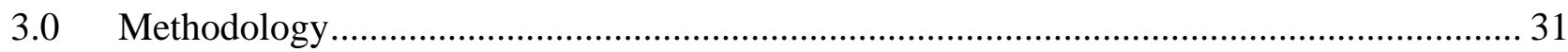

3.1 TWAS Pre-Treatment with FNA - Experiment Setup ...................................................... 31

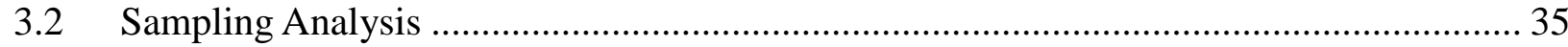

3.2.1 $\mathrm{pH}$

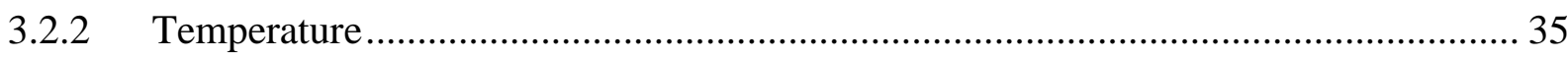

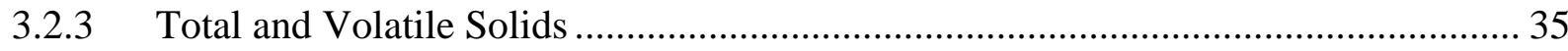

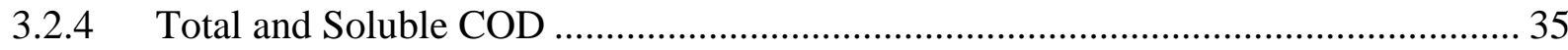

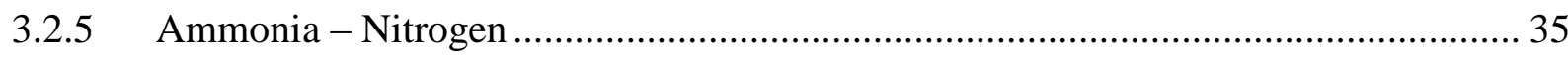

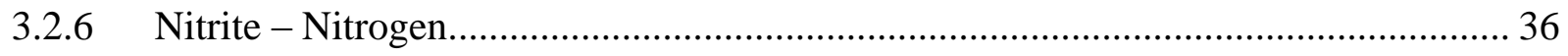

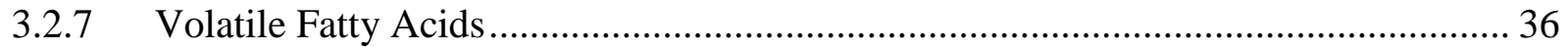

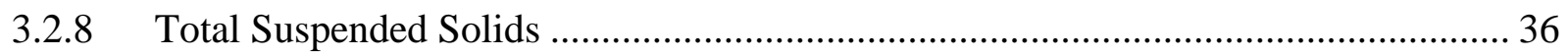

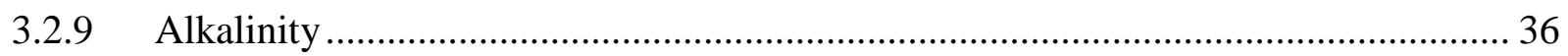

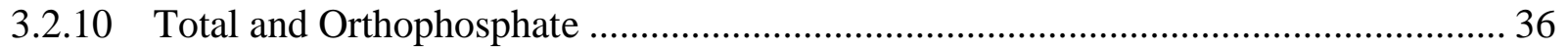

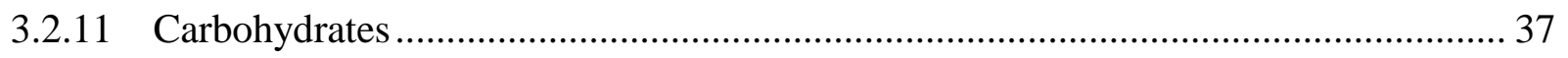

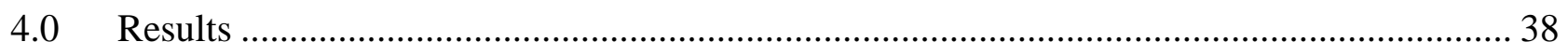

4.1 Effects of Pre-Treatment on Waste Characteristics ........................................................... 38

4.2 Acidification Test at SRT 1 Day …………………....................................................... 41

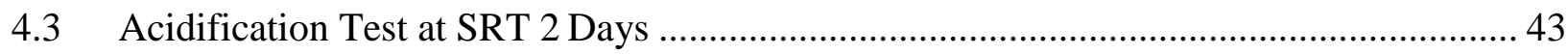

4.4 Comparing Acidification Tests (SRT 1-day vs SRT 2 day) ............................................... 45

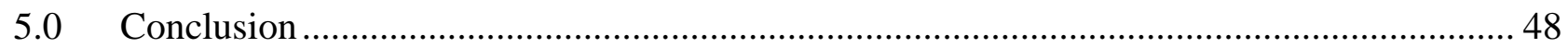

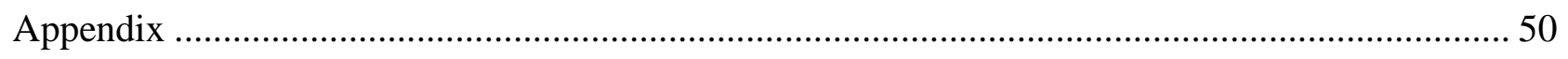

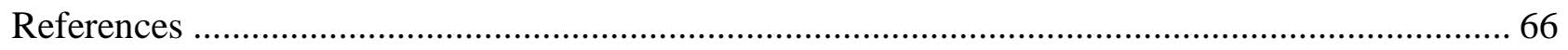




\section{List of Tables}

Table 2-1: Various wastes used for the production of VFA .................................................. 8

Table 3-1: Pre-treatment Characteristics of 2-day SRT ….................................................... 34

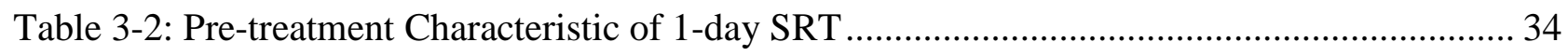

Table 4-1: Change in water quality parameters after pretreatment - SRT 1 day .......................... 42

Table 4-2: Change in water quality parameters after pretreatment - SRT 2 day ......................... 43 


\section{List of Figures}

Figure 2-1: Process Flow Diagram for Wastewater Treatment Plant............................................... 5

Figure 2-2: Sources and types of solids generated from wastewater treatment plants ....................... 9

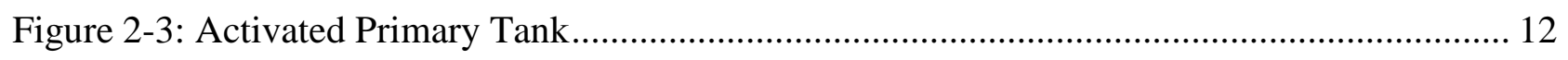

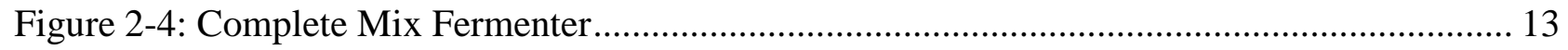

Figure 2-5: Single-Stage Fermenter/Thickener ………............................................................ 14

Figure 2-6: Two-Stage Complete Mix/Thickener Fermenter....................................................... 15

Figure 2-7: Schematic of the Stages of Anaerobic Digestion ........................................................ 16

Figure 2-8: Production of Volatile Fatty Acids from waste ........................................................... 18

Figure 3-1: Equipment set up for semi-continuous for anaerobic digestion .................................... 33

Figure 3-2: Grant OLS200 Shaking Water Bath .......................................................................... 34

Figure 4-1: Effects of pre-treatment on Soluble COD content ..................................................... 39

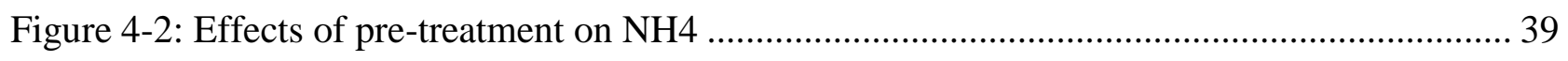

Figure 4-3: Effects of pre-treatment on Volatile Solids content ....................................................... 40

Figure 4-4: Percentage change in parameters compared to raw samples ......................................... 40

Figure 4-5: SCOD content with varying pre-treatment conditions - SRT 1 day .............................. 41

Figure 4-6: Ammonia content with varying pre-treatment conditions - SRT 1 day ........................ 42

Figure 4-7: Volatile Solids content with varying pre-treatment conditions - SRT 1 day ................. 43

Figure 4-8: SCOD content with varying pre-treatment conditions - SRT 2 days............................. 44

Figure 4-9: Ammonia content with varying pre-treatment conditions - SRT 2 days ....................... 44

Figure 4-10: Volatile Solids content with varying pre-treatment conditions - SRT 2 days ............ 45

Figure 4-11: SCOD test comparison: SRT 1-day vs SRT 2 days......................................................... 46

Figure 4-12: Ammonia test comparison: SRT 1-day vs SRT 2 days .............................................. 46

Figure 4-13: Volatile Solids test comparison: SRT 1-day vs SRT 2 days ....................................... 47 


\section{List of Appendices}

Table A-1: Table 6-2: Total Carbohydrate Concentration in 1-day ................................................ 50

Table A-2: Total Carbohydrate Concentration in 1-day ................................................................ 50

Table A-3: Total Carbohydrate Concentration in 2-day SRT ……….......................................... 51

Table A-4: Soluble Carbohydrate Concentration in 1-day SRT....................................................... 51

Table A-5: Soluble Carbohydrate Concentration in 1-day SRT......................................................... 52

Table A-6: Percentage Solubilization of Carbohydrates ................................................................. 52

Table A-7: Total Protein Concentration in 1-day SRT................................................................. 53

Table A-8: Total Protein Concentration in 2-day SRT ................................................................. 54

Table A-9: Soluble Protein Concentration in 1-day SRT ................................................................ 54

Table A-10: Soluble Protein Concentration in 2-day SRT .............................................................. 55

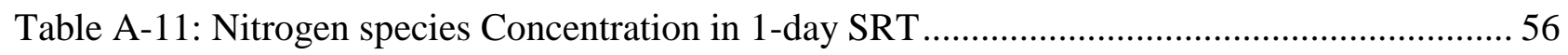

Table A-12: Nitrogen species Concentration in 2-day SRT ............................................................ 56

Table A-13: Ammonia Concentrations in 1-day and 2-day SRT .................................................... 58

Table A-14: Alkalinity Concentrations in 1-day and 2-day SRT ..................................................... 59

Table A-15: Total COD Concentrations in 1-day and 2-day SRT …………………..................... 60

Table A-16: Soluble COD Concentrations in 1-day and 2-day SRT ….................................................. 61

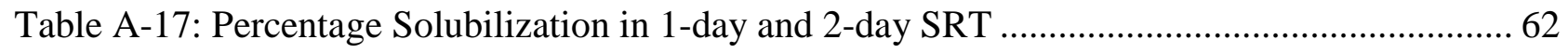

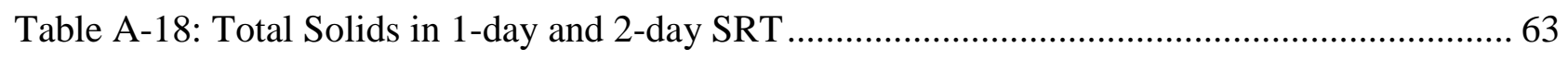

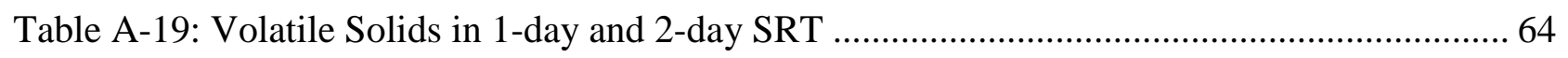

Table A-20: Total Phosphorus Concentrations in 1-day and 2-day SRT ........................................ 65

Figure A-1: Carbohydrate solubilization with varying pre-treatment conditions and varying SRT 53

Figure A-2: Protein solubilization with varying pre-treatment conditions and varying SRT .......... 55

Figure A-3: Nitrogen solubilization with varying pre-treatment conditions and varying SRT........ 57

Figure A-4: Total vs Soluble Nitrogen content (SRT 1 day) ........................................................... 57

Figure A-5: Total vs Soluble Nitrogen content (SRT 2 day) ………………………………….... 57

Figure A-6: Ammonia Concentrations in 1-day and 2-day SRT .................................................. 58

Figure A-7: Alkalinity Concentrations in 1-day and 2-day SRT..................................................... 59

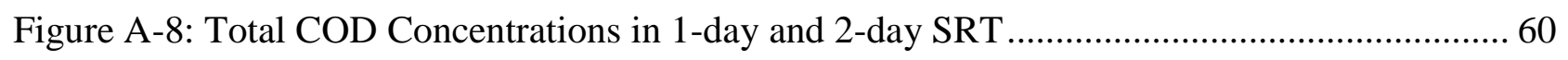

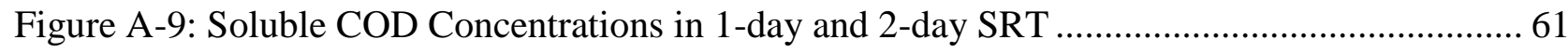

Figure A-10: Percentage Solubilization in 1-day and 2-day SRT .................................................... 62

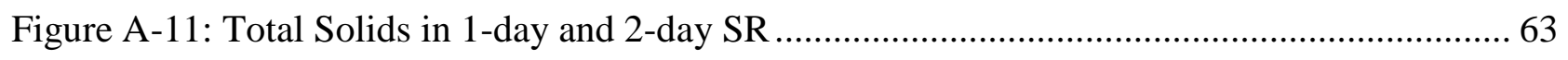

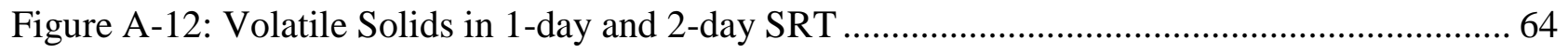


Figure A-13: Total Phosphorus Concentrations in 1-day and 2-day SRT. 


\begin{tabular}{lll} 
& & \multicolumn{1}{c}{ Abbreviations } \\
COD & - & Chemical Oxygen Demand \\
EBPR & - & Enhanced Biological Phosphorus Removal \\
FNA & - & Free Nitrous Acid \\
HPTH & - & High Pressure Thermal Hydrolysis \\
HRT & - & Hydraulic Retention Time \\
MFC & - & Microbial Fuel Cell \\
OLR & - & Organic Loading Rate \\
PHA & - & Polyhydroxyalkanoates \\
SDBS & - & Sodium Dodecylbenzene Sulfonate \\
SDS & - & Sodium Dodecyl Sulfate \\
STR & - & Solids Retention Time \\
VFA & - & Volatile Fatty Acids \\
VS & - & Volatile Solids \\
VSS & - & Volatile Suspended Solids \\
WAS & - & Waste Activated Sludge
\end{tabular}




\subsection{Introduction}

The world is facing severe pollution problems due to rapid population growth and the global economy. Pollution is caused by by-products of fossil fuels, which are increasing $\mathrm{CO}_{2}$ levels and impacting the greenhouse gas effect and global warming. Also, the energy demand, which is mostly dependent on reserves of fossil fuels, is on the rise. The current waste management processes only treat the waste to meet environmental regulations and neglects the potential of viewing waste as feedstock for the production of value-added chemicals, which in turn reduces the quantities of waste. Different ways to harness the energy from clean renewable sources are being developed via reliable energy sources. The focus of this paper is the production of VFA from primary sludge via fermentation.

VFA are short-chain fatty acids consisting of six or fewer carbon atoms which can be distilled at atmospheric pressure (American Public Health Association, 1992). They include fatty acids from $\mathrm{C}_{2}$ to $\mathrm{C}_{6}$ (acetic, propionic, butyric, etc.) which are produced either synthetically from fossil resources or as metabolic intermediates in acidification (fermentation) step of anaerobic digestion process (Reeta Rani Singhania, Anil Kumar Patel, Gwendoline Christophe, Pierre Fontanille, \& Christian Larroche, 2013) and are the building blocks of various organic compounds including alcohols, aldehydes, ketones, esters and olefins (Lee, Chua, Teoh, \& Ngoh, 2014). VFAs can be seen as an alternative to fossil fuels in the future and while serving as a platform for the production of biodiesel and biohydrogen, valuable chemical compounds which have diverse uses in the market (Lee, Chua, Teoh, \& Ngoh, 2014) Organic wastes are the substrate for VFA platform that is of low production cost, making VFA an intermediate product. VFAs could be obtained from lignocellulosic agro industrial wastes, sludge, and various biodegradable organic wastes as key intermediates through dark fermentation (Reeta Rani Singhania, Anil Kumar Patel, Gwendoline Christophe, Pierre Fontanille, \& Christian Larroche, 2013). In general, the production of VFA from waste is an anaerobic process involving hydrolysis and acidogenesis (the latter is also known as acidogenic fermentation or dark fermentation) with conditions of production including $\mathrm{pH}$, temperature, HRT, SRT, organic loading rate and additives (Lee, Chua, Teoh, \& Ngoh, 2014).

VFA is an inexpensive energy source that can be used for the generation of different forms of energy such as the production of biogas, under anaerobic conditions (Lee, Chua, Teoh, \& Ngoh, 2014). Microbial lipid can be synthesized from VFA's as a sensible alternative to edible lipids obtained from agricultural commodities. VFA is also an important carbon substrate which helps in the biological removal of nitrogen and phosphorus from wastewater (Jiang, Chen, \& 
Zhou, Effect of Sodium Dodecyl Sulfate on Waste Activated Sludge Hydrolysis and Acidification, 2007). VFAs offer several biotechnological applications such as; a substrate for various microbiological processes, e.g. for biodiesel production through the synthesis of single cell oils (SCO) by oleaginous yeast and can serve as substrate for microbial fuel cell (Lee, Chua, Teoh, \& Ngoh, 2014). These can serve as alternate carbon source for microbial biolipid, biohydrogen, MFC productions, mechanization and denitrification. Utilization of VFA for various purposes has opened a new avenue for waste treatment via anaerobic fermentation (Jiang, Chen, \& Zhou, Effect of Sodium Dodecyl Sulfate on Waste Activated Sludge Hydrolysis and Acidification, 2007). It offers an economically as well as ecologically sustainable platform for value addition. The objective of this report is to evaluate the effects of chemical pre-treatment on municipal solid waste acidification for VFA production.

Initially, the different wastes used in VFA production is presented. VFA production methods are introduced and the effects of main operational parameters, i.e., $\mathrm{pH}$, temperature, retention time and organic loading rate are discussed in a literature review. Chapter four discusses the methodology and procedures of the experiments that were undertaken in terms of pre-treatment, semi-continuous tests as well as analysis that were done. The results obtained are presented and discussed in chapter five. Finally, the report is concluded and summarized with the findings of the investigation. 


\subsection{Literature Review}

Wastewater treatment plants are designed to convert influent sewage into less polluted final effluent. This is done by removing biodegradable compounds, organic and inorganic particles by means of settling and filtration. Effluent standards are established by the Ministry of Environment and takes into account the ability of the receiving waters to assimilate the waste and the uses to which the receiving waters are put.

\subsection{Levels of Treatment}

The treatment process may be classified as "preliminary", "primary", "secondary" or "advanced" (tertiary). Under these processes, the methods of treatment in which the application of physical forces predominate are known as unit operations while those in which the removal of contaminants is brought about by chemical or reactions are known as unit processes (Boucher \& Van Eeden).

\subsubsection{Preliminary Treatment}

The purpose of preliminary treatment is to remove deleterious materials which damage equipment and interfere with the satisfactory operation of equipment such as rags, grits, sticks, floatable objects and large objects. The screening element is the first unit operation generally encountered and may be in the form of screens and/or bar racks.

\subsubsection{Primary Treatment}

In primary treatment, a physical operation, usually sedimentation, is used to remove the floating and settleable materials in wastewater. In a typical plant, in a primary settling process, the dry weight of the primary sludge solids is about $50 \%$ of that for the total sludge solids (Turovskiy \& Mathai, 2006). Primary treatment can usually be expected to remove 50 to $60 \%$ suspended solids and 25 to 35\% BOD (Elbeshbishy, 2016). The weight of sludge produced is directly proportional to the dry weight of solids concentration in the waste sludge stream (Boucher \& Van Eeden). In some plants, an advanced primary process is included where organic matter and suspended solids are removed, typically be chemical addition or filtration (Metcalf \& Eddy, 2002)

\subsubsection{Secondary Treatment}

During secondary treatment, biodegradable organic matter (soluble and suspended) and suspended solids are removed (Metcalf \& Eddy, 2002). Different biological process units are 
deployed in secondary treatment. Secondary treatment using conventional biological processes may remove up to $90 \%$ of suspended solids and 75 to $90 \%$ BOD. Disinfection is also typically included in the definition of conventional secondary treatment. In the absence of tertiary or advanced treatment, nutrients such as nitrogen and phosphorus is removed during secondary treatment.

\subsubsection{Tertiary/Advanced Treatment}

Additional configurations of unit operations and processes are used to remove residual suspended solids and other constituents that are not reduced significantly by the previous treatment processes and operations (Metcalf \& Eddy, 2002). Disinfection and nutrient removal is typically included a part of this treatment Tertiary or advanced treatment may be expected to remove over $95 \%$ of both $\mathrm{BOD}$ and $\mathrm{SS}$ in addition to reducing some undesirable chemicals (Elbeshbishy,2016) 


\section{PLANT WATER}

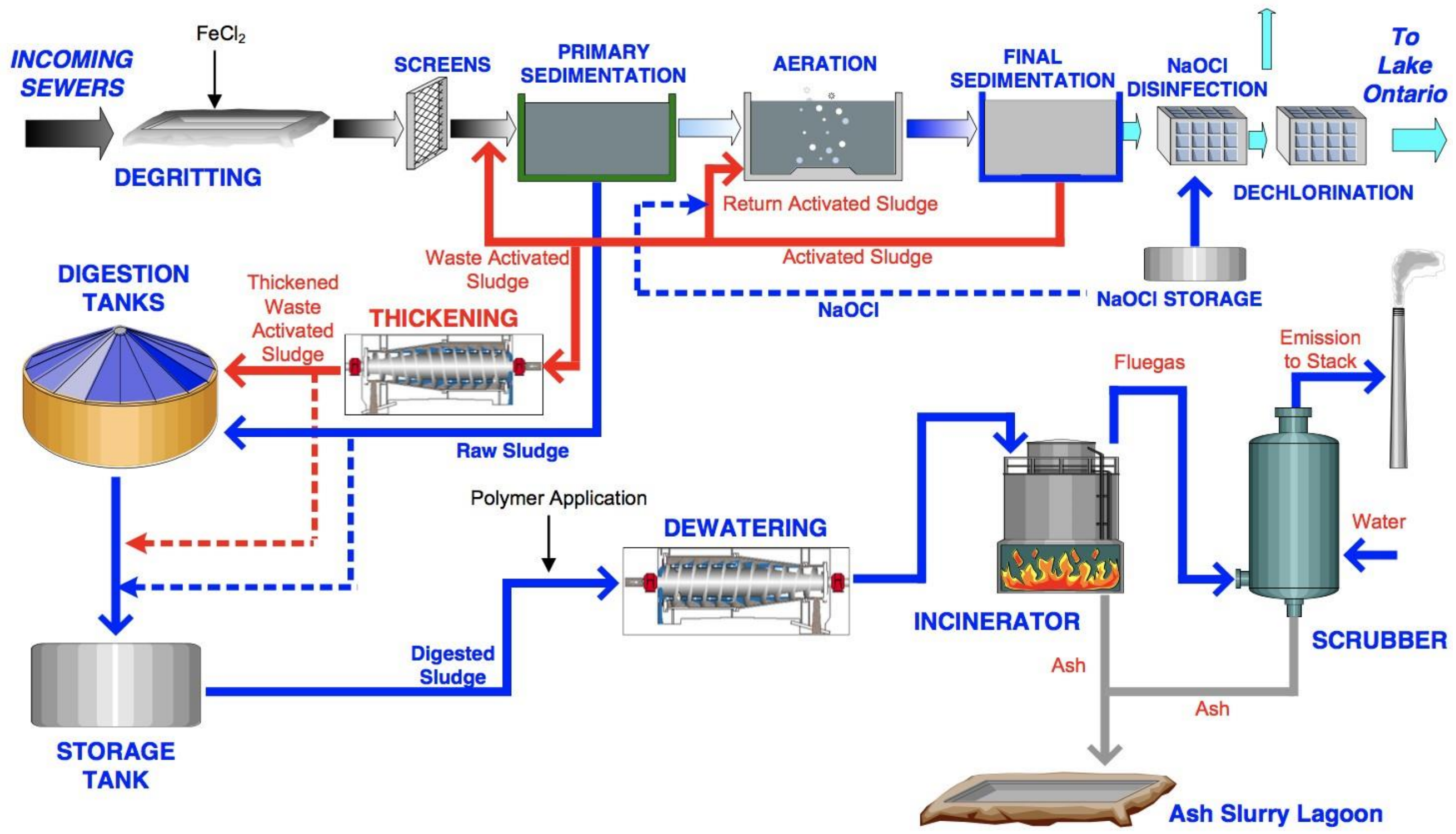

Figure 1: Process Flow Diagram for Wastewater Treatment Plant

Source: Adapted from Highland Creek Wastewater Treatment Plant 2017 


\subsection{Sludge}

Sewage sludge is a byproduct of municipal wastewater treatment and generated from primary and secondary sedimentation. Majority of wastewater treatment plants use the physical process of primary settling to remove settleable solids from raw wastewater (Boucher \& Van Eeden). Sludge is characterized by a high percentage of volatile solids and a high-water content, which results in extremely large volumes of sludge, even though the volume of sludge produced in a wastewater treatment plant only represents $1 \%$ of the volume of influent wastewater to be treated (Gupta, 2016).

Currently, sludge is reduced by reducing the volume of wet sludge or reducing the dry mass, with the main options for sludge disposal as agricultural use, landfill, incineration or composting. The disposal of raw sludge in landfill site is limited due gaseous emissions which contribute to global warming, hazardous compounds in leachate to be treated, nutrients and organic matter lost to recycling. For example, in Canada the sludge has to be dewatered, dried, incinerated and only the ash disposed of in landfills. Incineration is another final option for sludge disposal, but this process remains cost intensive and results in the loss of organic matter and nutrients. In many situations, a case-by-case solution is evaluated in order to optimize the choice and to avoid unexpected costs.

A variety of waste sludge are presented in Table 1. as potential substrates for VFA production. Among them, sludge, food waste, primary sludge and waste activated sludge. Primary sludge and WAS generated from municipal wastewater treatment plant is often studied for VFA production because of large volumes generated from the widespread use of biological wastewater treatment (Jiang, Chen, \& Zhou, Influence of Alkyl Sulfates on Waste Activated Sludge Fermentation at Ambient Temperature, 2007). They are rich in organic matter with the total COD ranging from $14,800 \mathrm{mg} / \mathrm{L}$ to $23,000 \mathrm{mg} / \mathrm{L}$ (Jiang, Chen, \& Zhou, Effect of Sodium Dodecyl Sulfate on Waste Activated Sludge Hydrolysis and Acidification, 2007) (Jiang, Chen, Zhou, \& Gu, Biological Short- Chain Fatty Acids (SCFAs) Production from Waste-Activated Sludge Affected by Surfactant, 2007) making them promising wastes for the production of VFA.

\subsubsection{Primary Sludge}

Primary sludge (also known as raw sludge) is obtained from primary sedimentation tanks. It contains all the readily settleable matter from wastewater with $1 \%$ collected as scum; rich in organic matter (mainly faecal matter and food scraps) (Boucher \& Van Eeden). In its fresh state, it is grey in colour with a heavy faecal odour. Both colour and odour intensify on prolonged 
storage under anoxic conditions, leading to putrefaction and extremely unpleasant odour. It is fibrous and coarse in nature with $60 \%$ - $80 \%$ representing volatile solids (Boucher \& Van Eeden)

\subsubsection{Primary Sludge Formation}

Most wastewater treatment plants use the physical process of primary settling to remove settleable solids from raw wastewater. In some treatment plants, grit (heavy and coarse materials such as sand and similar inorganic matter) is settled in the primary clarifiers along with the primary sludge. The grit is then separated from the sludge in vortex-type grit separators. The production of primary sludge is related to the amount of settleable solids in raw wastewater whose solids content is typically of 50-60 gTSS PE-1 d-1 or 110-170 gTSS/m3 of treated wastewater (Tchobanoglous, Burton, Stensel, \& Metcalf \& Eddy, 2002) It can vary typically form 800 to 2500lb/MG of wastewater (Turovskiy \& Mathai, 2006) 


\section{Type of Wastes}

Organic Content

(mg COD/L)
Operating Conditions

\begin{tabular}{|c|c|c|c|}
\hline \multirow[t]{5}{*}{ Waste Activated Sludge } & $5470^{\mathrm{a}}$ & $\mathrm{pH} 11,60^{\circ} \mathrm{C}, 7 \mathrm{~d}, 0.02 \mathrm{~g} \mathrm{SDBS}^{\mathrm{b}} / \mathrm{g}$ VSS & $2561 \mathrm{mg}$ TOC/L \\
\hline & 18,657 & $\mathrm{pH} 9,35{ }^{\circ} \mathrm{C}, 5 \mathrm{~d}$ & $298 \mathrm{mg} \mathrm{COD} / \mathrm{g}$ VSS \\
\hline & 18,657 & $\mathrm{pH} 8,55^{\circ} \mathrm{C}, 9 \mathrm{~d}$ & $368 \mathrm{mg}$ COD/g VSS \\
\hline & 14,878 & $21{ }^{\circ} \mathrm{C}, 6 \mathrm{~d}$ & $339 \mathrm{mg} \mathrm{COD} / \mathrm{L}$ \\
\hline & 14,890 & $21{ }^{\circ} \mathrm{C}, 6 \mathrm{~d}$ & $191 \mathrm{mg}$ COD/L \\
\hline \multirow[t]{3}{*}{ Primary Sludge } & 22,838 & $21{ }^{\circ} \mathrm{C}, 6 \mathrm{~d}$ & $85 \mathrm{mg} \mathrm{COD} / \mathrm{g}$ VSS \\
\hline & 20,631 & $\mathrm{pH} 10$, room temp., $5 \mathrm{~d}$ & $60 \mathrm{mg} \mathrm{COD} / \mathrm{g} \mathrm{VSS} / \mathrm{d}$ \\
\hline & $343^{c}$ & $25^{\circ} \mathrm{C}, \mathrm{HRT} 1.25 \mathrm{~d}, \mathrm{SRT} 10 \mathrm{~d}$ & $31 \mathrm{mg} / \mathrm{g} \mathrm{VSS} / \mathrm{d}$ \\
\hline \multirow{2}{*}{$\begin{array}{l}\text { Primary Sludge }+ \text { Waste } \\
\text { Activated Sludge }\end{array}$} & 22,256 & $21^{\circ} \mathrm{C}, 6 \mathrm{~d}$, mixing ratio $1: 1$ (on VSS basis) & $118 \mathrm{mg} \mathrm{COD} / \mathrm{g} \mathrm{VSS}$ \\
\hline & 15,480 & $37^{\circ} \mathrm{C}, \mathrm{HRT}=\mathrm{SRT} 5 \mathrm{~d}$ & $114 \mathrm{mg} \mathrm{COD} / \mathrm{g}$ VSS \\
\hline \multirow[t]{2}{*}{$\begin{array}{l}\text { Primary Sludge }+ \text { Starch Rich } \\
\text { Wastewater }\end{array}$} & $545^{\mathrm{c}}$ & $\begin{array}{c}22^{\circ} \mathrm{C}, \text { HRT } 0.75 \mathrm{~d}, \text { SRT } 7 \mathrm{~d} \text {, mixing ratio } 1: 1 \text { (on } \\
\text { volume basis) }\end{array}$ & $57 \mathrm{mg} / \mathrm{g} \mathrm{VSS} / \mathrm{d}$ \\
\hline & $392^{c}$ & $25^{\circ} \mathrm{C}$, HRT $1.25 \mathrm{~d}$, SRT $10 \mathrm{~d}$, mixing ratio $1: 1$ & $45 \mathrm{mg} / \mathrm{g} \mathrm{VSS} / \mathrm{d}$ \\
\hline \multirow[t]{3}{*}{ Food Waste + Sludge } & Not available & $\begin{array}{c}\mathrm{pH} 6.99,35{ }^{\circ} \mathrm{C}, \mathrm{HRT}=\mathrm{SRT} 8.92 \mathrm{~d}, \text { OLR } \\
8.31 \mathrm{~g} \mathrm{VSS} / \mathrm{L} / \mathrm{d}, 88 \% \text { food waste }+12 \% \text { dewatered } \\
\text { sludge (on VSS basis) }\end{array}$ & $29,100 \mathrm{mg} \mathrm{COD} / \mathrm{L}$ \\
\hline & 22,125 & $\mathrm{pH} 8,20^{\circ} \mathrm{C}, 4 \mathrm{~d}$ & 8237 mg COD/L \\
\hline & 29,050 & $\begin{array}{c}\mathrm{pH} 5.5-5.9,18{ }^{\circ} \mathrm{C}, \mathrm{HRT} 1 \mathrm{~d}, 25 \% \text { food waste }+75 \% \\
\text { primary sludge (on weight basis) }\end{array}$ & $3610 \mathrm{mg} / \mathrm{L}$ \\
\hline
\end{tabular}

\section{VFA Production}

\section{Performance}

Table 2-1: Various wastes used for the production of VFA Source: Adapted from (Lee, Chua, Teoh, \& Ngoh, 2014) 


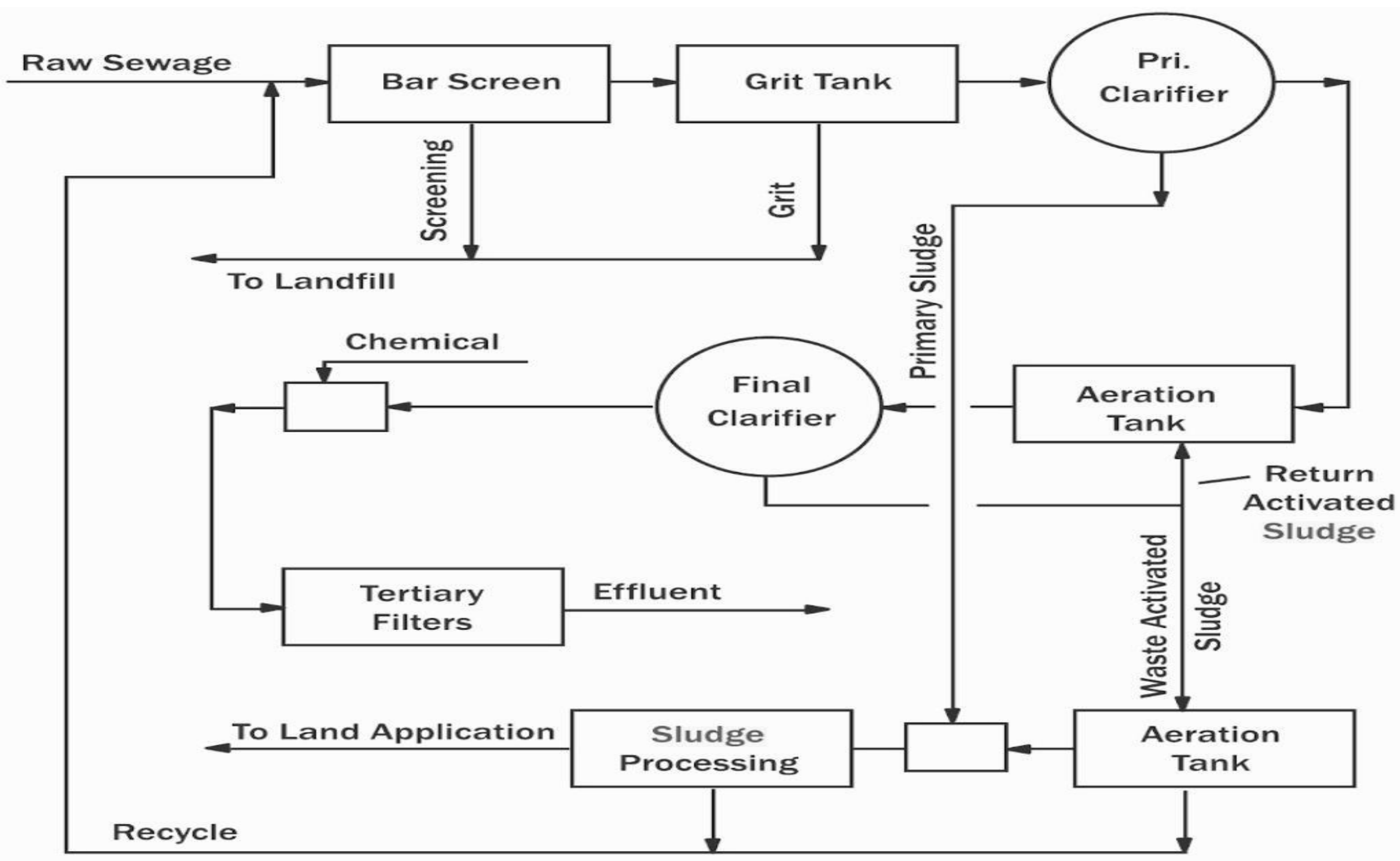

Figure 2: Sources and types of solids generated from wastewater treatment plants Source: (Turovskiy \& Mathai, 2006) 


\subsection{Anaerobic Digestion}

Anaerobic digestion is the biological degradation of solid waste under anaerobic conditions, meaning that no oxygen is present, by converting solids are to non-cellular end products (Boardman, 2003). In the anaerobic digestion of sludge, the goals are to reduce sludge volume, insure the remaining solids are chemically stable, reduce disease-causing pathogens and enhance the effectiveness of subsequent dewatering methods, sometimes recovering methane as a source of energy (Boardman, 2003).

Anaerobic digestion can be commonly applied to high-load wastewater treatment because anaerobic treatment has the following benefits compared with aerobic treatment: production of excess sludge is kept at a minimum with low minimum operation and maintenance requirements, and low energy demand without aeration and production of biogas with a renewable energy content, which can be used as a fuel (Kurniawan, Kwon, Shin, Hur, \& Cho, 2016). The states of anaerobic digestion process are shown in Figure 4. The processes involved in VFA production are hydrolysis and fermentation, as shown in the diagram.

The microorganisms that digest the sludge anaerobically are often classified in two groups, the acid formers and the methane formers. The acid formers are microbes that create, among others, acetic and propionic acids from the sludge. The methane formers convert the acids and by-products resulting from prior metabolic steps (e.g., alcohols, hydrogen, and carbon dioxide) to methane (Boardman, 2003). (Gujer \& Zehnder, 1983) presented a more detailed sixstep process for anaerobic digestion, as follows:

- Hydrolysis of biopolymers (carbohydrates, proteins and lipids).

- Fermentation of amino acids and sugars.

- Anaerobic oxidation of long chain fatty acids and alcohol.

- Anaerobic oxidation of intermediatory products such as VFAs (except acetate).

- Conversion of acetate to methane.

- Conversion of hydrogen to methane.

In very general terms, the overall biochemical reaction is simplified to:

$$
\text { Organic Material } \rightarrow \quad \mathrm{CH}_{4}+\mathrm{CO}_{2}+\mathrm{H}_{2}+\mathrm{NH}_{3}+\mathrm{H}_{2} \mathrm{~S} \quad \text { Equation (1) }
$$




\subsubsection{Hydrolysis}

This is the first, rate-limiting step in anaerobic degradation. The term hydrolysis is used for the degradation of a defined particulate or macromolecular substrate to its soluble monomers (IWA Task Group for Mathematical Modelling of Anaerobic Digestion Processes, 2002). During hydrolysis, complex insoluble organic polymers such as carbohydrates, cellulose, proteins and fats, are broken down and liquefied by extracellular enzymes produced by hydrolytic bacteria (Evans, 2001). Proteins are converted to amino acids, fats into long-chain fatty acids and carbohydrates into simple sugars, making them more easily available for use by the acidogenic bacteria in the subsequent stage. The rate at which hydrolysis takes place is affected by substrate availability, bacterial population density, temperature and $\mathrm{pH}$ (Evans, 2001) Hydrolysis can be presented by one of two conceptual models:

- The organisms secrete enzymes to the bulk liquid where they absorb onto a particle or react with a soluble substrate.

- The organisms attach to the particle, produce enzymes in the vicinity of the particle and benefit from soluble products released by the enzymatic reaction. (IWA Task Group for Mathematical Modelling of Anaerobic Digestion Processes, 2002)

\subsubsection{Fermentation}

Also known as acidogenesis, this is the most rapid conversion step in the anaerobic food chain. The fermentation process is a form of energy-yielding microbial metabolism which utilizes microorganisms to convert substrates into various products, with any material that supports microbial growth being a potential substrate (Chisti, 1999). Simply put, it is a process for the production of product by the mass culture of an organism (Stanbury, Whitaker, \& Hall, 1995). The two components to be considered in the fermentation process are the organizms that biosynthesize the molecule of interest and the surrounding environment that supports growth and metabolism. All these aspects need to be controlled for efficiency. The compounds produced include volatile fatty acids, alcohols, lactic acid, $\mathrm{CO}_{2}, \mathrm{H}_{2}, \mathrm{NH}_{3}$ and $\mathrm{H}_{2} \mathrm{~S}$ as well as new cell material (Henze, et al., 2008). Neutral compounds such as sugar and protein are converted into VFAs and carbonic acid, being the main end products. This document will focus more on dark (anaerobic) fermentation.

Primary sludge fermentation is an efficient way to increase the VFA content of the 
influent even and likely to have lower operational costs than supplementing external sources and provides the required retention time \& mixing for VFA production not likely in Anaerobic Zones (Lei, Rabinowitz, Leaf, Bishop, \& Kresge, 2009). The acid- phase digestion products may be highly influenced by operational parameters such as hydraulic retention time, solids retention time and environmental factors such as $\mathrm{pH}$, temperature, oxidation-reduction potential, reactor configuration, wastewater characteristics, and available trace minerals (Elefsiniotis \& Oldham, 1993)

\subsubsection{Common Primary Sludge Fermentation Processes}

These processes use gravity liquid-solids separation (Grady, Jr., Daigger, Love, \& Filipe, 2011). The choice of configuration is primarily dependent on the VFA requirement and the structures available for conversion in existing retrofitted plants (Atherton, 1995).

\subsection{Activated Primary Clarifier}

The underflow from the primary clarifier is recycled to the inlet of the clarifier, either directly or through a gravity thickener, maintaining a thick sludge blanket in the primary clarifier (Atherton, 1995). The recycling has the following purpose: maintaining the sludge blanket and elutriating the acids. A portion of the sludge is wasted from the primary clarifier to sludge handling facilities (Lei, Rabinowitz, Leaf, Bishop, \& Kresge, 2009).

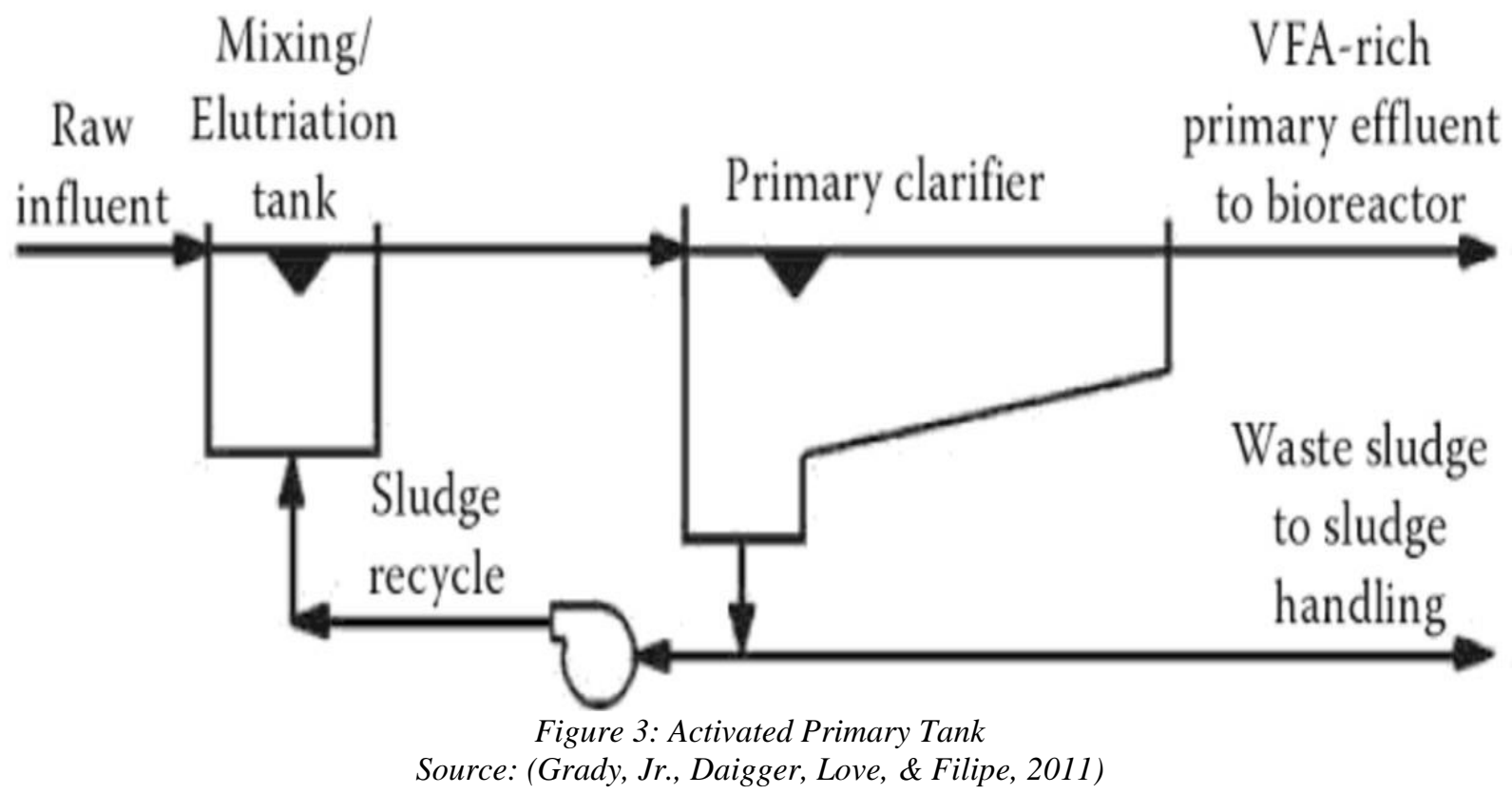




\subsection{Complete-Mix Fermenter}

A portion of the fermenter mixed liquor is returned to the primary clarifier where VFAs are removed by the wastewater flow and fermented solids are wasted to control the SRT (Grady, Jr., Daigger, Love, \& Filipe, 2011). The VFA formed is elutriated in primary effluent to bioreactors. No thickening occurs, with higher recycle and wasting flows (Lei, Rabinowitz, Leaf, Bishop, \& Kresge, 2009)

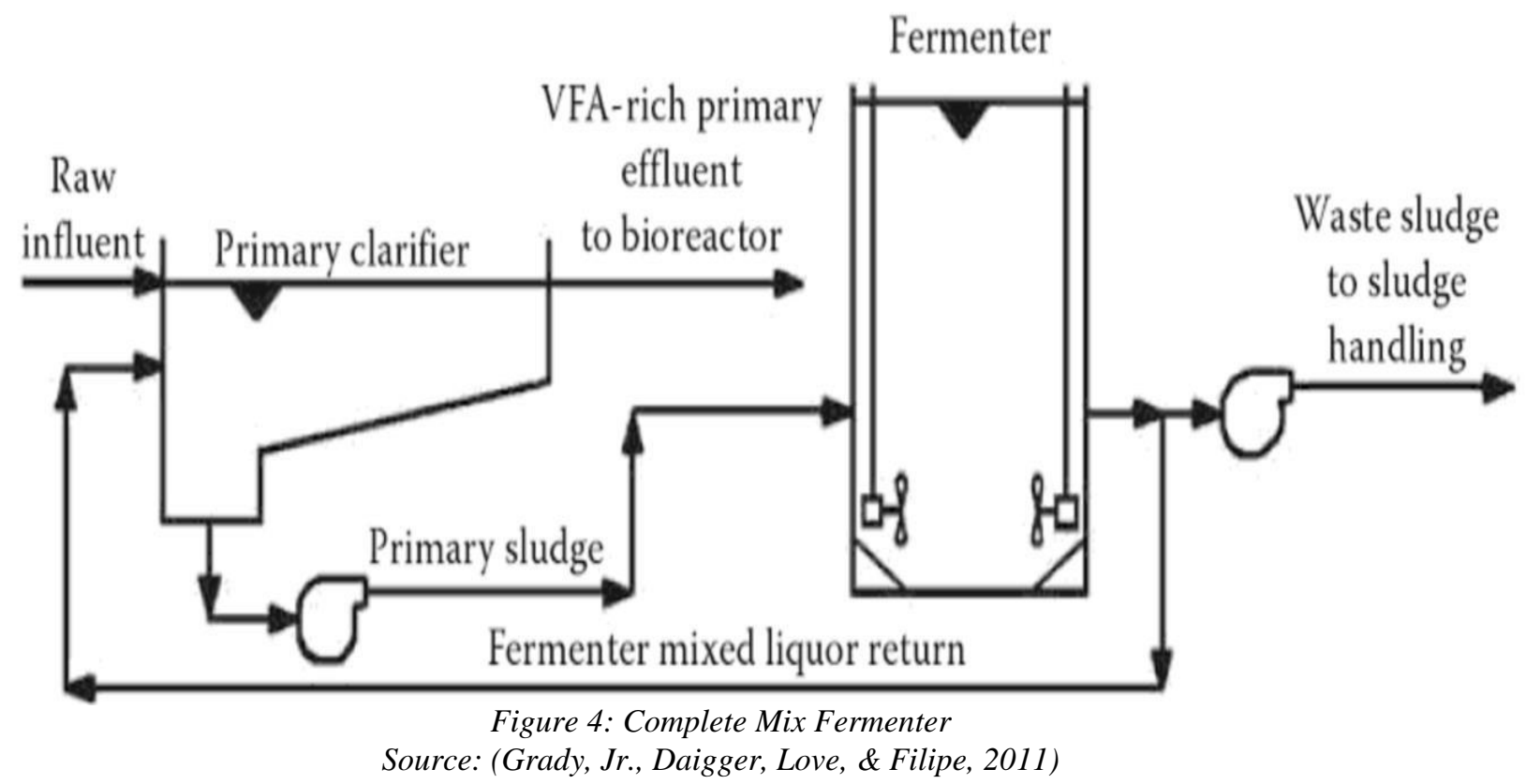

\subsection{Single-Stage Fermenter/Thickener}

In the single-stage fermenter/thickener, primary solids are added to an oversized gravity thickener where both solids fermentation and liquid-solids separation occur using a static fermenter for fermentation and thickening. Solids wasting is controlled to achieve the desired SRT, and VFAs are removed in the overflow (Grady, Jr., Daigger, Love, \& Filipe, 2011). There is no sludge recycle with an independent primary clarifier and fermenter/thickener. The sludge blanket depth and solids concentrations are frequently measured (Lei, Rabinowitz, Leaf, Bishop, \& Kresge, 2009). 


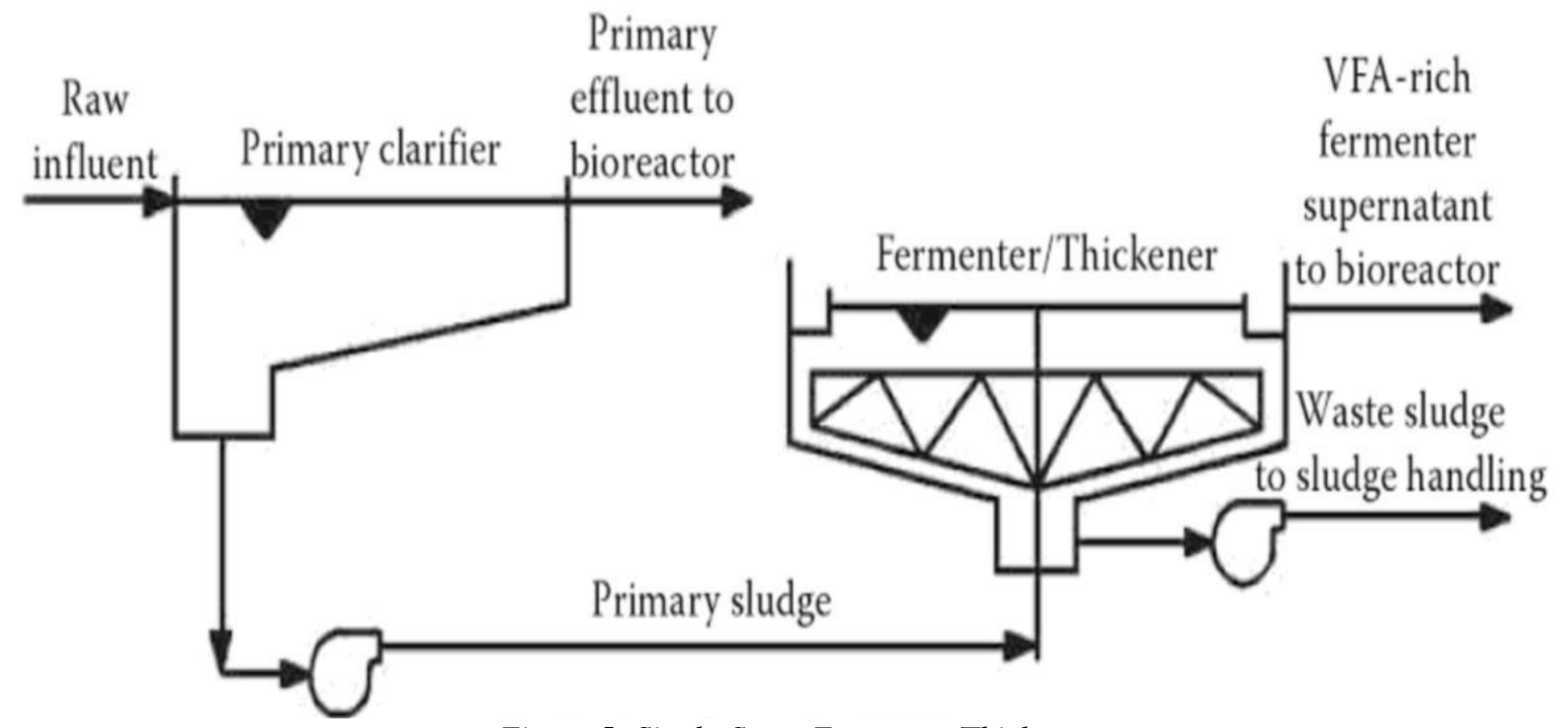

Figure 5: Single-Stage Fermenter/Thickener

Source: (Grady, Jr., Daigger, Love, \& Filipe 2011)

\subsection{Two-Stage Complete- Mix Fermenter/Thickener}

The fermentation and solids thickening steps are separated into two unit operations; complete-mix fermenter and gravity thickener (Lei, Rabinowitz, Leaf, Bishop, \& Kresge, 2009). Optional primary effluent addition point provides operational flexibility to control the SRT and VFA elutriation (Grady, Jr., Daigger, Love, \& Filipe, 2011). The thickened sludge is recycled back to fermenter with excess sludge wasted. The primary clarifier and fermenter are independent with no recycle to the primary clarifier (Lei, Rabinowitz, Leaf, Bishop, \& Kresge,

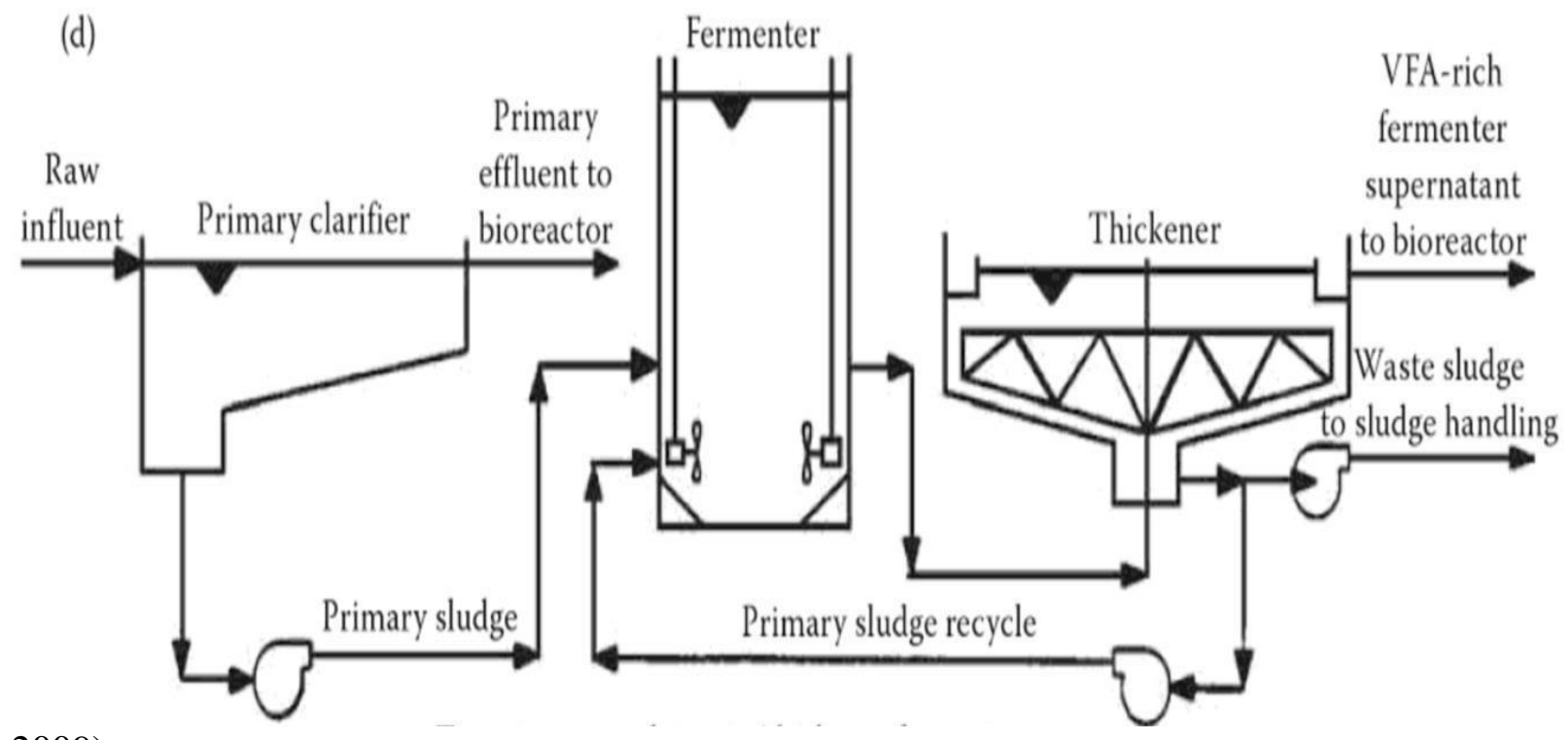

2009) 


\subsubsection{Acetogenesis}

In this phase, short chain fatty acids (SCFA) produced in the fermentation stage are converted into acetic acid, hydrogen gas and $\mathrm{CO}_{2}$ as well as new cell material by the acetogenic bacteria (particularly VFAs) (Henze, et al., 2008). The most important substrates are propionate and butyrate. Syntrophic bacteria that oxidize organic acids to acetate, $\mathrm{H}_{2}$ and $\mathrm{CO}_{2}$ are reliant on the subsequent oxidation of $\mathrm{H}_{2}$ by the next group, the methanogens, to lower the $\mathrm{H}_{2}$ concentration and prevent end-production inhibition (Ravindra, 2015)

\subsubsection{Methanogenesis}

In the final phase, acetates, hydrogen plus carbonate, methanol are converted into methane, $\mathrm{CO}_{2}$ and new cell material. (Henze, et al., 2008) This can take place through two different pathways: $\mathrm{CH}_{4}$ is produced hydrogenotrophic bacteria that operate under the anaerobic oxidation of $\mathrm{H}_{2}$ while the second path (acetoclastic) provides the dismutation of anaerobic acetic acid with formation of methane and carbon monoxide (De Falco \& Basile, 2015) 


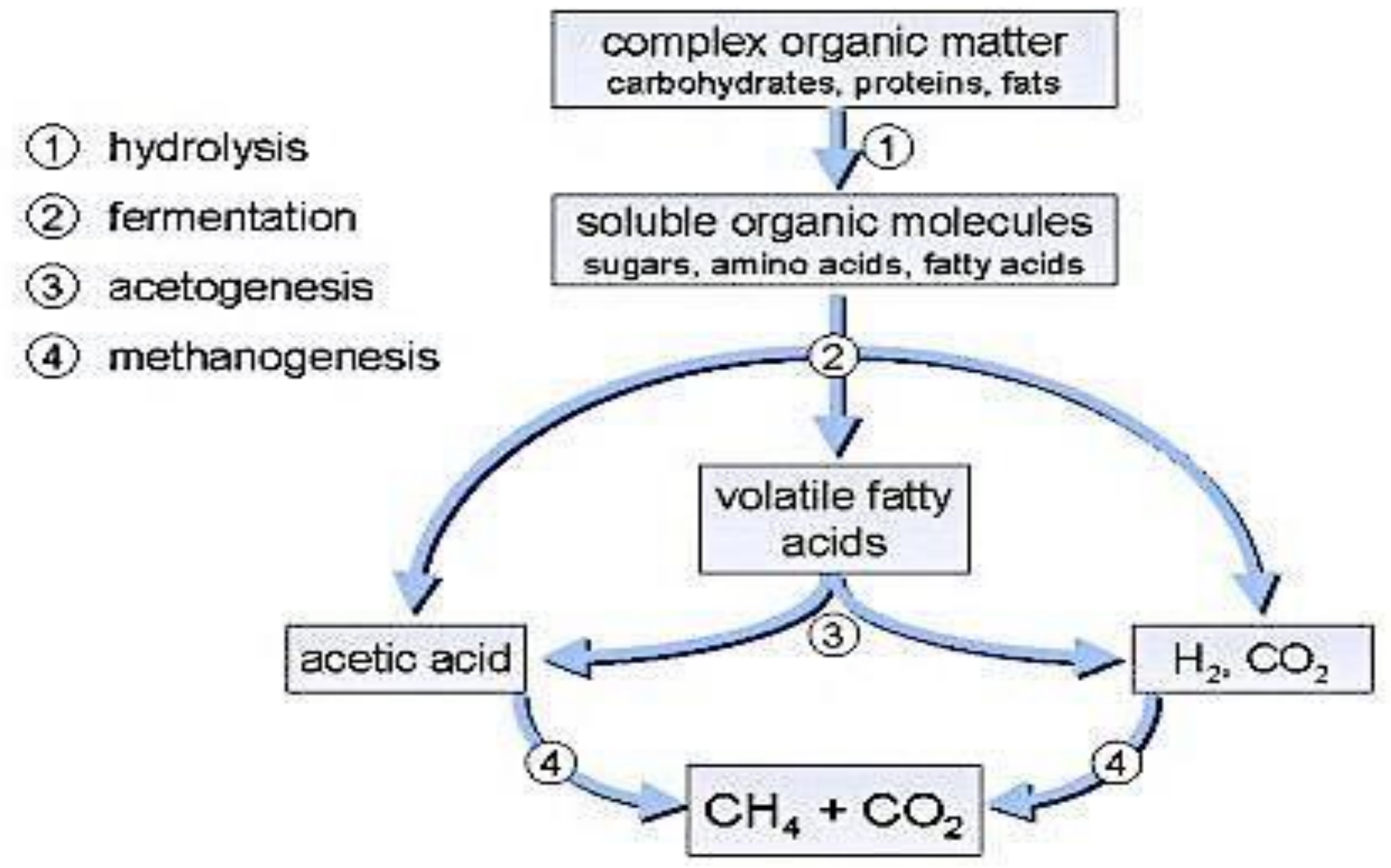

Figure 7: Schematic of the Stages of Anaerobic Digestion Source: (Long, 2010) 


\subsection{Volatile Fatty Acids Production}

At present, commercial production of VFA is mostly accomplished by chemical routes (Huang, Wu, Zhang, Cheung, \& Yang, 2002) In biological VFA production, pure sugars such as glucose and sucrose which are usually the main carbon source may be replaced by organic-rich wastes such as wastewater treatment sludge, food waste, organic percentage of municipal solid waste and industrial wastewater (Zigová, Vandák, Schlosser, \& Šturdík, 1999). Such transformation of waste into VFA also provides an alternative route to reduce the ever-increasing amount of waste generated. In general, the production of VFA from waste is an anaerobic process involving hydrolysis and acidogenesis (the latter is also known as acidogenic fermentation or dark fermentation) (Lee, Chua, Teoh, \& Ngoh, 2014)

In hydrolysis, complex organic polymers in waste are broken down into simpler organic monomers by the enzymes excreted from the hydrolytic microorganisms (Lee, Chua, Teoh, \& Ngoh, 2014). Subsequently, acidogens ferment these monomers into mainly VFA such as acetic, propionic and butyric acids. Both processes involve a complex consortium of obligate and facultative anaerobes such as Bacteriocides, Clostridia, Bifidobacteria, Streptococci, and Enterobacteriace (Weiland, 2010)

\subsubsection{Carbohydrates}

Carbohydrates like cellulose are hydrolyzed into simple sugars, primarily glucose, with traces of galactose, arabinose and mannose by microorganisms including Aceiavibrio celluliticus and several species of Clostridia and some fungi to produce glucose (the main product of the hydrolysis of polysaccharides) (Gujer \& Zehnder, 1983). Glucose is converted into pyruvate with different products like VFAs and alcohols forming, depending on the species of microorganisms' present (Banerjee, 1997). The products formed are utilized as substrates by methanogenic bacteria. 


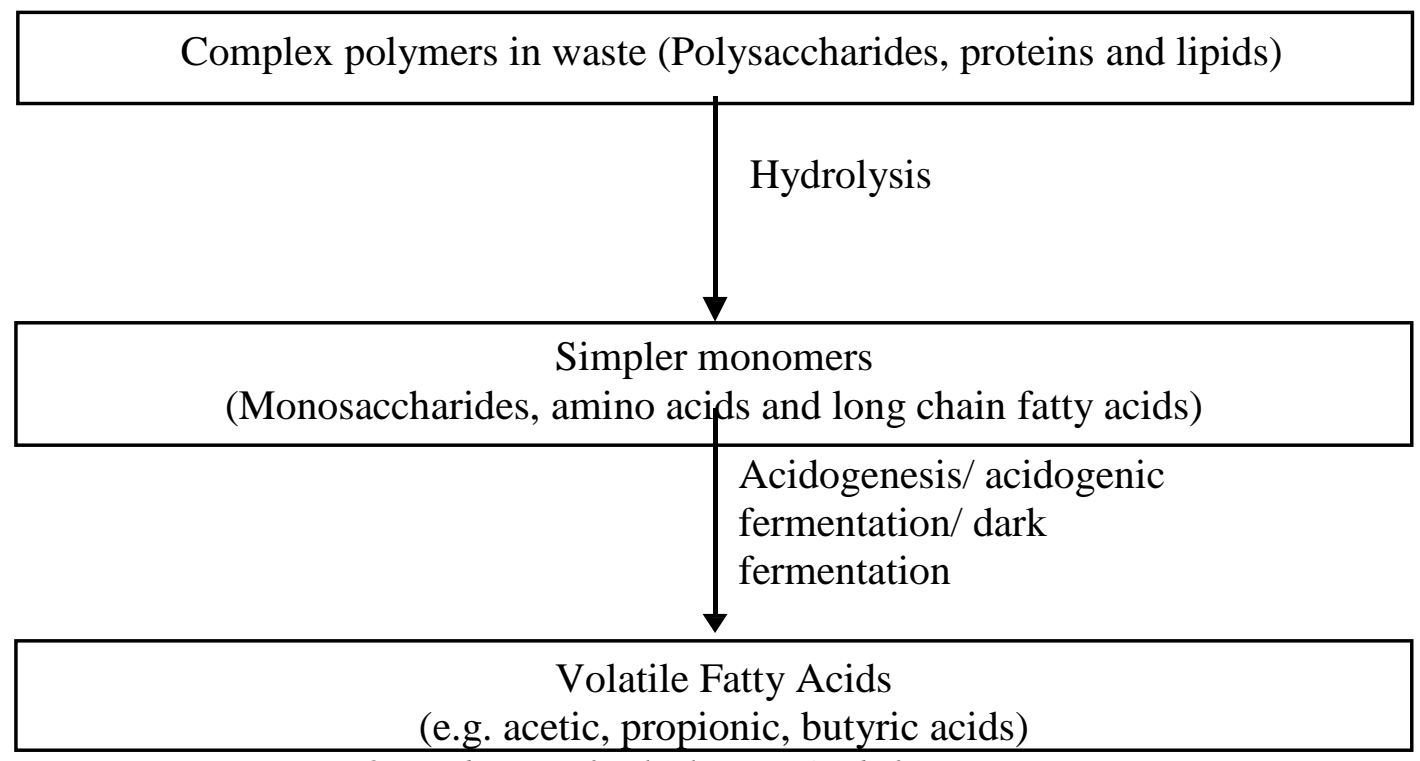

Figure 8: Production of Volatile Fatty Acids from waste

Source: Adapted from (Lee, Chua, Teoh, \& Ngoh, 2014)

\subsubsection{Proteins}

Proteins secrete proteolytic enzymes that hydrolyze the proteins and polypeptides to amino acids by Proteus vulgaris to be used as fermentation substrates (Gujer \& Zehnder, 1983). Amino acids are first deaminized by transamination. The organic acid resulting from the deamination can be converted to other acids to release energy. VFAs are also formed in the fermentation of some amino acids without passing through pyruvic acid as an intermediate compound (Banerjee, 1997).

\subsubsection{Lipids}

Lipids are first hydrolyzed to glycerol and long chain fatty by microorganisms belonging to the groups Bacillus, Clostridium and Serratia (Banerjee, 1997). There are two main groups of enzymes that are responsible for the hydrolysis of lipids: lipases (catalyzes the reversible hydrolysis of fatty acid ester bonds to simpler lipids) and phosphoiipases (involved in the hydrolysis of phospholipids) (Elefsiniotis \& Oldham, 1993). Glycerol can also be converted to pyruvic add via glycolysis and then fermented to VFAs

\subsection{Factors Affecting VFA Production}

The operational $\mathrm{pH}$, temperature, retention time, organic loading rate, as well as additives used have great effects on the concentration, the yield and the composition of VFA produced from waste. 


\subsection{1 pH}

The $\mathrm{pH}$ value in the reactor is important to the production of VFA because most of the acidogens cannot survive in extremely acidic $(\mathrm{pH} 3)$ or alkaline $(\mathrm{pH} 12)$ environments (Liu, et al., 2012) The optimal $\mathrm{pH}$ values for the production of VFA are mainly in the range of 5.25-11, but the specific ranges are dependent on the type of waste used. The alkaline condition enhances the hydrolysis of sludge through ionization of the charged groups of the extracellular polymeric substances in the sludge (Oktem, Ince, Sallis, \& Ince, 2006). The alkaline environment is not conducive to methanogenesis, thus preventing the consumption of the produced VFA for methane formation (Zhang, Chen, \& Zhou, 2009). In addition, pH can also affect the type of VFA produced from acidogenic fermentation, particularly acetic, propionic and butyric acids (Bengtsson, Hallquist, Werker, \& Welander, 2008).

\subsubsection{Temperature}

The production of VFA from waste had been carried out under different temperature ranges. Unlike $\mathrm{pH}$, the influence of temperature on the type of VFA produced is minor. Several studies reported VFA production in the temperate ambient temperature range of between $10^{\circ} \mathrm{C}$ to $30^{\circ} \mathrm{C}$ (Gupta, 2016)

\subsubsection{Retention Time}

In acidogenic fermentation of waste for the production of VFA, the retention time of the waste and the mixed microbial cultures in the anaerobic reactor are critical operational parameters. The hydraulic retention time can easily be manipulated to encourage the growth of selected species of microorganisms such as the acid producers, as it governs the amount and type of substrate utilized by the bacteria (Atherton, 1995) The solids retention time is another operational parameter that can be used as a selective factor because it tends to select for species of organisms in accordance with their generation times (Atherton, 1995) Most studies report no clear distinction between the individual influence of the two parameters.

\subsubsection{Organic Loading Time}

Organic loading rate shows the amount of waste fed into the reactor daily per unit reactor volume. This can be expressed in terms of COD, VS, VSS or DOC. In literature, the influence of OLR on VFA production seemed inconsistent but could be rationalized by the presence of an optimum. The frequency of feeding can also affect the production of VFA under semi-continuous 
conditions. The study of (Nebot, Romero, Quiroga, \& Sales, 1995) found that lower feeding frequency at 3 times per day can lead to a higher concentration of VFA as compared to that at 24 times per day. Less frequent feeding also offers easier reactor operation and reduces the wear and tear on the feed pumps (Lee, Chua, Teoh, \& Ngoh, 2014).

\subsubsection{Additives}

In recent years, additives such as surfactants and enzymes have been utilized to improve the production of VFA from sludge. Some additives have hydrolytic/solubilizing effects on the waste but are not considered as pre-treatment agents because they are added during the acidogenic fermentation instead of before (Lee, Chua, Teoh, \& Ngoh, 2014). Sodium dodecyl sulfate and sodium dodecylbenzene sulfonate are the surfactants commonly used to boost the production of VFA (Jiang, Chen, \& Zhou, Effect of Sodium Dodecyl Sulfate on Waste Activated Sludge Hydrolysis and Acidification, 2007). Chemical inhibitors might enhance the production of VFA by suppressing the activity of VFA-consuming methanogens. The chemical inhibitors can be categorized as specific and nonspecific inhibitors. The former inhibits the specific enzymes only existing in methanogens while nonspecific inhibitors affect the activity of both methanogens and non-methanogens. Examples of nonspecific inhibitor are ethylene, acetylene and several halogenated aliphatic hydrocarbons like chloroform and methyl fluoride (Lee, Chua, Teoh, \& Ngoh, 2014). For VFA production, it is necessary to evaluate and clarify the effects (if any) of these inhibitors, particularly the non-specific ones, on the viability of acidogenesis.

\subsection{Potential Applications of VFA}

Utilization of VFA for various purposes has opened a new avenue for waste treatment via anaerobic fermentation (Jiang, Chen, \& Zhou, Effect of Sodium Dodecyl Sulfate on Waste Activated Sludge Hydrolysis and Acidification, 2007). It offers an economically as well as ecologically sustainable platform for value addition. VFAs offer several biotechnological applications such as; a substrate for various microbiological processes, e.g. for biodiesel production through the synthesis of single cell oils by oleaginous yeast and can serve as substrate for microbial fuel cell (Lee, Chua, Teoh, \& Ngoh, 2014). These can serve as alternate carbon source for microbial biolipid, biohydrogen, microbial fuel cells productions and for denitrification. 


\subsubsection{Polyhydroxyalkanoates}

Polyhydroxyalkanoates are biodegradable polymers that can be synthesized by microorganisms using renewable resources such as VFA. Although PHA has a broad range of applications in various industries and is environmental-friendly, its substitution over the conventional petrochemical-based plastic is limited by high production costs (Lee, Chua, Teoh, \& Ngoh, 2014). Before the fermented waste that is rich in VFA can be utilized for PHA production, it is important to regulate its ammonium and phosphorus contents because excessive nutrients would favor the growth of microorganisms and reduce the conversion of VFA to PHA (Albuquerque, Eiroa, Torres, Nunes, \& Reis, 2007)

In mixed culture PHA production, acetic and butyric acids favor the production of 3hydroxybutyrate (3HB) whereas propionic and valeric acids promote the synthesis of 3hydroxyvalerate (3HV) (Lee, Chua, Teoh, \& Ngoh, 2014). The incorporation of 3HV into $\mathrm{P}(3 \mathrm{HB})$ leads to the formation of copolymer $\mathrm{P}(3 \mathrm{HB}-\mathrm{co}-3 \mathrm{HV})$ which is flexible and tough (Holems, 1985). It is less permeable to oxygen as compared to the commercial polyethylene and polypropylene, making it a suitable food packaging material (Salehizadeh \& Van Loosdrecht, 2004). Hence it is essential to regulate the VFA composition during acidogenic fermentation to facilitate the production of PHA with desired properties.

\subsubsection{Bioenergy}

It is essential to develop alternative energy generation route and to diversify the energy source available in the current market. Waste-derived VFA is an inexpensive energy source that can be used for the generation of different forms of energy such as electricity generation (through the use of microbial fuel cell) and the production of various valuable fuels such as biogas, hydrogen and biodiesel. Microbial fuel cell (MFC) is a bioelectrochemical system that uses microorganisms to harness the chemical energy of the organic substrate as a source of electricity.

Several types of MFCs had been used for electricity generation. In most of the MFC operation, VFA-rich fermented waste can be used directly for electricity generation without any treatment, making this technology economically attractive (Lee, Chua, Teoh, \& Ngoh, 2014). The type of VFA used in MFC has considerable influence on the performance of electricity generation. It is also feasible to produce biogas from waste using single anaerobic digester with VFA as the intermediate product. Biogas is commonly used for heat and power generation because of its high methane content (65- 70 v/v \%) (Metcalf \& Eddy, 2002). Other than as a byproduct of the two-phase anaerobic digestion above, hydrogen production from the waste-derived 
VFA can be achieved. Electro hydrolysis of VFA is another option for hydrogen production. Biodiesel is usually a methyl ester of long-chain fatty acids that can be produced from lipids through transesterification process. The microbial lipid synthesized from waste-derived VFA by oleaginous microorganisms offers a sensible alternative to edible lipid obtained from agricultural commodities such as rapeseed oil, palm oil and soybean oil (Chi, Zheng, Ma, \& Chen, 2011). The microbial lipid synthesized from VFA has similar fatty acid compositions to soybean oil and jatropha oil, thus making it suitable for biodiesel production (Fei, et al., 2011). To date, there is limited research work that explored the microbial lipid production from waste-derived VFA (Chi, Zheng, Ma, \& Chen, 2011) as most of the studies used synthetic VFA instead (Fei, et al., 2011)

\subsubsection{Biological Nutrient Removal}

VFA is an important carbon substrate to assist the biological removal of nitrogen and phosphorus from wastewater. It is known that nitrogen removal can be accomplished through the aerobic nitrification followed by anoxic denitrification while phosphorus can be removed via enhanced biological phosphorus removal process conducted under alternating anaerobic and aerobic conditions (Lee, Chua, Teoh, \& Ngoh, 2014). Simultaneous nitrogen and phosphorus removal is feasible through the application of alternate anaerobic-aerobic-anoxic conditions.

\subsection{Pre-Treatment of Municipal Sludge}

Anaerobic digestion is employed to reduce the volume and weight of sludge. Most of the organics present in sludge are compartmentalized within the microbial cell membrane. Microbial cell walls contain glycan strands cross-linked by peptide chains, causing resistance to biodegradation. Hence, conventional biological digestion techniques require long hydraulic retention times of the order 20-30 days (Fuzhou, 2008). To improve digestion efficiency, the microbial cells in the sludge need to be disrupted.

Pre-treatment methods could be applied to obtain a higher energy recovery. It can nevertheless be unsustainable in terms environmental footprints. The effects of various pretreatment methods are highly different depending on the characteristics of the substrates and the pre-treatment type. The pre-treatment of waste can include processes such as source separation, manual sorting, energy recovery, rendering, anaerobic/aerobic digestion, thermal treatment, biological treatment, mechanical treatment (crushing, grading, trammeling etc.) and composting (Environmental Protection Agency, 2009) 


\subsubsection{Physical Pre-Treatment}

Physical techniques can include the use of thermal, mechanical and freeze - thawing action on substrates to enhance hydrolysis (Xu, Yuan, Lin, \& Yuan, 2014). Thermal pre- treatment techniques have been extensively studied and are used in the field not only for disintegration but to improve dewaterability and remove pathogens from substrates (Ariunbaatar J., Panico, Esposito, Pirozzi, \& Lens, 2014). The optimal temperature and time required for pre-treatment depends on the substrate but temperature ranges from 70 to $200^{\circ} \mathrm{C}$ have been used. The temperature applied and efficiency of the pre- treatment process are positively correlated as an increase in solubilization of organic material has been observed at higher temperatures. However, it has been reported that at over $170^{\circ} \mathrm{C}$, compounds which are inhibitory to microbial communities are released and complex substrates that are difficult to degrade are formed thus reducing the efficiency of AD (Wang, Jiang, \& Yuan, 2014) (Yi, Han, \& Zhuo, 2013). When used to treat readily available substrates, thermal pre-treatment can lead to the destruction of volatile organic matter resulting in reduced methane production. In recalcitrant substrates, thermal pre-treatment has resulted in increased methane production of up to $78 \%$. While mesophilic AD is usually enhanced by this technique, the improved effect is less in thermophilic AD (Appels, Baeyens, Degrève, \& Dewil, 2008) (Yi, Han, \& Zhuo, 2013).

\subsubsection{Mechanical Pre-Treatment}

Mechanical pre-treatment is based on the disruption of microbial cell walls by shear stresses (Fuzhou, 2008). It disintegrates and/or grinds solid particles of the substrates, releasing cell compounds and increasing the specific surface area. An increased surface area provides better contact between substrate and anaerobic bacteria, enhancing the digestion process (Ariunbaatar J. , Panico, Esposito, Pirozzi, \& Lens, 2014) Mechanical pre-treatment is advantageous because there is no odour generation, better dewaterability of the final anaerobic residue, moderate energy consumption and easy implementable. The cons include no significant effect on pathogen removal and the possibility of equipment clogging or scaling (Toreci, Kennedy, \& Droste, 2009) Mechanical pre-treatment methods include sonication, lysiscentrifuge, liquid shear, collision, high-pressure homogenizer, maceration, and liquefaction are conducted in order to reduce the substrate particle size (Ariunbaatar J. , Panico, Esposito, Pirozzi, \& Lens, 2014). 


\subsubsection{Thermal Pre-Treatment}

Thermal pre-treatment has successfully been applied at an industrial scale. Thermal pretreatment mainly disintegrates cell membranes, resulting in solubilization of organic compounds. Like mechanical pre-treatment, it also leads to pathogen removal, improved dewatering performance and reduced viscosity of the substrate. It can also result in loss of volatile organics and/or potential biomethane production from easily biodegradable substrates. Therefore, the effects of thermal pre-treatment depend on the substrate type and temperature range (Ariunbaatar J., Panico, Esposito, Pirozzi, \& Lens, 2014)

\subsubsection{Freeze-Thaw Pre-Treatment}

In cold climate conditions, freeze-thaw pre-treatment can be used to enhance AD. Ice crystals that form during the freezing stage compress and compromise the cell wall. When freeze-thaw is used to treat wastewater sludge, the release of EPS and solubilization of organic matter has been observed, leading to up to $36 \%$ improvement in methane yield. Sludge dewatering and settling is also enhanced once the thaw cycle is completed. Efficiency of this pretreatment is affected by freezing temperature and curing time (Miah, Tada, Yang, \& Sawayama, 2005).

\subsubsection{Biological Pre-Treatment}

Biological pre-treatment includes both anaerobic and aerobic methods, as well as the addition of specific enzymes such as peptidase, carbohydrolase and lipase to the anaerobic digestion system to pre-hydrolyse the waste (Álvarez-Gallego, Fdez-Güelfo, Romero Aguilar, \& Romero García, 2015) The hydrolytic-acidogenic step (first step) of a two-phase anaerobic digestion process is considered as a biological pre-treatment method by some researchers while others consider it as a process configuration of anaerobic digestion, but not a pre-treatment method. Physically separating the acidogens from the methanogens can result in a higher methane production and COD removal efficiency at a shorter hydraulic retention time (HRT) as to conventional single- stage digesters (Ariunbaatar J., Panico, Esposito, Pirozzi, \& Lens, 2014)

\subsubsection{Chemical Pre-Treatment}

Chemical pre-treatment is used to break down organic compounds by means of strong acids, alkalis or oxidants. Anaerobic Digestion generally requires an adjustment of the $\mathrm{pH}$ by increasing alkalinity, thus alkali pre-treatment is the preferred chemical method $(\mathrm{Li}, \mathrm{Li}, \mathrm{Liu}, \&$ 
Zou, 2012). The effectiveness of chemical pre-treatment depends on the type of method applied and the characteristics of the substrates. Chemical pre- treatment is not suitable for easily biodegradable substrates containing high amounts of carbohydrates because of their fast degradation and resulting accumulation of VFA, which leads to failure of the methanogenesis step (Wang, Mattson, Rundstedt, \& Karlsson, 2011)

\subsubsection{Alkali Pre-Treatment}

During alkali pre-treatment, the first reactions that occur are solvation and saphonication (this will induce the swelling of solids), thus increasing the specific surface area and the substrates are easily accessible to anaerobic microbes (Ariunbaatar

J., Panico, Esposito, Pirozzi, \& Lens, 2014). COD solubilization is increased and neutralization of various acids formed by the degradation of the particulates occurs. When substrates are pretreated with alkali methods, an important aspect is that the biomass itself consumes some of the alkali, thus higher alkali reagents might be required for obtaining the desired anaerobic digestion enhancement (Hendriks \& Zeeman, 2009)

\subsection{Sodium Hydro-oxide}

Many studies have observed that increasing the concentrations of sodium hydroxide for WAS pre-treatment results in increasing COD solubilization. Kim et al. reported $44 \%$ increase when $7 \mathrm{~g} / \mathrm{L} \mathrm{NaOH}$ was used in the pre-treatment. Higher concentrations than this yielded lower solubilization. The removal efficiency of SCOD after digestion improved with the use of $\mathrm{NaOH}$. Compared with the control, the study recorded 4 times the removal S COD and over 9\% VS reduction. In addition, methane generation after treatment of pH 12 was improved by 12\% (Valo, Carrere, \& Delgenes, 2004).

\subsection{Potassium Hydro-oxide}

Valo et al. observed that treatment with $\mathrm{KOH}$ for 1 hour at $\mathrm{pH} 10$ and 12 yield $9.3 \%$ and $30.7 \%$ increase in COD solubilization. However, further study showed that at $\mathrm{pH} 10$, the increase in soluble solids were not due to a change in VS but corresponded to the addition of $\mathrm{KOH}$. While majority of the solubilized solids was from an increase of VS at pH 12, a significant amount was also due to $\mathrm{KOH}$. No significant improvement to biogas generation was recorded using $\mathrm{KOH}$. This was attributed to either the inhibition of methanogens by refractory molecules that were solubilized by the alkali or the limited amount of solubilized organic matter (Valo, Carrere, \& Delgenes, 2004). 


\subsubsection{Oxidation Pre-Treatment}

The traditional oxidation technique utilized air or oxygen at elevated temperatures or pressures for sludge disintegration. The odor problems associated with this method were addressed in the Cambi process in which thermal pre-treatment was incorporated with the oxidative process. Of recent, advanced oxidation which is the use of strong oxidants such as ozone $\left(\mathrm{O}_{3}\right)$ and hydrogen peroxide $\left(\mathrm{H}_{2} \mathrm{O}_{2}\right)$, originally used as disinfectants have been of more research interest and field application as pre-treatments to AD. These are particularly favored since they do not produce salt or chemical residue during the pre-treatment process (Yi, Han, \& Zhuo, 2013) (Appels, Baeyens, Degrève, \& Dewil, 2008).

The hydroxyl ions produced during advanced oxidation have high oxidation potential and contribute to hydrolysis through reaction with and destruction of organic cellular material. Peracetic acid is another oxidant used for water purification in the industry that has been recently studied because it is readily biodegradable. Appels et al. observed $21 \%$ improvement in biogas yield during AD of WWTP sludge.

\subsection{Fenton Process}

When iron ions $\left(\mathrm{Fe}^{2+}\right)$ and $\mathrm{H}_{2} \mathrm{O}_{2}$ are combined, the oxidation pre-treatment is referred to as the Fenton process. Ferrous iron is used to catalyze the splitting reaction of $\mathrm{H}_{2} \mathrm{O}_{2}$ to form hydroxyl radical (Xu, Chen, Shi, Wang, \& Zhu, 2010). This process requires a low pH for optimum treatment however other peroxidants such as peroxymonosulphate (POMS) and dimethyldioxirane (DMDO) that do not require extreme conditions are being studied (Appels, Baeyens, Degrève, \& Dewil, 2008)

\subsection{Ozone}

Studies have gone into optimizing ozone oxidation pre-treatment. $\mathrm{O}_{3}$ promotes osmosis through cell walls which compromises its integrity and releases intracellular material. Microbubble systems are one such way in which sludge solubilization by ozonation has been enhanced though the effect on anaerobic digestibility is yet to be seen (Erden \& Filibeli, 2011). Erden \& Filibeli and Bougrier et al showed that cell lysis is a predominant mechanism in enhancing hydrolysis with $\mathrm{O}_{3}$ pre-treatment. $\mathrm{O}_{3}$ generates radicals that oxidize organic matter. Higher concentrations of oxidants appear to increase VFA concentrations which is toxic in excessive amounts to methanogens. The ability for strong oxidants to react with sludge enhances mineralization of the solids thus increasing sludge volume. 
The combination of ultrasound and $\mathrm{O}_{3}$ is another type of advanced oxidation process that is fairly new. Ultrasound radiation makes ozonation more efficient by improving the mass transfer rate of ozone into the substrate of interest. Studies have shown up to two times the methane production from using this method but more research is required to optimize the process in terms of $\mathrm{O}_{3}$ concentration (Xu, Chen, Shi, Wang, \& Zhu, 2010)

\subsubsection{Acid Pre-Treatment}

Acid pre-treatment is a better option for lignocellulosic substrates, because it breaks down lignin and acclimatizing hydrolytic microbes to acidic conditions. The main reaction that occurs during acid pre-treatment is the hydrolysis of hemicellulose into perspective monosaccharides, while the lignin condensates and precipitates (Ariunbaatar J., Panico, Esposito, Pirozzi, \& Lens, 2014) The disadvantages associated with acid pre-treatment include the loss of fermentable sugar due to the increased degradation of complex substrates, a high cost of acids and the additional cost for neutralizing the acidic conditions prior to the anaerobic digestion process (Ariunbaatar J., Panico, Esposito, Pirozzi, \& Lens, 2014)

\subsection{FNA Pre-Treatment}

Free nitrous acid $\left(\mathrm{HNO}_{2}\right)$ is a renewable and low-cost unstable, protonated form of nitrite (Law, et al., 2015). It can be produced on site by nitration of the anaerobic digestion liquor and has been demonstrated to be a strong biocidal agent. It is effective in enhancing WAS biodegradability and methane production. FNA pre-treatment as a novel cell disruption technique has many advantages over other methods such as less intensive energy inputs and chemical consumptions since FNA is a renewable and cost- effective chemical that could be obtained in situ by partial nitrification of the anaerobic WAS (Pijuan, Ye, \& Yuan, 2010). Recently, FNA, serving as a pre-treatment method to stimulate sludge hydrolysis has drawn much attention, at parts per million levels, acts as a strong biocidal agent for a broad range of microorganisms in WAS (Wang, et al., 2013).

Due to the likelihood for degradation of FNA in any form other than in very dilute and cold solutions, FNA cannot be stored much less sold as is. However, it can be produced during the reaction of strong acids with inorganic nitrites. For industrial or commercial purposes, sodium nitrite is a major source. For example, in a reaction with hydrochloric acid, FNA can be formed thus:

$$
\mathrm{NaNO}_{2}+\mathrm{HCl} \quad \rightarrow \quad \mathrm{HNO}_{2}+\mathrm{NaCl}
$$


To determine the concentration of FNA, the relationship between $\mathrm{pH}$ and nitrite concentrations is generally used along with the equilibrium acid dissociation constant which varies with temperature. These are given by Equation (3) and Equation (4). Where $\mathrm{Ka}$ is the ionization constant which is dependent on temperature $\mathrm{T}$ in ${ }^{\circ} \mathrm{C}$ and $\mathrm{S}[-\mathrm{N}]$ is the concentration expressed as nitrogen (Jiang, Gutierrez, \& Yuan, 2011).

$$
\begin{gathered}
K \mathrm{a}=\frac{\mathrm{e}^{-2300}}{273+\mathrm{T}} \\
S\left[\mathrm{HNO}_{2}-\mathrm{N}\right]=\frac{\mathrm{S}\left[\mathrm{NO}_{2}-\mathrm{N}\right]}{\left(\mathrm{Ka} * 10^{\mathrm{pH}}\right)}
\end{gathered}
$$

Equation (3)

Equation (4)

Significant emission of nitrous oxide has been observed in the use of sodium nitrite to produce FNA. Nitrous oxide, commonly known as laughing gas, is of environmental concern because it is a greenhouse gas with almost 300 times the ability to trap heat within the atmosphere. FNA decomposes to form nitrous oxide through the following reaction (House \& House, 2011):

$4 \mathrm{HNO}_{2} \quad \rightarrow \quad 2 \mathrm{HNO}_{3}+\mathrm{N}_{2} \mathrm{O}+\mathrm{H}_{2} \mathrm{O}$

Equation (5)

In the field of chemistry, FNA is used to test for the presence of primary, secondary and tertiary amines based on the products that form during its reaction with amines. In addition, its reaction with primary aromatic amines produces intermediate diamine salt $\mathrm{s}$ that in turn combine with other compounds to form synthetic dyes. These dyes can be used in the production of consumer goods such as food, cosmetics, clothes etc.

The biocidal effect of FNA has been exploited in field scale tests to inhibit the activity of sulfate reducing bacteria (SRB) in sewer networks. SRB action in sewer pipes leads to the production of hydrogen sulfide that emits strong offensive odors through manholes or pumping stations and cause corrosion of pipes. Through intermittent dosing, concentration of hydrogen sulfide was reduced by over $95 \%$ at about $830 \mathrm{~m}$ downstream of the dosing point. In addition, the long - term use of FNA resulted in slower recovery of the SRB within the sewer network. Cost analysis showed that incorporating an FNA dosing regime is much cheaper than other chemicals that have been used for similar purpose (Jiang, Gutierrez, \& Yuan, 2011)

Another recently developed use of FNA is as a pre-treatment of algal cells that are essential to the production of biodiesel. In large - scale production, the extract ion of lipids from 
these algal cells is a key limiting process. The ability of FNA to disrupt algal cell envelopes and increase the yield of lipid extraction was examined in a study. After 48 hours of pre-treatment with FNA, experiments showed an $89 \%$ increase in lipid yields over untreated samples and a $4 \%$ increase over microwave pre-treatment which is known to be an efficient pre-treatment method (Law, et al., 2015)

The addition of FNA to sludge has been observed to improve its biodegradability which in turn reduces the volume of sludge. A study was conducted on the biodegradation of sludge from a denitrifying sequencing batch reactor (SBR). After 6 days of aerobic digestion, the sludge that had been treated with FNA showed 50\% degradation as opposed to the untreated sludge in which degradation was almost undetected. The pre-treatment of WAS with FNA has also been seen to improve methane generation from the sludge via anaerobic process.

Methane generation from anaerobic processes has gained popularity as a source of renewable bioenergy. A lab scale study showed that by increasing the concentration of FNA that is used to treat WAS through contact for 24 hours, the methane potential of the sludge also increases. This was confirmed in a full - scale study that was carried out on a waste water treatment plant where $30 \%$ increase in methane production was observed when the sludge was treated with FNA at $2.13 \mathrm{mg} \mathrm{N} / \mathrm{L}$. This method of pre-treatment is environmentally friendly as it boasts a net reduction in $\mathrm{CO}_{2}$ emission (Wang, et al., 2013)

\subsubsection{Limitations of Chemical Pre-treatment}

Some of the limitations that are associated with the use of chemical reagents in treating material prior to undergoing AD are outlined below (Ariunbaatar J., Panico, Esposito, Pirozzi, \& Lens, 2014):

- Cost of reagents - the operating costs for purchasing chemicals that are required for the pre-treatment process can be significant. This can be due to consumption of the reagent by the biomass such that higher chemical doses are required to sufficiently enhance AD. In addition, extreme $\mathrm{pH}$ conditions that characterize chemical pre-treatment methods need to be re - neutralized prior to AD with other chemicals thus contributing to higher costs.

- Equipment damage - extreme $\mathrm{pH}$ conditions can be problematic for equipment maintenance because of scaling and corrosion.

- Loss of fermentable sugar - during pre-treatment, the breakdown of complex substrates can reduce the available material for methane production during $\mathrm{AD}$ due to the long 
contact time required.

- Environmental impacts at the end of sludge treatment process

- Adverse effects on agricultural application

- Effect of ions - some of the cations that are present in chemicals can be inhibitory to biogas production in certain concentrations 


\subsection{Methodology}

TWAS were collected from the Ashbridges Bay Wastewater Treatment Plant in Ontario, Canada. Ashbridges Bay WWTP is one of the largest treatment facilities in Canada receiving $818,000 \mathrm{~m}^{3}$ /day of raw wastewater, serving over 1.5 million people in Toronto. The semi continuous experiment was conducted using this TWAS. WAS from the final clarifier is thickened with air flotation tanks and thickening polymer such that the resulting TWAS has average of $3.4 \%$ TS content and VS content of $71 \%$ of TS. TWAS samples for the experiment were collected at the outflow from the flotation tanks. Ashbridges Bay WWTP has 20 digesters that receive a total of $6,530 \mathrm{~m}^{3} /$ day of sludge. This sludge is comprised of one - third TWAS and two - thirds primary sludge. The digester tanks are 30 to $33 \mathrm{~m}$ in diameter, operating at a mesophilic temperature range between 34 and $38^{\circ} \mathrm{C}$. The average SRT is 23 days, resulting in biogas production of $64,560 \mathrm{~m}^{3} /$ day that is re purposed within the plant as fuel and flared when in excess. The summary of sample characteristics is presented in below.

\subsection{TWAS Pre-Treatment with FNA - Experiment Setup}

After sample was picked up, the TWAS was stored in the refrigerator below $4^{\circ} \mathrm{C}$ until it was needed. Other studies reported that beyond $2.13 \mathrm{mg}$ N/L FNA pre- treatment had no positive effect. Therefore, concentrations between 0 and $2.8 \mathrm{mg}$ N/L FNA were selected to be studied at a contact temperature of $25^{\circ} \mathrm{C}$ and $\mathrm{pH}$ of $5.5 \pm 0.2$ for contact time of 24 hours which had been determined to be optimum levels for pre- treatment (Pijuan, Wang, Ye, \& Yuan, 2012), (Wang, Jiang, \& Yuan, 2014). Using the $\mathrm{NO}_{2}$ - FNA equilibrium equation, Equation (6), the corresponding nitrite $\left(\mathrm{NO}_{2}\right)$ concentrations were used to apply the required FNA concentrations to the TWAS. These values are presented in Table 3-2. Bottle 2 was used to ensure that the effect of lowering the $\mathrm{pH}$ to 5.5 was accounted for while Bottle 1 represented the true raw sample without any pre-treatment. The $\mathrm{pH}$ of the TWAS was adjusted using various concentrations of $\mathrm{HCl}$ and $\mathrm{NaOH}$ (depending on the $\mathrm{pH}$ of the TWAS batch obtained) was kept on hand for readjusting the $\mathrm{pH}$ if needed. $5 \mathrm{~g} \mathrm{NO}_{2}-\mathrm{N} / \mathrm{L}$ stock solution was prepared by dissolving $12.3 \mathrm{~g}$ of sodium nitrite $\left(\mathrm{NaNO}_{2}\right)$ salt in $500 \mathrm{~mL}$ deionized distilled water (DDW). Once the required concentrations of $\mathrm{NO}_{2}$ were determined for the desired FNA, the corresponding volumes of the stock solution were calculated using Equation (3) and added to the bottles of TWAS.

$$
V_{\text {sol }}=S\left[N \mathrm{O}_{2}-N\right] * \frac{V_{T W A S}}{\frac{5 g}{l}}
$$


Where $\mathrm{V}_{\text {sol }}$ is the volume of stock solution required, $\mathrm{V}_{\text {TwAS }}$ is the volume of TWAS to be treated $(600 \mathrm{~mL})$ and $\mathrm{S}\left[\mathrm{NO}_{2}-\mathrm{N}\right]$ is the selected $\mathrm{NO}_{2}$ concentration. Once the stock solution was added and well mixed, the test bottles were placed in Grant Combined Orbital/Linear Shaking Water Bath, Model OLS200, gently mixing at 100 - $150 \mathrm{rpm}$ to prevent any mechanical breakdown of particles for 24 hours.

There were two parameters in setting up depending on SRT; 1-day and 2-day. In setting up for 2-day SRT, the reactors were fed once every day by extraction $600 \mathrm{ml}$ of sample and feeding $600 \mathrm{ml}$ of pretreated samples per respective FNA concentrations to the reactors. This feed batch system test lasted 12 days. In setting up for 1-day SRT, the reactors were fed once every 12 hours by extraction $300 \mathrm{ml}$ of sample and feeding $300 \mathrm{ml}$ of pretreated samples per respective FNA concentrations to the reactors. This feed batch system test lasted 6 days.

Each reactor was seeded with $1.2 \mathrm{~L}$ of digested sludge from working digesters at Ashbridges Bay WWTP. Digested sludge volume was extracted from the lower sprout after which the same volume of raw or pretreated TWAS was subsequently fed into the reactor via the upper sprout using Masterflex L/S digital pump system and Masterflex C- flex tubing. The stirrer was left on during the feeding and extraction process which took less than 10 minutes per reactor. The liquid samples were collected once a day and measured for $\mathrm{pH}$ and saved after the $6^{\text {th }}$ day (for 2 days SRT) and the $3^{\text {rd }}$ day (for 1-day SRT). The $\mathrm{pH}$ and temperature of the effluent samples were measured immediately, poured into plastic $250 \mathrm{~mL}$ sample bottles, and placed in the refrigerator below $4{ }^{\circ} \mathrm{C}$ until wet chemistry analysis were completed. The numbers of tips were recorded from each of the gas meters and reset each day. 


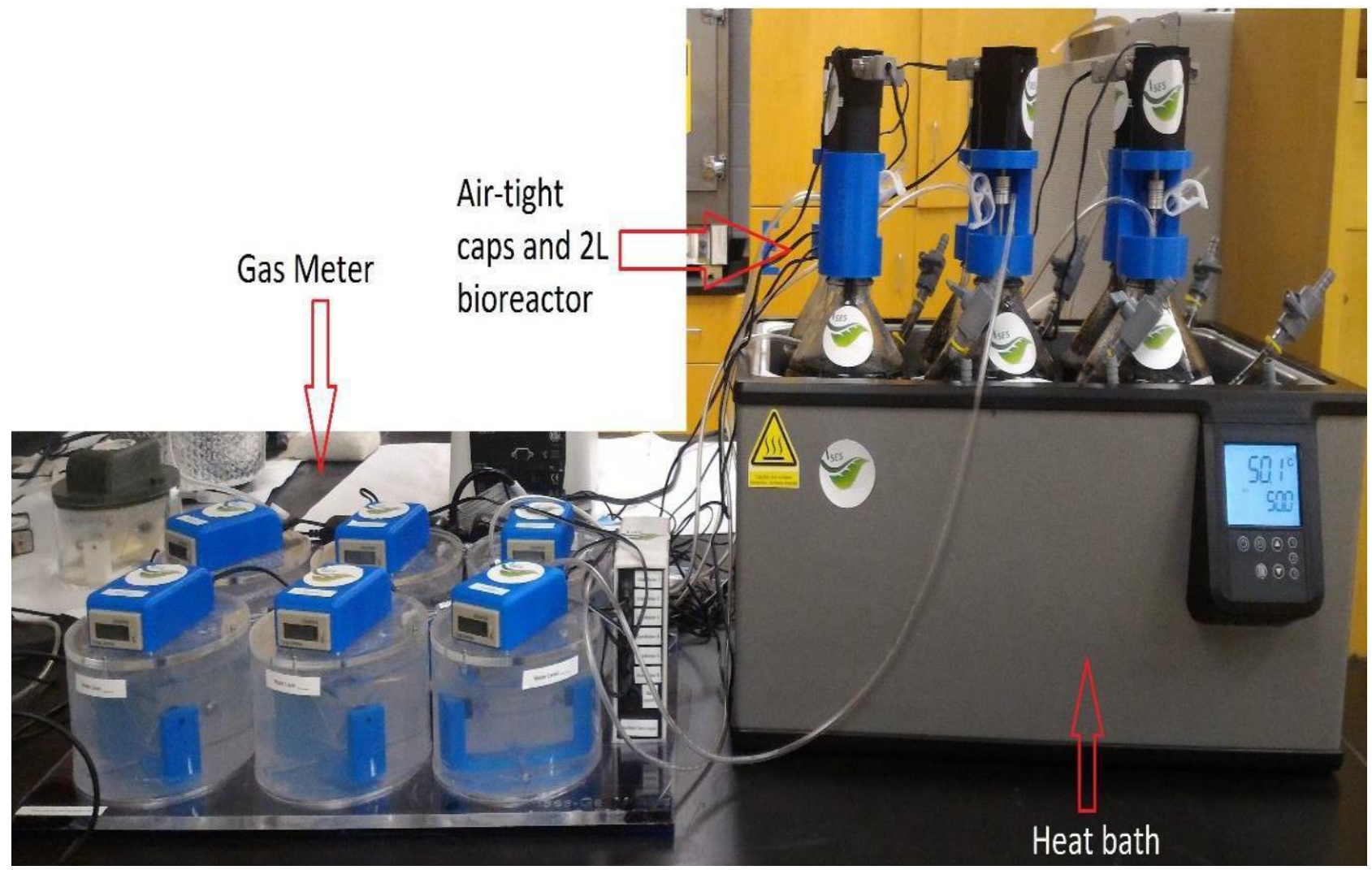

Figure 9: Equipment set up for semi-continuous for anaerobic digestion

To pre-treat the samples, the required volume for feeding was measured into $600 \mathrm{ml}$ polyethylene sampling bottle. The required volumes of FNA to achieve the desired concentrations was added to the volumes. The bottles were then put into the Grant OLS200 water batch at a temperature of $25^{\circ} \mathrm{C}$ and at an RPM of 120 - 150 for 24 hours. About 9 litres of water is added to the bath and adjusted to suit the level of the bottles placed so that at least $2 / 3$ rds of the bottle is covered with water. After 24 hours, the bottles are taken out of the bath and fed to the reactor. 


\begin{tabular}{|c|c|c|}
\hline Bottle Number & Volume of Sample (mL) & Volume of FNA (mL) \\
\hline 1 & 600 & 0 \\
\hline 2 & 600 & 0 \\
\hline 3 & 600 & 6 \\
\hline 4 & 600 & 12 \\
\hline 5 & 600 & 24 \\
\hline 6 & 600 & 48 \\
\hline
\end{tabular}

Table 3-1: Pre-treatment Characteristics of 2-day SRT

\begin{tabular}{|c|c|c|}
\hline Bottle Number & Volume of Sample (mL) & Volume of FNA (mL) \\
\hline 1 & 300 & 0 \\
\hline 2 & 300 & 0 \\
\hline 3 & 300 & 3 \\
\hline 4 & 300 & 6 \\
\hline 5 & 300 & 24 \\
\hline 6 & 300 & 12 \\
\hline
\end{tabular}

Table 3-2: Pre-treatment Characteristic of 1-day SRT

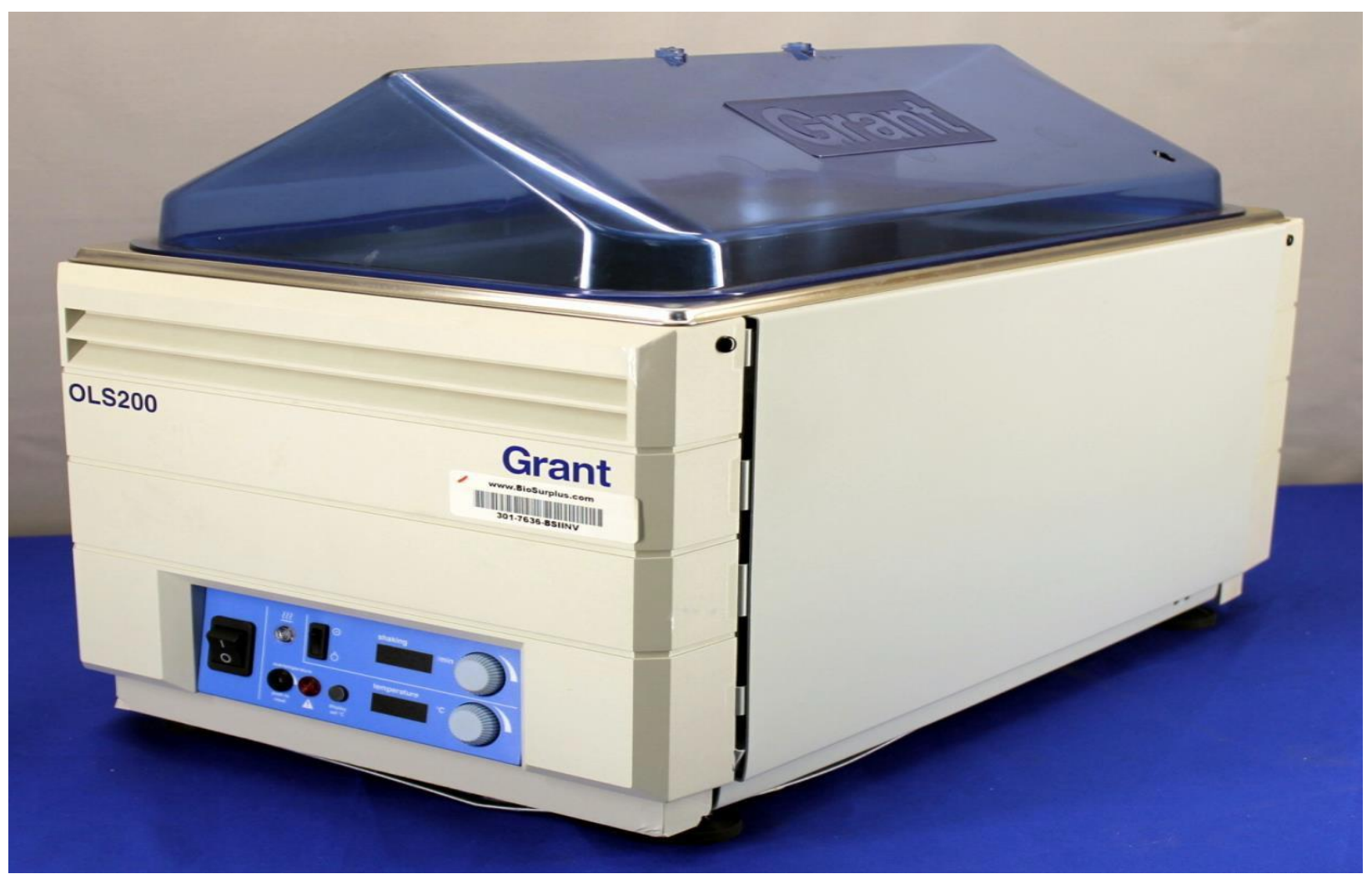

Figure 10: Grant OLS200 Shaking Water Bath 


\subsection{Sampling Analysis}

The analyses that were performed are $\mathrm{pH}$, temperature, alkalinity, TS, volatile solids (VS), total and soluble chemical oxygen demand (TCOD and SCOD), ammonia - nitrogen $\left(\mathrm{NH}_{3}-\mathrm{N}\right)$, nitrite - nitrogen $\left(\mathrm{NO}_{2}-\mathrm{N}\right)$, VFAs, total and orthophosphate. With the exception of the solids and total COD tests, the raw, pretreated, and digester effluent samples for all tests were filtered through $0.45 \mu \mathrm{m}$ VWR Vacuum Filtration Systems, Model 10040 - 462 in order to perform the soluble analysis. Samples were diluted with DDW in different dilution ratios to reduce filtration time. The procedure for each test that was completed is listed below.

\subsection{1 pH}

The $\mathrm{pH}$ for each sample was measured immediately it was collected using VWR Benchtop pH Meter and refillable glass probe, model B10P. This meter was calibrated twice a week with $\mathrm{pH}$ reference standards 4,7 and $10 \pm 0.1$ (BDH®).

\subsubsection{Temperature}

Durac Bi - metallic thermometer, a thermal pin, was used to measure the temperature of samples during collection and to ensure that the bio reactors that were used for the semi continuous study was maintained under mesophilic conditions.

\subsubsection{Total and Volatile Solids}

$5 \mathrm{~mL}$ of each sample in aluminum plates were used to measure the solids content by following the standard guidelines provided in Methods 2540B and 2540E for TS and VS respectively (City of Toronto, 2016)

\subsubsection{Total and Soluble COD}

High range $(20-1500 \mathrm{mg} / \mathrm{L}) \mathrm{COD}$ reagent vials from $\mathrm{HACH}$ were used to follow Method 8000 [2]. This method is based on the reaction digestion method dev eloped by Jirka and Carter (Xu, Yuan, Lin, \& Yuan, 2014). The COD content was then measured using HACH DR3900 spectrophotometer.

\subsubsection{Ammonia - Nitrogen}

High range $(0.4-50 \mathrm{mg} / \mathrm{L})$ Amver Nitrogen Ammonia reagent set was used as per Method 10031, the Salicylate method (City of Toronto, 2016). Concentrations of ammonia - 
nitrogen were determined using the HACH DR3900 spectrophotometer.

\subsubsection{Nitrite - Nitrogen}

The Ferrous Sulfate procedure, Method 8153 was used in measuring the nitrite content as nitrogen in the samples (City of Toronto, 2016). This method is based on the work of McAlpine and Soule (Statistics Canada, 2016). The NitriVer® 2 Nitrite reagent Powder pillows were used with HACH sample cells and the HACH DR 3900 for measurement.

\subsubsection{Volatile Fatty Acids}

The liquid samples were further filtered with $0.2 \mu \mathrm{m}$ DISMIC Ion Chromatography syringe filter units, Model 25HP. A HP 5890 Series II Gas chromatograph (GC) system was fitted with a Nukol fused silica capillary column and flame ionization detector (FID) to measure acetate, propionate, n-butyrate, n-valerate, iso-butyrate and iso-valerate concentrations. Helium was used as the inert, carrier gas. The initial temperature of the column was $110^{\circ} \mathrm{C}$ rising at $8^{\circ} \mathrm{C}$ per minute to $195^{\circ} \mathrm{C}$. This final temperature was held in the column for 9 minutes. The injector and detector temperatures were $220^{\circ} \mathrm{C}$ and $280^{\circ} \mathrm{C}$ respectively.

\subsubsection{Total Suspended Solids}

The mass balance method was used. The sample was filtered using a $47 \mathrm{~mm}$ glass microfiber filter disk. The filtrate was dried in an oven at $103-105{ }^{\circ} \mathrm{C}$ for one hour in an aluminum dish. The dish was removed from the oven, desiccated and weighed.

Total Suspend Solids $=(\mathrm{A}-\mathrm{B}) \mathrm{x}(1000 / \mathrm{C})$

Where: $\quad \mathrm{A}=$ weight of filter and dish + residue

$\mathrm{B}=$ weight of filter and dish

$\mathrm{C}=$ volume of sample filtered

\subsubsection{Alkalinity}

The colorimetric method was used to test the samples for alkalinity. The TNTplus 870 vials were used and concentrations of alkalinity were determined using the HACH DR3900 spectrophotometer.

\subsubsection{Total and Orthophosphate}

High range $(0.4-50 \mathrm{mg} / \mathrm{L})$ Amver Nitrogen Ammonia reagent set was used as per Method 10127 and 8114, the molybdovanadate with acid persulfate digestion method (City of Toronto, 
2016). Concentrations of total and orthophosphate were determined using the HACH DR3900 spectrophotometer and test ' $\mathrm{N}$ ' tube vials.

\subsubsection{Carbohydrates}

Phenol-sulphuric acid method for exopolysaccharides was used for the detection of total carbohydrate. 5\% (w/v) Phenol and sulphuric acid concentrated at $35.7 \mathrm{~N}$ reagents were used. Glucose was used as the standard. To $1 \mathrm{ml}$ of sample, $1 \mathrm{ml} \mathrm{5 \% (w/v)} \mathrm{phenol} \mathrm{was} \mathrm{added} \mathrm{followed}$ by $5 \mathrm{ml}$ concentrated Sulphuric acid. 


\subsection{Results}

The effect of FNA pre-treatment on the TWAS characteristics was investigated by applying different FNA doses to the TWAS with two (2) different SRTs i.e. 1-day SRT and 2-day SRT. The FNA doses were; $0.35,0.7,1.4$ and $2.8 \mathrm{mg} \mathrm{N} / \mathrm{L}$. FNA doses were applied to the TWAS at a constant temperature of $25^{\circ} \mathrm{C}$ and $\mathrm{pH}$ of 5.5 for 24 hours. The raw sample refers to the TWAS without any pre-treatment, i.e. no FNA addition nor $\mathrm{pH}$ adjustment and the sample was stored in the refrigerator at about $4^{\circ} \mathrm{C}$. The control sample (FNA $=0 \mathrm{mg} \mathrm{N} / \mathrm{L}$ ) refers to the sample that used to investigate the effect of $\mathrm{pH}$ adjustment and differentiate between the effects of FNA and $\mathrm{pH}$ adjustment. For the control sample, the $\mathrm{pH}$ was adjusted to 5.5 and kept at a constant temperature of $25^{\circ} \mathrm{C}$ for $24 \mathrm{hrs}$ without any FNA additions. This was done in addition to the FNA concentrations mentioned above.

\subsection{Effects of Pre-Treatment on Waste Characteristics}

Figure 4-1 shows the effects of pre-treatment on the samples as compared to the raw sample. The is a general increase in SCOD content after the samples are pre-treated in SRT 1 with a slight decrease after pre-treatment in SRT 2. Samples for SRT 2 had higher SCOD concentrations with regard to SRT 1. The SCOD increased from $1485 \mathrm{mg} / \mathrm{L}$ for the raw TWAS to $2300 \mathrm{mg} / \mathrm{L}$ for the control sample (i.e. $\mathrm{pH}$ was adjusted at 5.5 without adding any FNA). Higher levels mean a greater amount of oxidizable organic material in the sample, which will reduce dissolved oxygen levels, leading to anaerobic digestion.

Per Figure 4-2, shows the ammonia concentrations normalized per mass of VS for the raw and pre-treated samples. As the figure shows, there was an increase in $\mathrm{NH}_{4}$ after pre-treatment in SRT 1 from $553 \mathrm{mg} \mathrm{N} / \mathrm{L}$ in the untreated to $708 \mathrm{mg}$ N/L when the sample was adjusted to 5.5 without FNA addition. There was a slight decrease in $\mathrm{NH}_{4}$ content after pre-treatment in SRT 2 from $940 \mathrm{mg} \mathrm{N} / \mathrm{L}$ to $880 \mathrm{mg} \mathrm{N} / \mathrm{L}$ when the sample was adjusted to a $\mathrm{pH}$ of 5.5 without FNA addition. There is also a high concentration of $\mathrm{NH}_{4}$ in samples in SRT 2 as compared to samples in SRT 1. High loads of such materials are often correlated with anaerobic digestion instability.

Figure 4-3 also shows a slight increase in volatile solids after pre-treatment in both SRTs with samples in SRT 2 containing a higher concentration as compared to samples in SRT 1 representing the organic solids in water. Pre-treatment mainly converts the particulate organic fraction to soluble or colloidal matter. 


\section{Soluble COD}

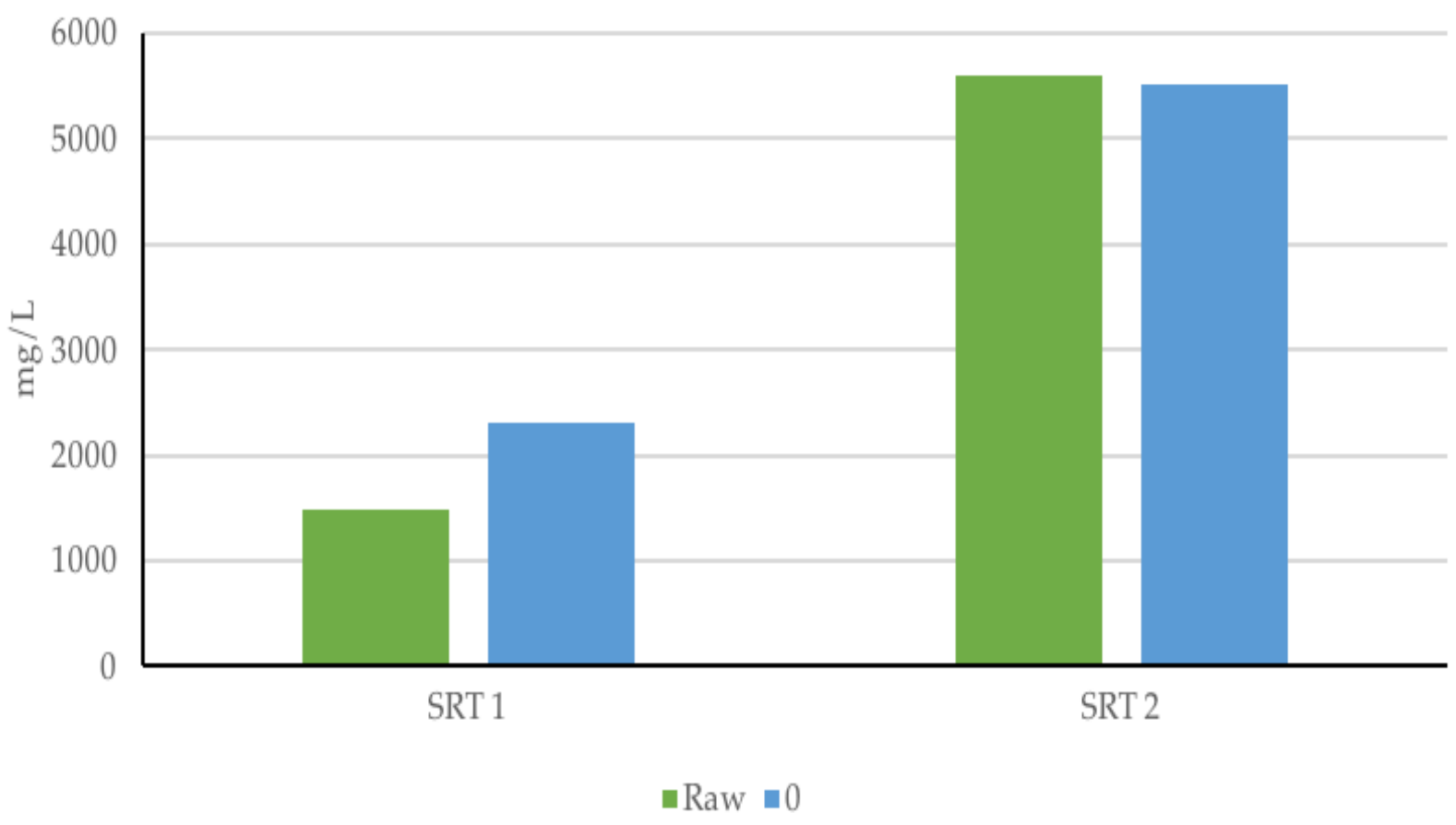

Figure 4-1: Effects of pre-treatment on Soluble COD content

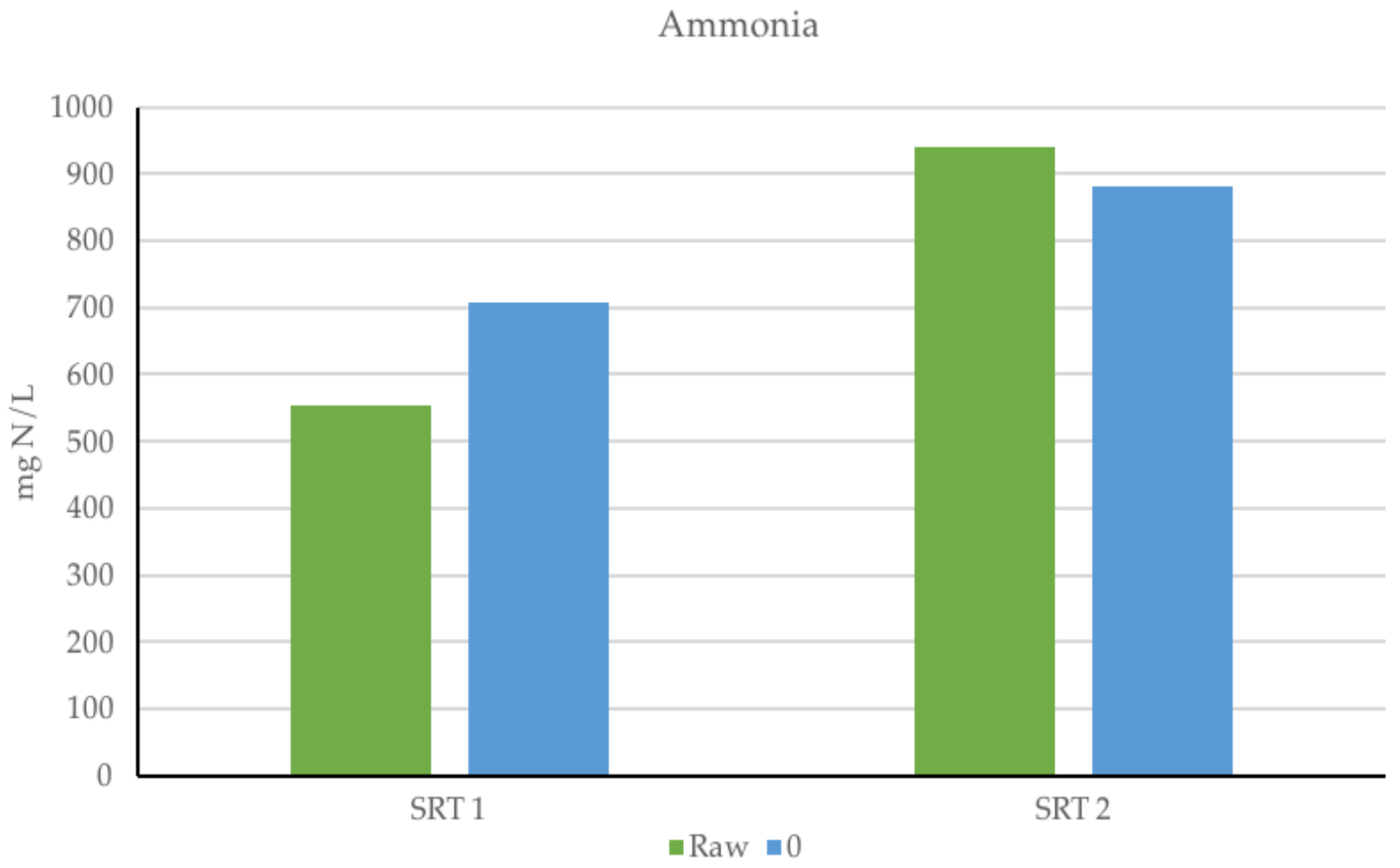

Figure 4-2: Effects of pre-treatment on NH4 


\section{Volatile Solids}

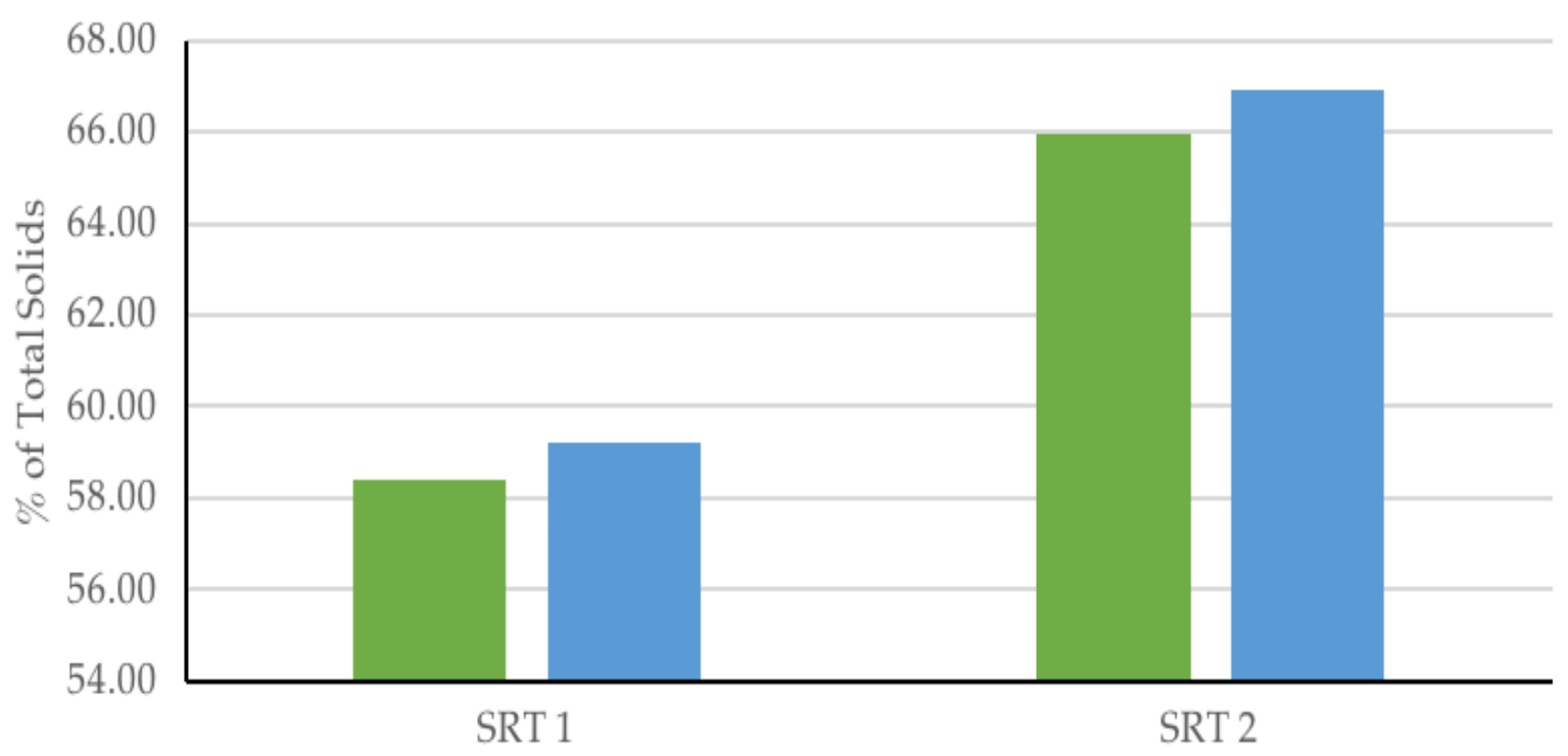

a Raw 10

Figure 4-3: Effects of pre-treatment on Volatile Solids content

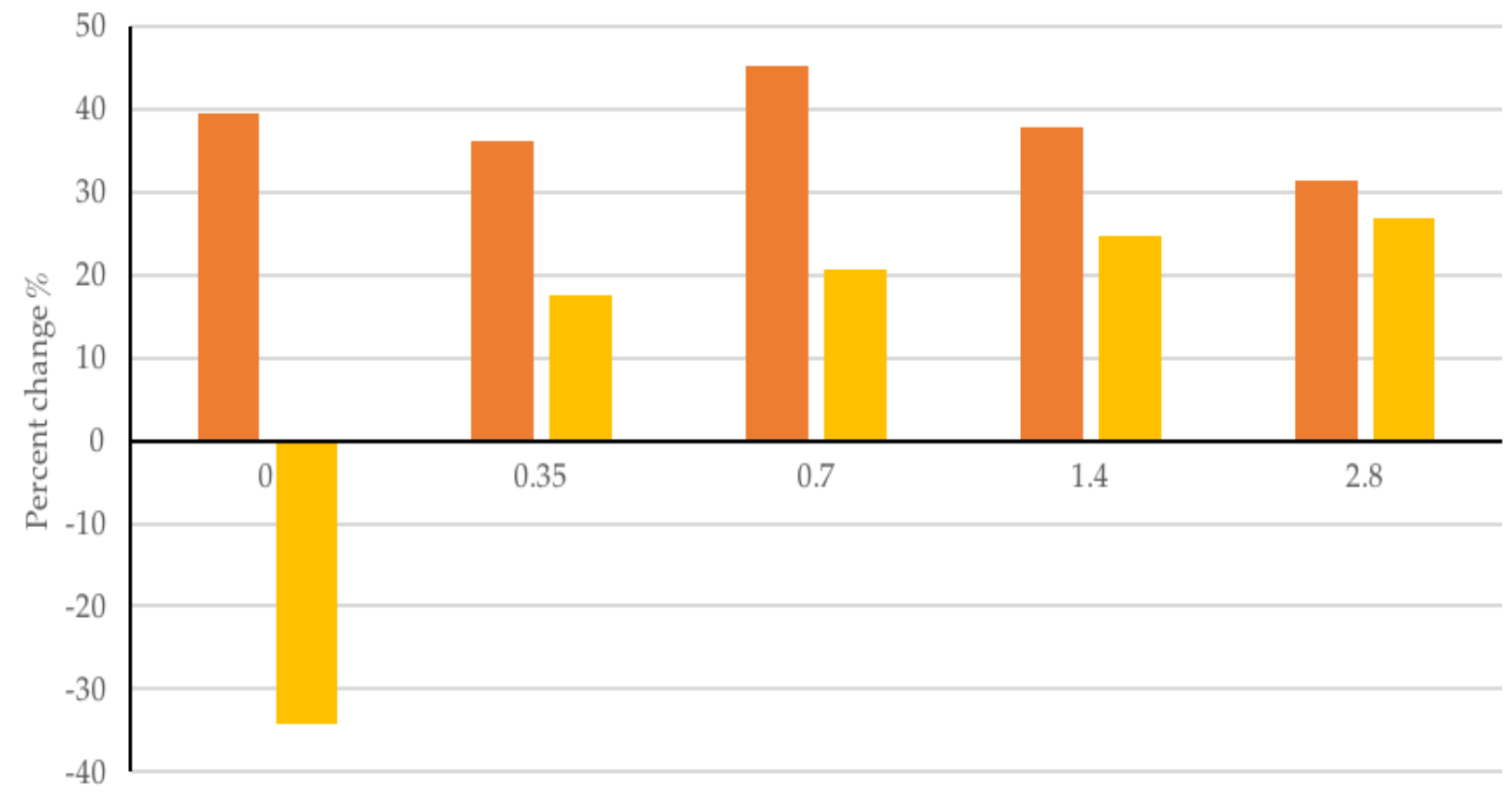

चVSS (mg/L) $\quad$-Orthophosphate $(\mathrm{mg} / \mathrm{L})$

Figure 4-4: Percentage change in parameters compared to raw samples 


\subsection{Acidification Test at SRT 1 Day}

Table 4-1 shows the different water quality characteristics for the raw and treated samples with different FNA doses at the end of the pretreatment procedure. Pre- treatment mainly converts the particulate organic fraction to soluble or colloidal matter. SCOD concentrations increased for all pretreatment levels. With increasing FNA dose from 0.35 to $1.4 \mathrm{mg} \mathrm{N} / \mathrm{L}$, the SCOD increased accordingly. The highest SCOD of $5025 \mathrm{mg} / \mathrm{L}$ was achieved at FNA dose of $2.8 \mathrm{mg} \mathrm{N} / \mathrm{L}$, the highest increase of $35 \%$ from the sample dosed at $1.4 \mathrm{mg}$ N/L FNA. This is demonstrated in Figure 4-5. There was a general trend of increase and this indicated that the pretreatment enhances solubilization. This solubilization could be due to the release of soluble organic matter from cells and the breakdown of EPS (Appels, et al., 2008).

\section{Soluble COD}

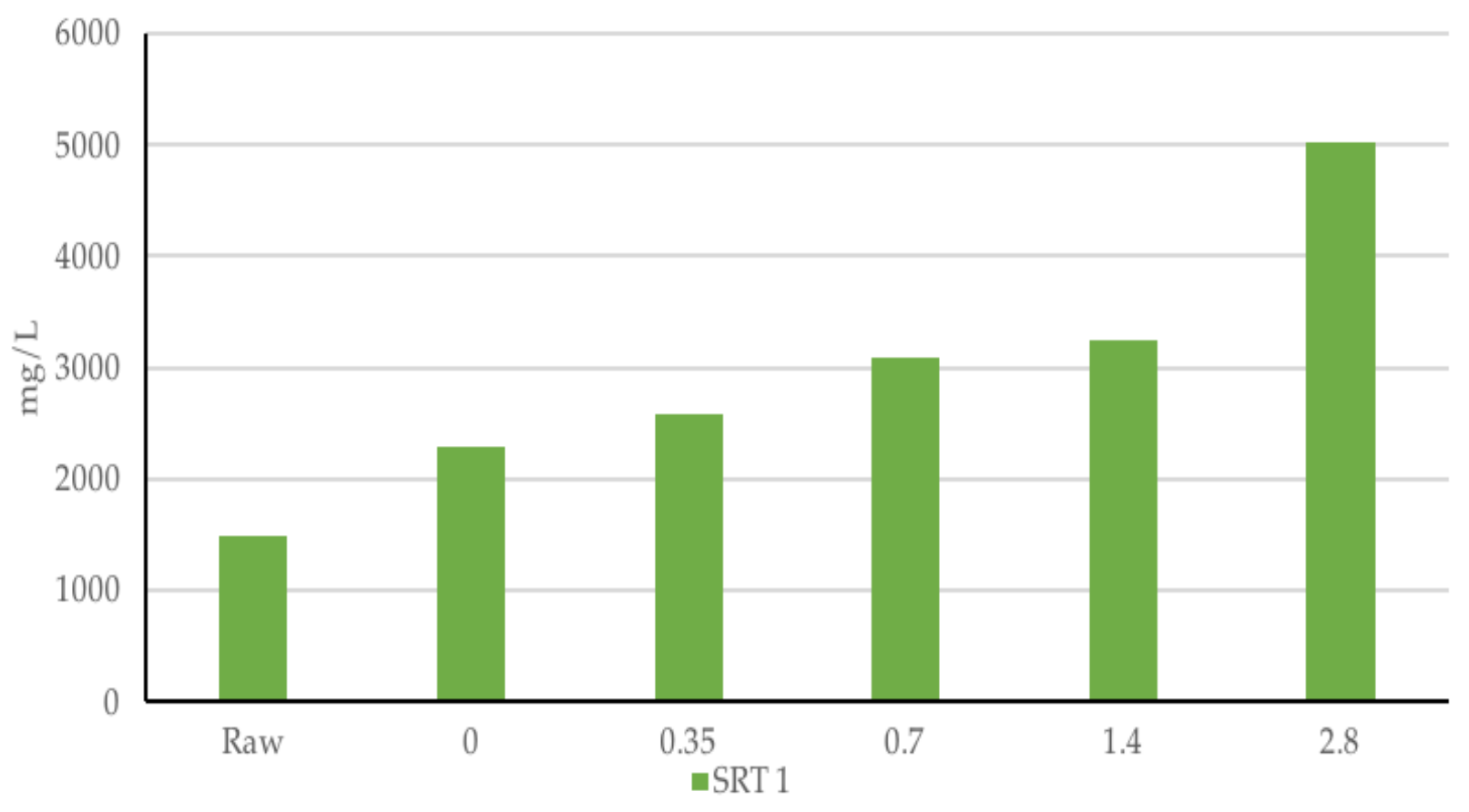

Figure 4-5: SCOD content with varying pre-treatment conditions - SRT 1 day 


\begin{tabular}{|c|c|c|c|}
\hline $\begin{array}{c}\text { FNA Concentration } \\
(\mathbf{m g} \text { N/L) }\end{array}$ & $\begin{array}{c}\text { Ammonia } \\
(\mathbf{m g} \text { N/L) }\end{array}$ & $\begin{array}{c}\text { SCOD } \\
(\mathbf{m g} \text { N/L) }\end{array}$ & $\begin{array}{c}\text { Volatile Solids } \\
(\mathbf{m g} \text { N/L) }\end{array}$ \\
\hline Raw & 553 & 1485 & 58.38 \\
\hline 0 & 708 & 2300 & 59.22 \\
\hline 0.35 & 725 & 2575 & 58.18 \\
\hline 0.7 & 730 & 3085 & 57.73 \\
\hline 1.4 & 930 & 3245 & 58.77 \\
\hline 2.8 & 698 & 5025 & 56.84 \\
\hline
\end{tabular}

Table 4-1: Change in water quality parameters after pretreatment - SRT 1 day

The table also shows the ammonia concentrations for the untreated and the treated samples. As shown in Figure 4-6, the ammonia content increased when FNA was added. There was little increase in FNA samples $0.37 \mathrm{mg} \mathrm{N} / \mathrm{L}$ and $0.7 \mathrm{mg} \mathrm{N} / \mathrm{L}$ and spike of $930 \mathrm{mg} \mathrm{N} / \mathrm{L}$ in ammonia concentrations $1.4 \mathrm{mg} \mathrm{N} / \mathrm{L}$ FNA concentrations. The trend then decreased to $698 \mathrm{mg} \mathrm{N} / \mathrm{L}$ in the 2.8 mg N/L FNA sample.

\section{Ammonia}

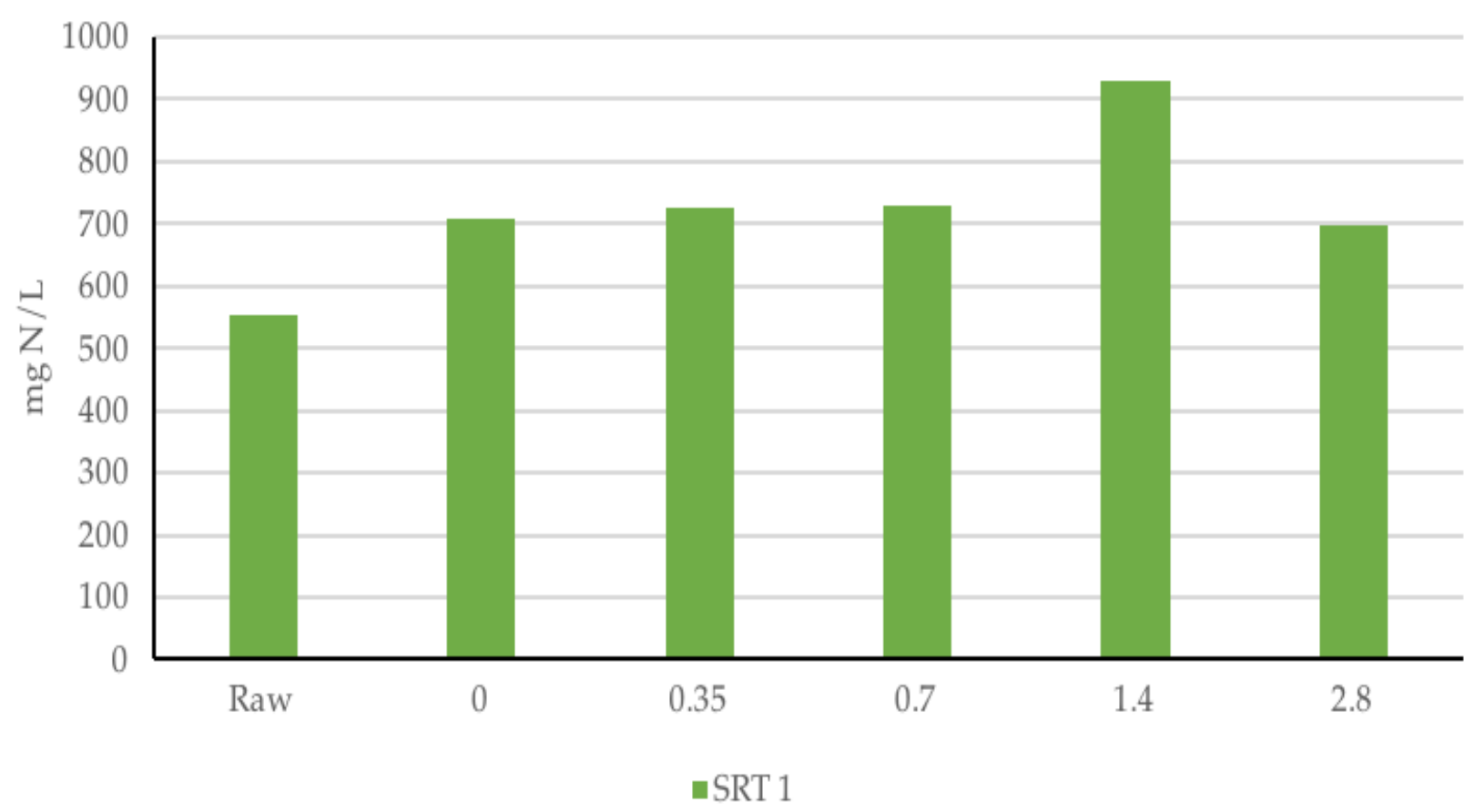

Figure 4-6: Ammonia content with varying pre-treatment conditions - SRT 1 day 


\section{Volatile Solids}

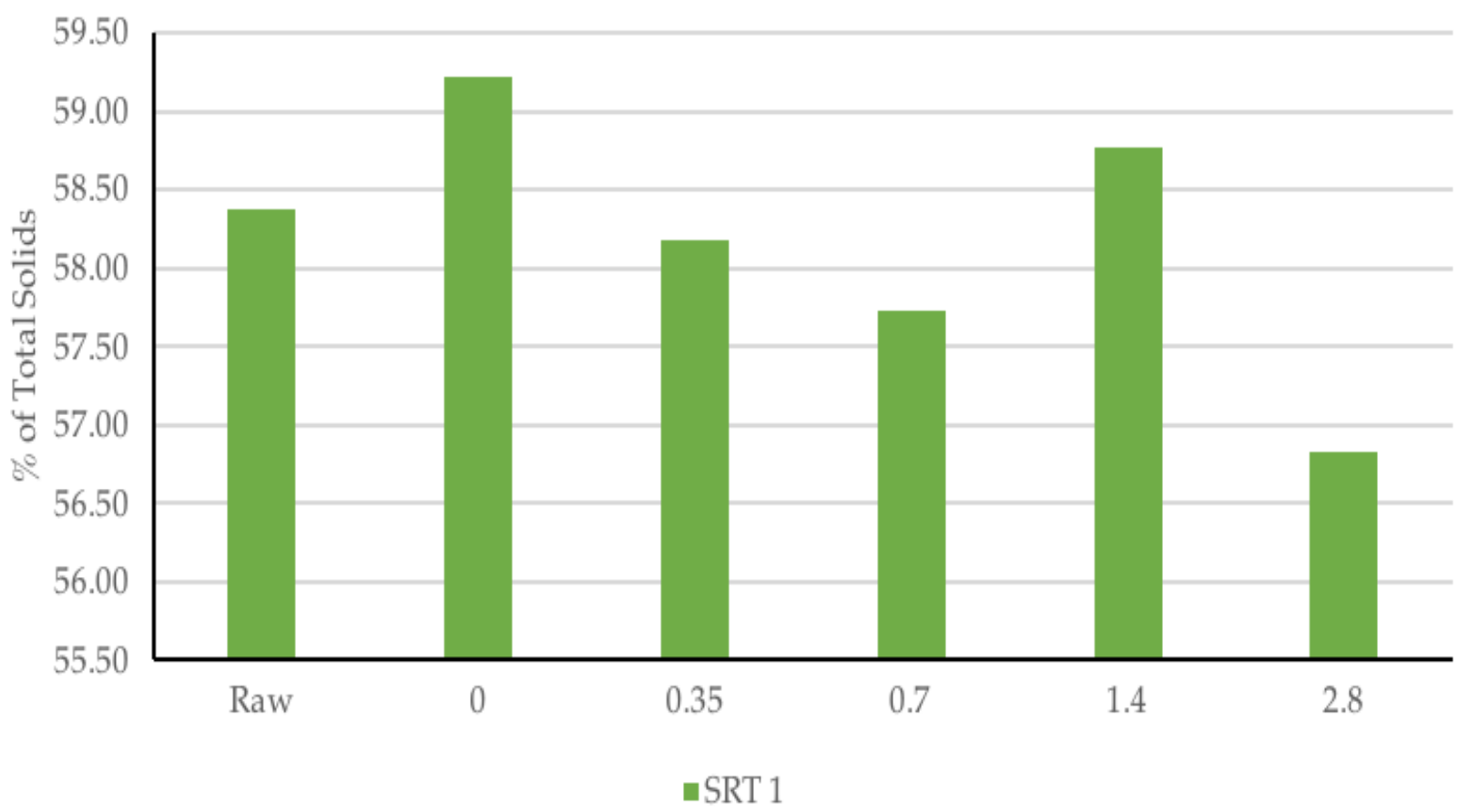

\subsection{Acidification Test at SRT 2 Days}

Table 4-2 shows the different water quality characteristics for the raw and treated samples with different FNA doses at the end of the pretreatment procedure for 2-day SRT. There was a general decrease in SCOD concentrations for pretreatment levels. With decreasing FNA dose from 0.35 to $1.4 \mathrm{mg} \mathrm{N} / \mathrm{L}$, the SCOD decreased accordingly. The highest SCOD of $5470 \mathrm{mg} / \mathrm{L}$ was achieved at FNA dose of $0.35 \mathrm{mg} \mathrm{N} / \mathrm{L}$, the lowest concentration of 4160 from the sample dosed at $2.8 \mathrm{mg}$ N/L FNA. This is demonstrated in Figure 4-8. There was a general trend of decrease and this indicated that the pretreatment of SRT 2 days decreased solubilization.

\begin{tabular}{|c|c|c|c|}
\hline $\begin{array}{c}\text { FNA Concentration } \\
\mathbf{m g ~ N} / \mathbf{L}\end{array}$ & $\begin{array}{c}\text { Ammonia } \\
\mathbf{m g ~ N} / \mathbf{L}\end{array}$ & $\begin{array}{c}\text { SCOD } \\
\mathbf{m g} \text { N/L }\end{array}$ & $\begin{array}{c}\text { Volatile Solids } \\
\mathbf{m g ~ N} / \mathbf{L}\end{array}$ \\
\hline Raw & 940 & 5600 & 65.97 \\
\hline 0 & 880 & 5525 & 66.92 \\
\hline 0.35 & 875 & 5470 & 63.57 \\
\hline 0.7 & 948 & 5130 & 65.10 \\
\hline 1.4 & 830 & 4945 & 60.63 \\
\hline 2.8 & 848 & 4160 & 50.24 \\
\hline
\end{tabular}

Table 4-2: Change in water quality parameters after pretreatment - SRT 2 day 
The table also shows the ammonia concentrations for the untreated and the treated samples under SRT 2 days. As shown in Figure 4-9, the ammonia content generally decreased when FNA was added in comparison to the raw samples. There was a spike in FNA samples $0.7 \mathrm{mg} \mathrm{N} / \mathrm{L}$ of 948 $\mathrm{mg} \mathrm{N} / \mathrm{L}$ in ammonia concentrations. The trend then decreased to $848 \mathrm{mg} \mathrm{N} / \mathrm{L}$ in the $2.8 \mathrm{mg} \mathrm{N} / \mathrm{L}$ FNA sample.

\section{Soluble COD}

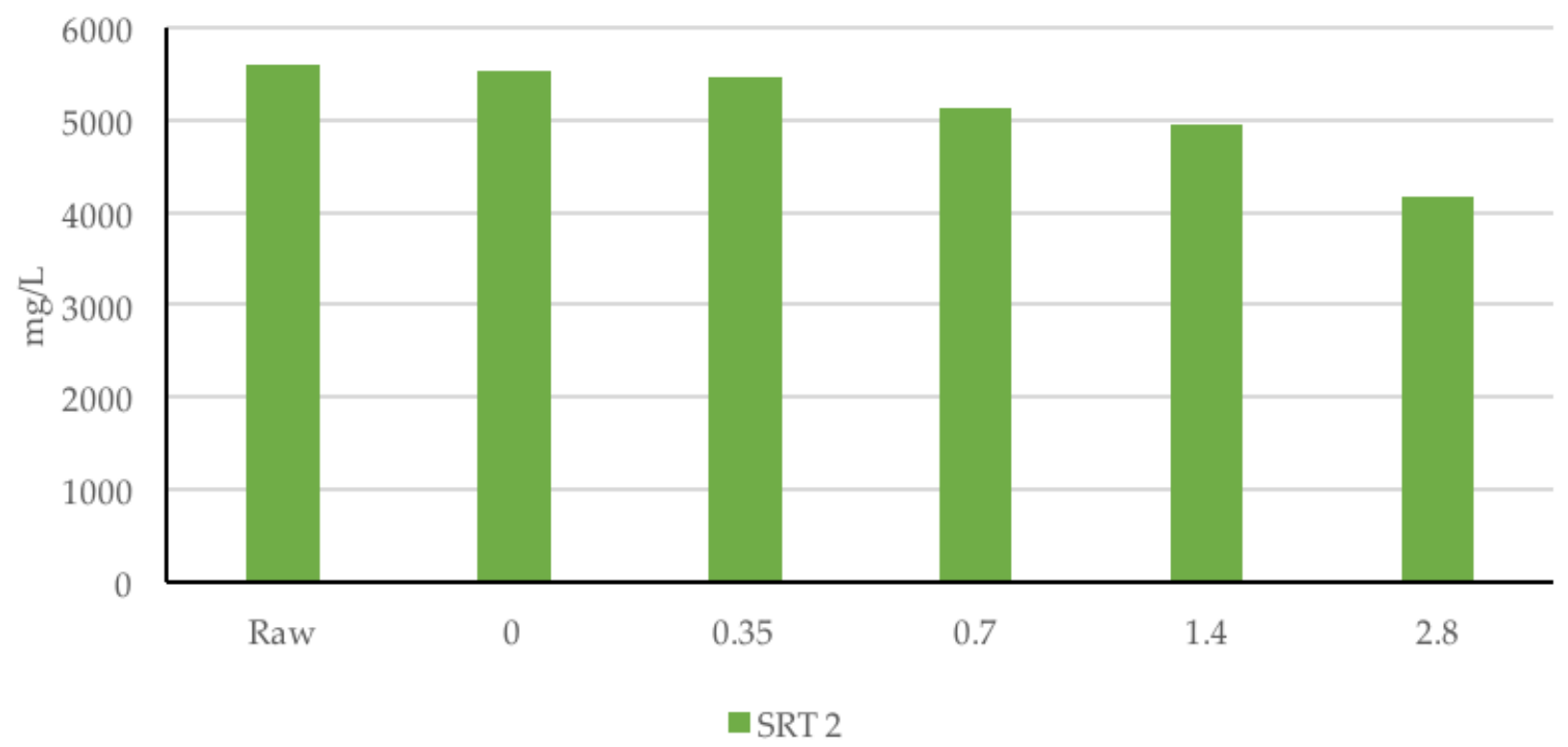

Figure 4-8: SCOD content with varying pre-treatment conditions - SRT 2 days

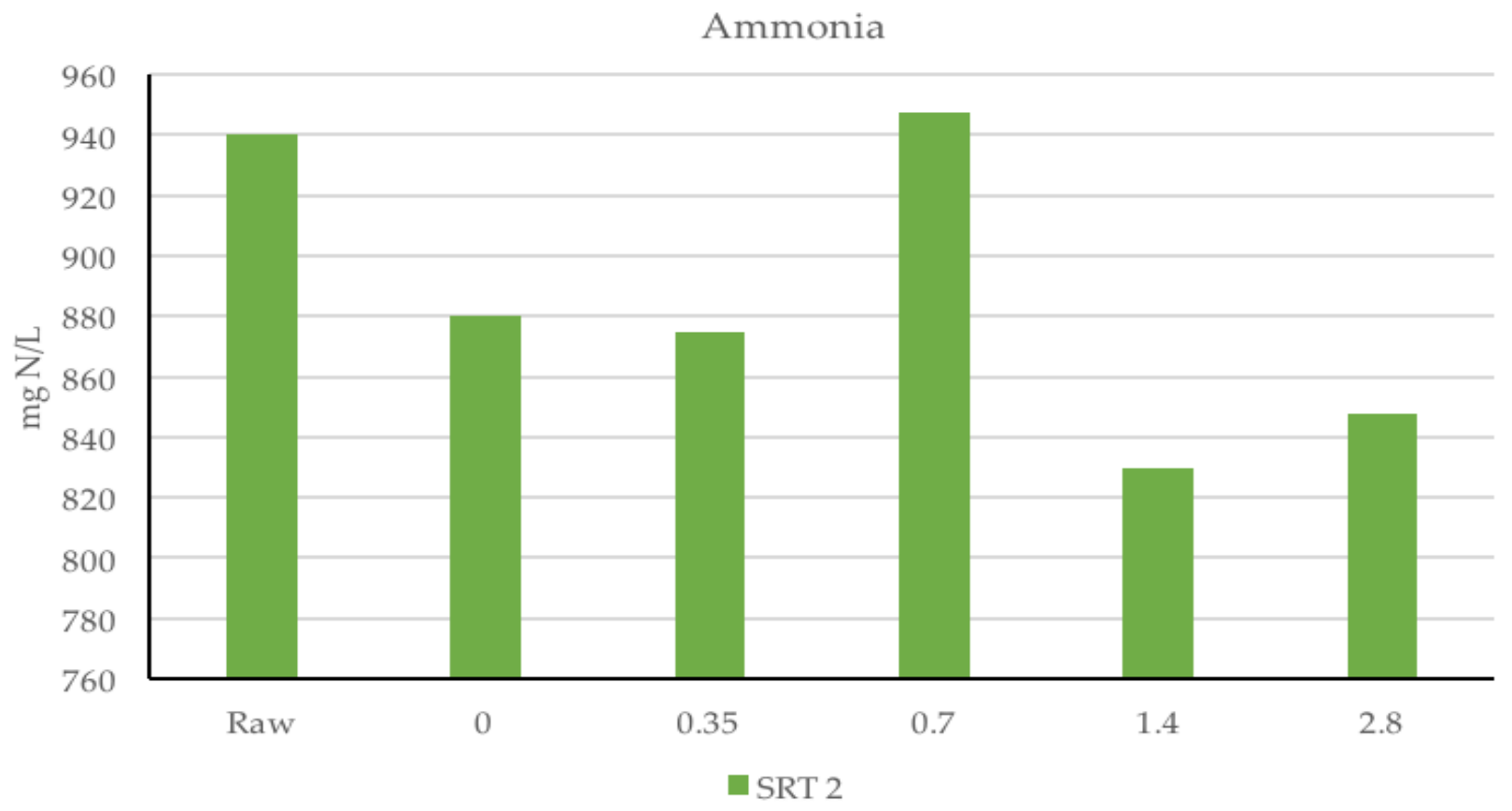

Figure 4-9: Ammonia content with varying pre-treatment conditions - SRT 2 days 


\section{Volatile Solids}

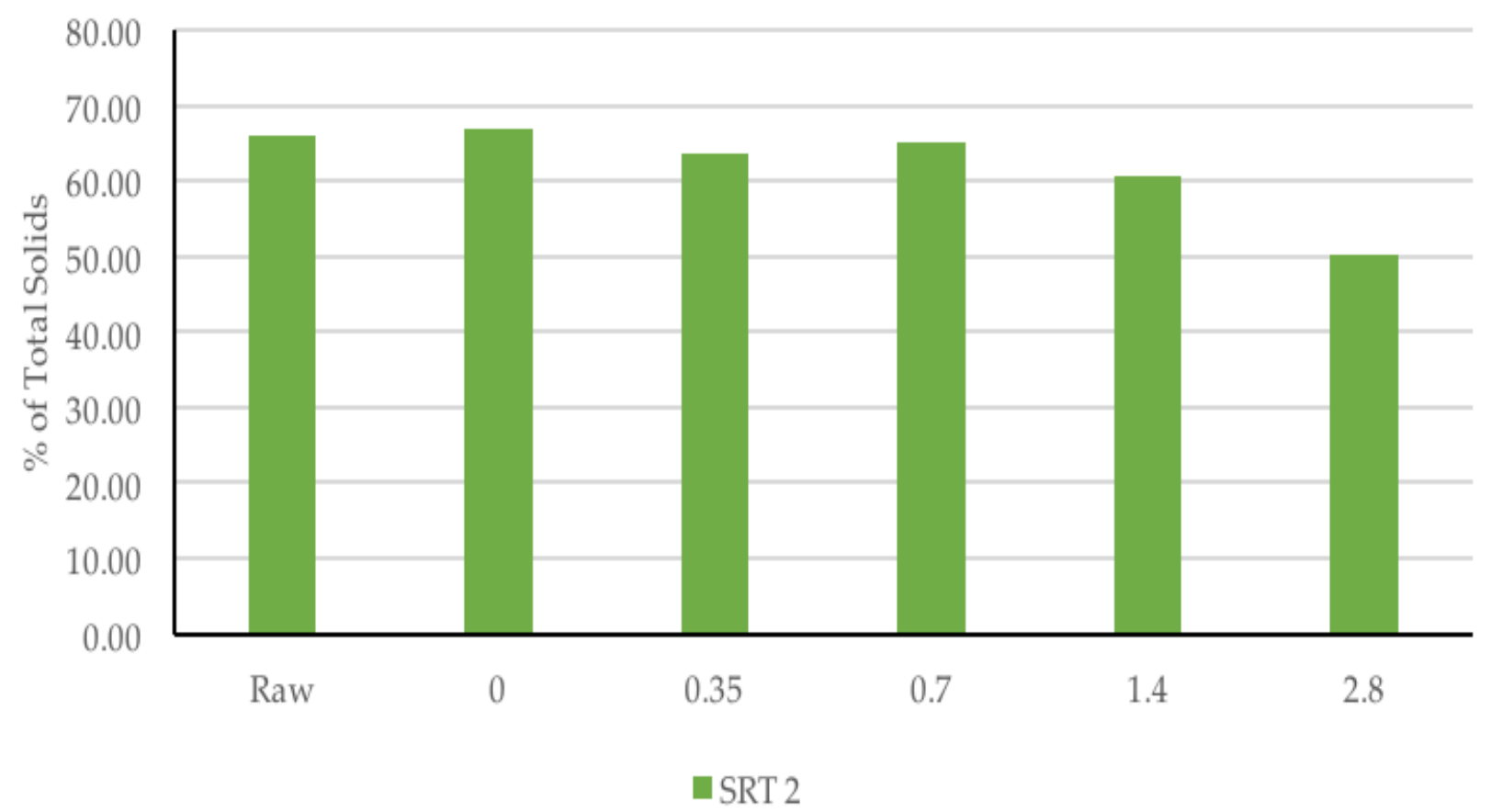

Figure 4-10: Volatile Solids content with varying pre-treatment conditions - SRT 2 days

\subsection{Comparing Acidification Tests (SRT 1-day vs SRT 2 day)}

The figures below show a comparison of the different parameters in the different acidification test performed i.e. SRT 1 day and SRT 2 days. Soluble COD was higher in SRT 2 days FNA concentrations compared to FNA concentrations in SRT 1-day tests. It is also noticed from Figure 4-11 that there was an increase per increase in FNA concentration in SRT 1 day while there was a decrease per increase in FNA concentration in SRT 2 days. This means that the high the FNA concentration, the lower the different in SCOD concentrations.

Ammonia concentration were also higher in SRT 2 days in comparison to SRT 1 day. Per Figure 4-12, there was at a $17 \%$ difference in the $\mathrm{NH}_{4}$ concentration and this occurred in 0.35 and $2.8 \mathrm{mg} \mathrm{NH} / \mathrm{L}$ FNA concentrations. There was however a spike in 1.4 FNA concentration where $\mathrm{NH}_{4}$ concentrations were higher in SRT 1 day $(930 \mathrm{mg} \mathrm{NH} / \mathrm{L}$ ) as compared to SRT 2 days (830 $\mathrm{mg} \mathrm{NH} / \mathrm{L}$ ). This a $10.8 \%$ increase in concentrations. 


\section{Soluble COD}

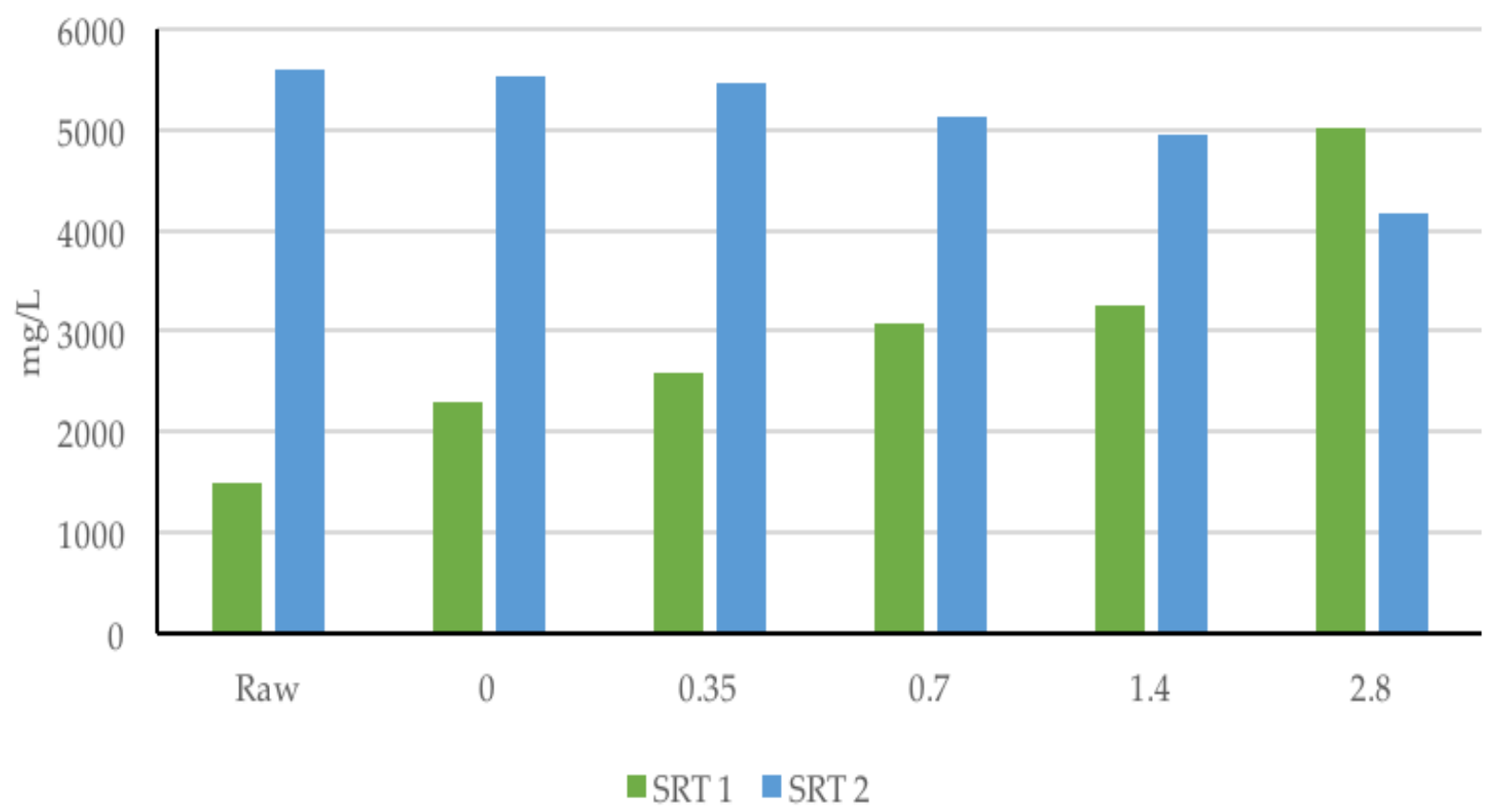

Figure 4-11: SCOD test comparison: SRT 1-day vs SRT 2 days

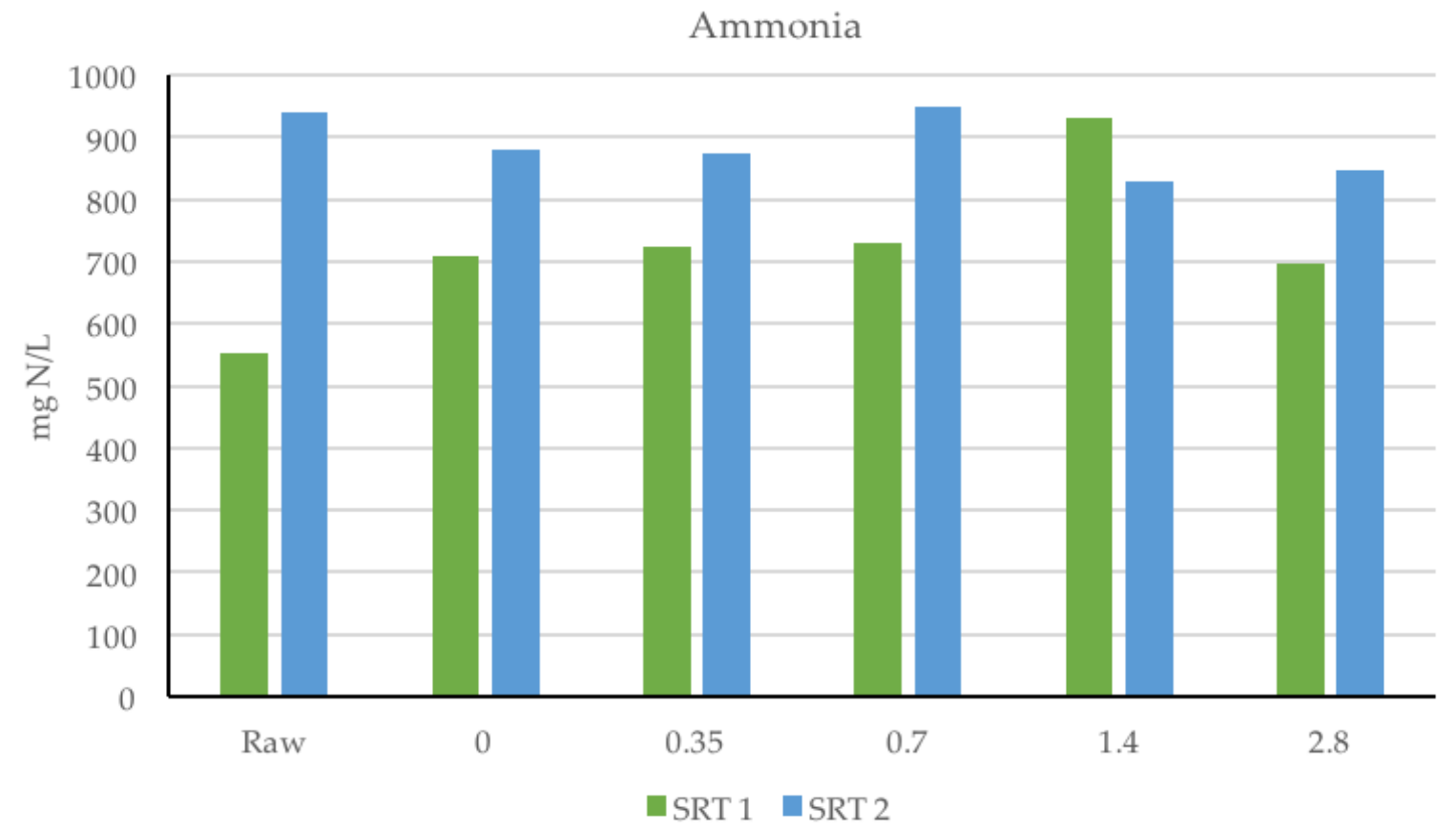

Figure 4-12: Ammonia test comparison: SRT 1-day vs SRT 2 days

Figure 4-13 shows the comparison of volatile solids in the acidification tests performed under SRT 1 day and SRT 2 days conditions. SRT 2 days had higher concentration in comparison to SRT 1 day under FNA conditions $0.35,0.7$ and $1.4 \mathrm{mg} / \mathrm{L}$. Under FNA concentration $1.4 \mathrm{mg} / \mathrm{L}$, 
there was a slight difference (3\%) while under FNA $2.8 \mathrm{mg} / \mathrm{L}$ conditions SRT 1 day had a higher concentration of VS as compared to SRT 2 days.

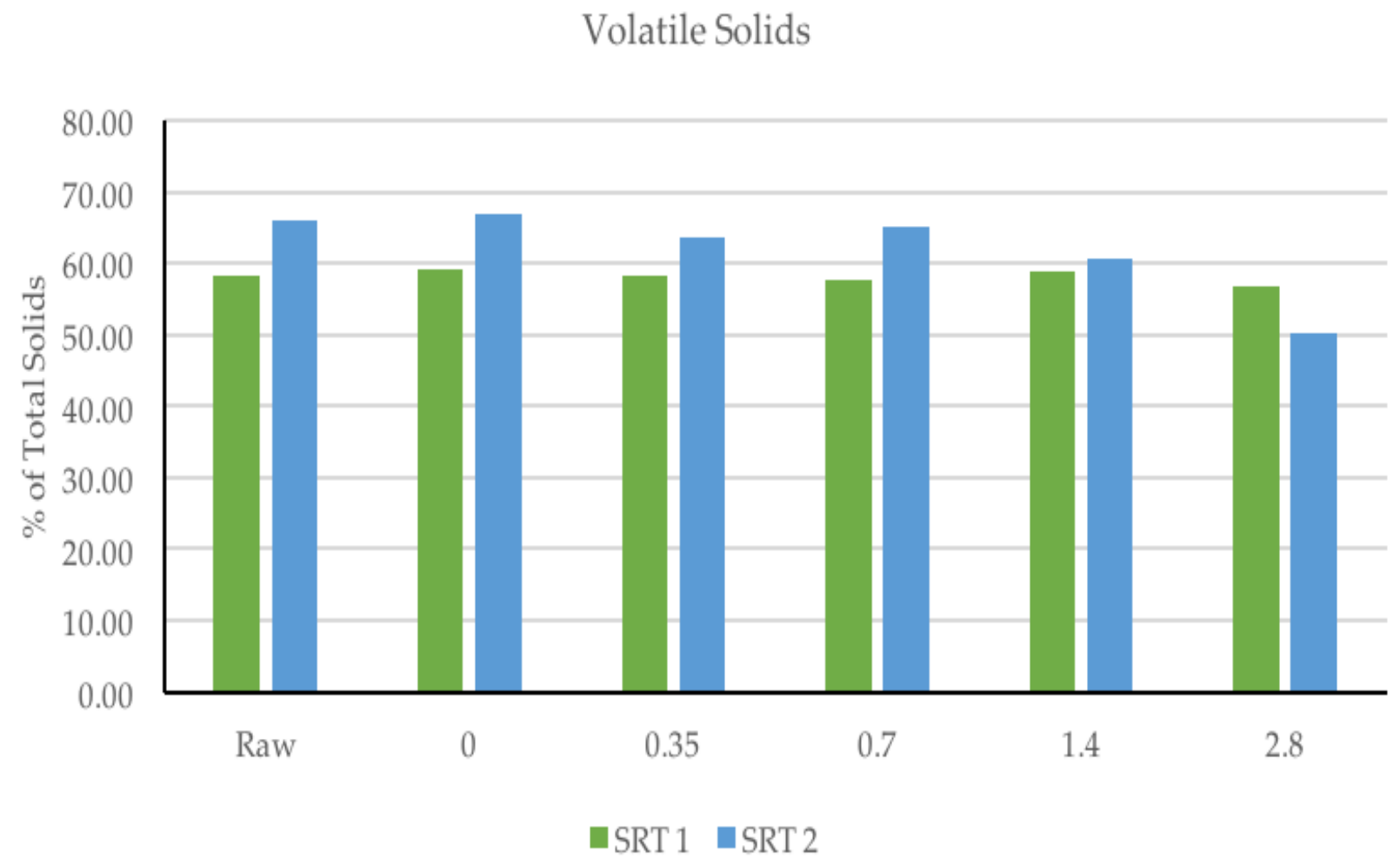

Figure 4-13: Volatile Solids test comparison: SRT 1-day vs SRT 2 days 


\subsection{Conclusion}

Anaerobic digestion is one of the most common biological sludge handling methods. In the anaerobic digestion of sludge, the goals are to reduce sludge volume, insure the remaining solids are chemically stable, reduce disease-causing pathogens and enhance the effectiveness of subsequent dewatering methods, sometimes recovering methane as a source of energy. One of the limitations of anaerobic digestion of sludge is the long retention time that is required to obtain a reasonably stable residue due to the complex structure that make up sludge. Techniques such as pre-treatments are required in order to disrupt these structures and disintegrate the cells and thus shorten the retention time, where they not only improve digestion efficiency but also improve biogas production. The pre-treatment methods may be classified under the following: physical, biological and chemical methods due to the mechanisms used for cell disintegration.

Free nitrous acid (FNA) was seen to be a promising chemical technique for pre- treatment since studies showed that it can work as a biocidal agent to disrupt cell walls making organic matter more accessible to microbes and will degrade in the wastewater treatment plant requiring no extra step for removal. Additionally, FNA can be produced in the wastewater treatment plant in a process that is beneficial to the biological nutrient removal stage. The purpose of this study was to investigate the effect of FNA pre-treatment on a lab scale, semi continuous anaerobic digestion process. The objective was to determine the optimum concentrations of FNA and optimum retention time for VFA production in waste acidification.

Four concentrations of FNA $(0.35,0.7,1.4$ and $2.8 \mathrm{mg} \mathrm{N} / \mathrm{L})$ were investigated in this study along with a blank and a control for $\mathrm{pH}$. The pre-treatment was conducted for 24 hours at $\mathrm{pH} 5.5$ and temperature $25^{\circ} \mathrm{C}$. The study was also conducted for two different SRTs and the change in characteristics of thickened waste activated sludge due to this were analyzed and discussed.

- There were generally higher concentrations of SCOD, NH4 and VS in SRT 2 days when compared to conditions under SRT 1 days

- SCOD increased with increasing FNA concentrations under SRT 1-day conditions.

- SCOD decreased with increasing FNA concentration under SRT 2 days conditions.

- NH4 concentrations were generally the same with a spike in FNA 1.4 concentrations under SRT 1-day conditions.

- VS decreased with increasing FNA concentrations under SRT 1-day conditions.

- It was noticed that there was usually a spike under FNA 1.4 concentrations.

- VS generally decreased with increasing FNA conditions under SRT 2 days conditions. 
It is suggested that the characteristics are also tested on pre-treated samples before they are fed into the reactor in order to compare levels under pretreatment conditions before and after anaerobic fermentation. 


\section{Appendix}

\begin{tabular}{|c|c|}
\hline Reactor Number & FNA Concentration \\
\hline 1 & Raw \\
\hline 2 & 0 \\
\hline 3 & 0.4 \\
\hline 4 & 0.7 \\
\hline 5 & 1.4 \\
\hline 6 & 2.8 \\
\hline
\end{tabular}

Table A-1: FNA concentrations in reactors

\begin{tabular}{|c|c|c|c|c|}
\hline Day & $\begin{array}{c}\text { Reactor } \\
\text { Number }\end{array}$ & abs & $\begin{array}{c}\text { Concentration } \\
\text { (mg/L glucose) }\end{array}$ & $\begin{array}{c}\text { Corrected Concentration } \\
\text { (mg/L glucose) }\end{array}$ \\
\hline 2 (evening) & 1 & 2.436 & 298.5874 & $2,985.87$ \\
\hline 2 (evening) & 2 & 2.452 & 300.4761 & $3,004.76$ \\
\hline 2 (evening) & 3 & 2.371 & 290.9148 & $2,909.15$ \\
\hline 2 (evening) & 4 & 2.409 & 295.4004 & $2,954.00$ \\
\hline 2 (evening) & 5 & 0.896 & 116.8058 & $1,168.06$ \\
\hline 2 (evening) & 6 & 0.687 & 92.13548 & $1,685.07$ \\
\hline 4 (morning) & 1 & 1.334 & 168.5074 & $3,206.61$ \\
\hline 4 (morning) & 2 & 2.623 & 320.6609 & $1,840.89$ \\
\hline 4 (morning) & 3 & 1.466 & 184.0886 & 955.59 \\
\hline 4 (morning) & 4 & 0.716 & 95.55864 & $2,073.43$ \\
\hline 4 (morning) & 5 & 1.663 & 207.3425 & $1,092.51$ \\
\hline 4 (morning) & 6 & 0.832 & 109.2513 & \\
\hline
\end{tabular}

Table A-1: Total Carbohydrate Concentration in 1-day 


\begin{tabular}{|c|c|c|c|c|}
\hline Day & $\begin{array}{c}\text { Reactor } \\
\text { Number }\end{array}$ & abs & $\begin{array}{c}\text { Concentration } \\
\text { (mg/L glucose) }\end{array}$ & $\begin{array}{c}\text { Corrected Concentration } \\
\text { (mg/L glucose) }\end{array}$ \\
\hline 3 & 1 & 2.436 & 298.5874 & $2,985.87$ \\
\hline 3 & 2 & 2.452 & 300.4761 & $3,004.76$ \\
\hline 3 & 3 & 2.371 & 290.9148 & $2,909.15$ \\
\hline 3 & 4 & 2.409 & 295.4004 & $2,954.00$ \\
\hline 3 & 5 & 0.896 & 116.8058 & $1,168.06$ \\
\hline 3 & 6 & 0.687 & 92.13548 & 921.35 \\
\hline 6 & 1 & 1.334 & 168.5074 & $3,206.61$ \\
\hline 6 & 2 & 2.623 & 320.6609 & $1,840.89$ \\
\hline 6 & 3 & 1.466 & 184.0886 & 955.59 \\
\hline 6 & 4 & 0.716 & 95.55864 & $2,073.43$ \\
\hline 6 & 5 & 1.663 & 207.3425 & $1,092.51$ \\
\hline 6 & 6 & 0.832 & 109.2513 & \\
\hline
\end{tabular}

Table A-2: Total Carbohydrate Concentration in 2-day SRT

\begin{tabular}{|c|c|c|c|c|}
\hline Day & $\begin{array}{c}\text { Reactor } \\
\text { Number }\end{array}$ & abs & $\begin{array}{c}\text { Concentration } \\
\text { (mg/L glucose) }\end{array}$ & $\begin{array}{c}\text { Corrected Concentration } \\
\text { (mg/L glucose) }\end{array}$ \\
\hline 2 (evening) & 1 & 0 & 11.042 & 110.42 \\
\hline 2 (evening) & 2 & 0.274 & 43.38496 & 533.85 \\
\hline 2 (evening) & 3 & 0.331 & 50.11324 & 360.66 \\
\hline 2 (evening) & 4 & 0.212 & 36.06648 & 278.04 \\
\hline 2 (evening) & 5 & 0.142 & 27.80368 & 274.50 \\
\hline 2 (evening) & 6 & 0.139 & 27.44956 & 41.93 \\
\hline 4 (morning) & 1 & 0.086 & 21.19344 & 541.27 \\
\hline 4 (morning) & 2 & 0.316 & 48.34264 & 596.74 \\
\hline 4 (morning) & 3 & 0.365 & 54.1266 & 514.12 \\
\hline 4 (morning) & 4 & 0.412 & 59.67448 & 488.15 \\
\hline 4 (morning) & 5 & 0.342 & 51.41168 & 48.8148 \\
\hline 4 (morning) & 6 & 0.32 & 634 & \\
\hline
\end{tabular}

Table A-3: Soluble Carbohydrate Concentration in 1-day SRT 


\begin{tabular}{|c|c|c|c|c|}
\hline Day & $\begin{array}{c}\text { Reactor } \\
\text { Number }\end{array}$ & abs & $\begin{array}{c}\text { Concentration } \\
\text { (mg/L glucose) }\end{array}$ & $\begin{array}{c}\text { Corrected Concentration } \\
\text { (mg/L glucose) }\end{array}$ \\
\hline 3 & 1 & 0.189 & 33.35156 & 333.52 \\
\hline 3 & 2 & 0.502 & 70.29808 & 702.98 \\
\hline 3 & 3 & 0.283 & 44.44732 & 544.47 \\
\hline 3 & 4 & 0.384 & 56.36936 & 563.69 \\
\hline 3 & 5 & 0.394 & 57.54976 & 741.93 \\
\hline 3 & 6 & 0.535 & 74.1934 & 301.64 \\
\hline 6 & 1 & 0.162 & 30.16448 & 348.70 \\
\hline 6 & 2 & 0.312 & 47.87048 & 318.17 \\
\hline 6 & 3 & 0.198 & 34.41392 & 364.21 \\
\hline 6 & 4 & 0.176 & 31.81704 & 363.03 \\
\hline 6 & 5 & 0.215 & 36.4206 & \\
\hline 6 & 6 & 0.214 & 36.30256 & \\
\hline
\end{tabular}

Table A-4: Soluble Carbohydrate Concentration in 1-day SRT

\begin{tabular}{|c|c|c|}
\hline \multirow{2}{*}{$\begin{array}{c}\text { FNA Concentration } \\
(\mathbf{m g} \text { N/L) }\end{array}$} & \multicolumn{2}{|c|}{ Solubilization (\%) } \\
\cline { 2 - 3 } & SRT 1 & SRT 2 \\
\hline Raw & 6.901263 & 16.87282 \\
\hline 0 & 14.76769 & 31.21488 \\
\hline 0.35 & 21.94507 & 21.56455 \\
\hline 0.7 & 24.48875 & 32.69409 \\
\hline 1.4 & 24.43799 & 37.67419 \\
\hline 2.8 & 37.8696 & 53.21442 \\
\hline
\end{tabular}

Table A-5: Percentage Solubilization of Carbohydrates 


\section{Carb Solubilization}

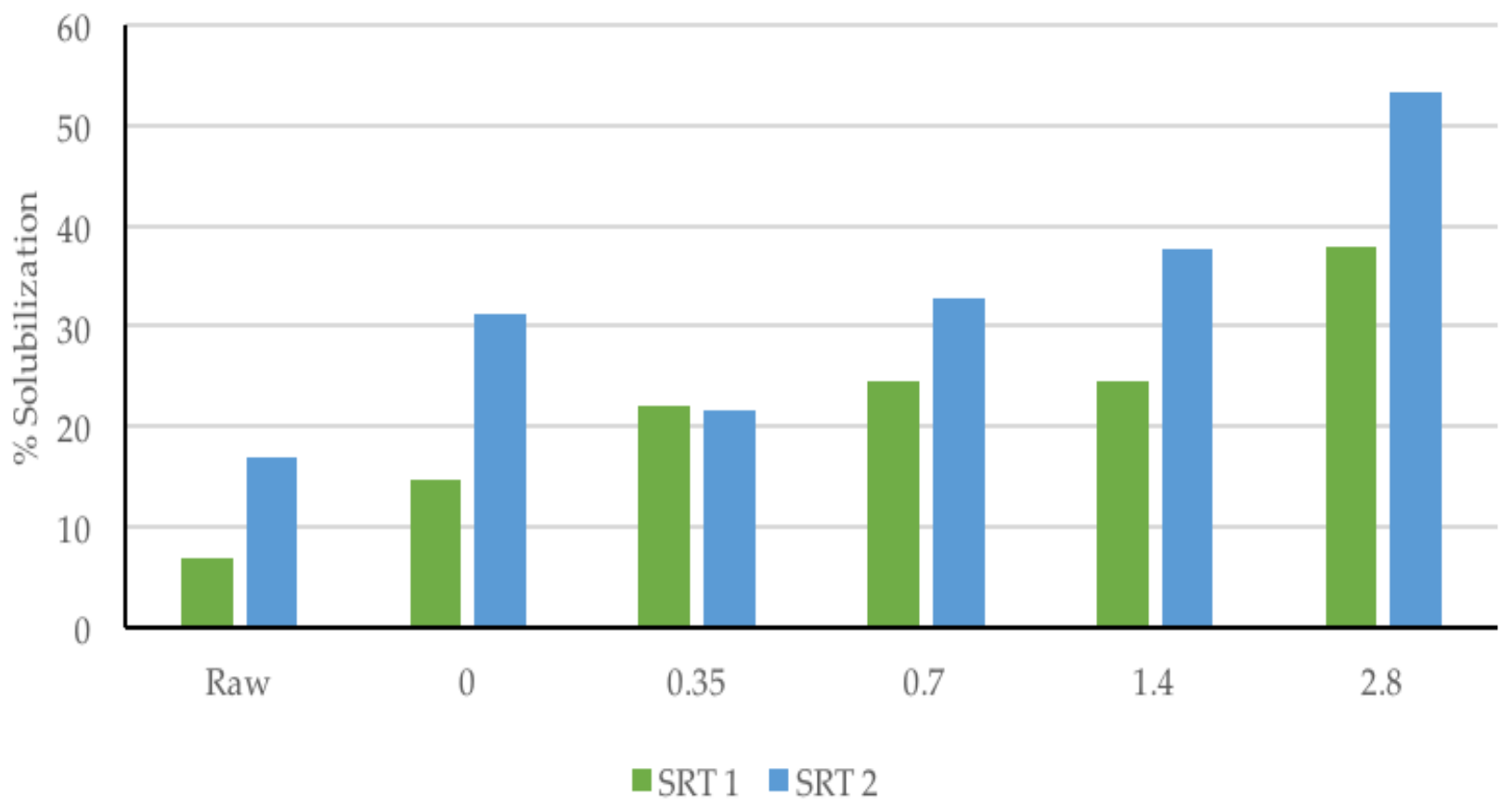

Figure A-1: Carbohydrate solubilization with varying pre-treatment conditions and varying SRT

\begin{tabular}{|c|c|c|c|c|}
\hline Day & $\begin{array}{c}\text { Reactor } \\
\text { Number }\end{array}$ & abs & $\begin{array}{c}\text { Concentration } \\
\text { (mg/L glucose) }\end{array}$ & $\begin{array}{c}\text { Corrected Concentration } \\
\text { (mg/L glucose) }\end{array}$ \\
\hline 2 (evening) & 1 & 1.019 & 458.5742 & 917.15 \\
\hline 2 (evening) & 2 & 1.021 & 460.7214 & 921.44 \\
\hline 2 (evening) & 3 & 1.127 & 579.3372 & $1,158.67$ \\
\hline 2 (evening) & 4 & 1.091 & 537.9921 & $1,075.98$ \\
\hline 2 (evening) & 5 & 1.097 & 544.8072 & $1,089.61$ \\
\hline 2 (evening) & 6 & 1.105 & 553.9411 & $1,107.88$ \\
\hline 4 (morning) & 1 & 1.037 & 478.0197 & 956.04 \\
\hline 4 (morning) & 2 & 1.092 & 539.1259 & $1,078.25$ \\
\hline 4 (morning) & 3 & 1.036 & 476.9322 & $1,060.16$ \\
\hline 4 (morning) & 4 & 1.084 & 530.0795 & $1,055.65$ \\
\hline 4 (morning) & 5 & 1.082 & 527.8263 & $1,035.46$ \\
\hline 4 (morning) & 6 & 1.073 & 517.7286 & \\
\hline
\end{tabular}

Table A-6: Total Protein Concentration in 1-day SRT 


\begin{tabular}{|c|c|c|c|c|}
\hline Day & $\begin{array}{c}\text { Reactor } \\
\text { Number }\end{array}$ & abs & $\begin{array}{c}\text { Concentration } \\
\text { (mg/L glucose) }\end{array}$ & $\begin{array}{c}\text { Corrected Concentration } \\
\text { (mg/L glucose) }\end{array}$ \\
\hline 3 & 1 & 0.998 & 436.2325 & 872.47 \\
\hline 3 & 2 & 0.998 & 436.2325 & 872.47 \\
\hline 3 & 3 & 1.015 & 454.29 & 908.58 \\
\hline 3 & 4 & 0.959 & 395.7255 & 931.45 \\
\hline 3 & 5 & 1.029 & 469.3436 & 538.69 \\
\hline 3 & 6 & 1.063 & 506.5889 & 673.18 \\
\hline 6 & 1 & 0.839 & 279.1179 & 665.99 \\
\hline 6 & 2 & 0.9 & 336.8789 & 576.74 \\
\hline 6 & 3 & 0.896 & 332.9954 & 734.87 \\
\hline 6 & 4 & 0.849 & 288.3723 & 845.18 \\
\hline 6 & 5 & 0.931 & 367.4331 & 422.588 \\
\hline 6 & 6 & 0.985 & & \\
\hline
\end{tabular}

Table A-7: Total Protein Concentration in 2-day SRT

\begin{tabular}{|c|c|c|c|c|}
\hline Day & $\begin{array}{c}\text { Reactor } \\
\text { Number }\end{array}$ & abs & $\begin{array}{c}\text { Concentration } \\
\text { (mg/L glucose) }\end{array}$ & $\begin{array}{c}\text { Corrected Concentration } \\
\text { (mg/L glucose) }\end{array}$ \\
\hline 2 (evening) & 1 & 0.801 & 6.106525 & 61.06525 \\
\hline 2 (evening) & 2 & 0.88 & 8.61244 & 86.1244 \\
\hline 2 (evening) & 3 & 0.905 & 9.414508 & 112.8304 \\
\hline 2 (evening) & 4 & 0.966 & 11.28304 & 86.61411 \\
\hline 2 (evening) & 5 & 1.311 & 8.661411 & 63.21629 \\
\hline 2 (evening) & 6 & 0.808 & 6.321629 & 46.97829 \\
\hline 4 (morning) & 1 & 0.753 & 4.697829 & 92.54895 \\
\hline 4 (morning) & 2 & 0.9 & 9.254895 & 117.0681 \\
\hline 4 (morning) & 3 & 0.981 & 11.70681 & 136.4978 \\
\hline 4 (morning) & 4 & 1.263 & 11.49832 & 137.106 \\
\hline 4 (morning) & 5 & 1.068 & 13.64978 & 13.7106 \\
\hline 4 (morning) & 6 & 1.194 & & \\
\hline
\end{tabular}

Table A-8: Soluble Protein Concentration in 1-day SRT 


\begin{tabular}{|c|c|c|c|c|}
\hline Day & $\begin{array}{l}\text { Reactor } \\
\text { Number }\end{array}$ & abs & $\begin{array}{l}\text { Concentration } \\
\text { (mg/L glucose) }\end{array}$ & $\begin{array}{c}\text { Corrected Concentration } \\
\text { (mg/L glucose) }\end{array}$ \\
\hline 3 & 1 & 1.292 & 9.927297 & 99.27297 \\
\hline 3 & 2 & 1.298 & 9.548598 & 95.48598 \\
\hline 3 & 3 & 1.16 & 14.13644 & 141.3644 \\
\hline 3 & 4 & 0.939 & 10.47898 & 104.7898 \\
\hline 3 & 5 & 1.374 & 2.946867 & 29.46867 \\
\hline 3 & 6 & 1.4 & -0.17197 & 0 \\
\hline 6 & 1 & 0.932 & 10.26363 & 102.6363 \\
\hline 6 & 2 & 0.904 & 9.382629 & 93.82629 \\
\hline 6 & 3 & 0.919 & 9.857952 & 98.57952 \\
\hline 6 & 4 & 1.141 & 14.21481 & 142.1481 \\
\hline 6 & 5 & 1.29 & 10.04931 & 100.4931 \\
\hline 6 & 6 & 0.821 & 6.726173 & 67.26173 \\
\hline
\end{tabular}

Table A-9: Soluble Protein Concentration in 2-day SRT

\section{Protein Solubilization}

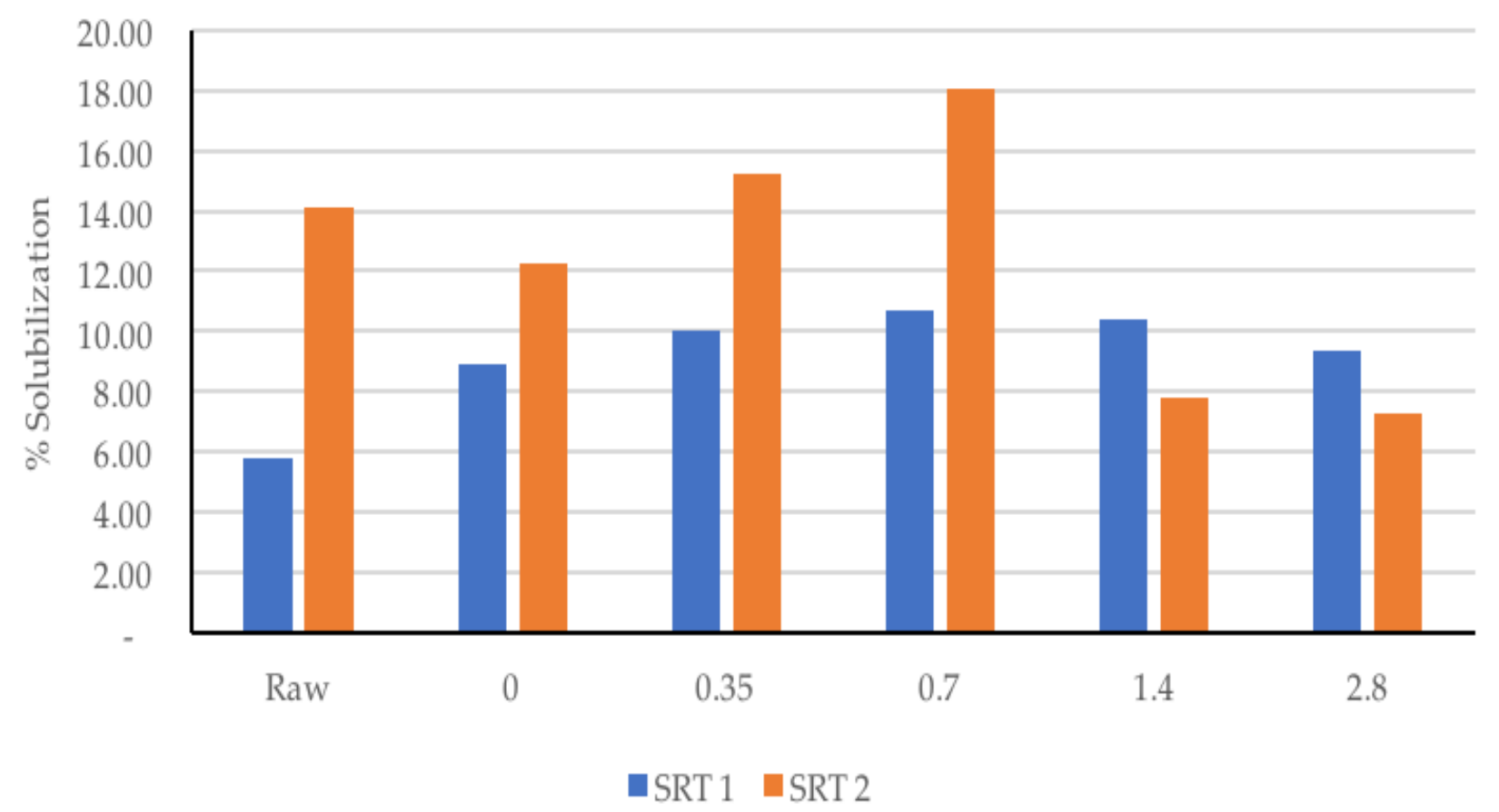

Figure A-2: Protein solubilization with varying pre-treatment conditions and varying SRT 


\begin{tabular}{|c|c|c|c|c|c|}
\hline Day & $\begin{array}{r}\text { Reactor } \\
\text { Number }\end{array}$ & $\begin{array}{l}\text { Nitrite } \\
\text { (mg/L) }\end{array}$ & $\begin{array}{l}\text { Nitrate } \\
(\mathrm{mg} / \mathrm{L})\end{array}$ & $\begin{array}{c}\text { Total Soluble } \\
\text { Nitrogen }(\mathrm{mg} / \mathrm{L})\end{array}$ & $\begin{array}{c}\text { Total Nitrogen } \\
(\mathrm{mg} / \mathrm{L})\end{array}$ \\
\hline 2 (evening) & 1 & 3.6 & 3 & 170 & 2050 \\
\hline 2 (evening) & 2 & 0.2 & 2 & 410 & 2800 \\
\hline 2 (evening) & 3 & 3.3 & 2 & 260 & 3350 \\
\hline 2 (evening) & 4 & 2.9 & 3 & 630 & 3450 \\
\hline 2 (evening) & 5 & 3.3 & 4 & 540 & 2500 \\
\hline 2 (evening) & 6 & 4.2 & 2 & 600 & 2200 \\
\hline 4 (morning) & 1 & 2.2 & 2 & 340 & 1900 \\
\hline 4 (morning) & 2 & 2.4 & 4 & 570 & 2200 \\
\hline 4 (morning) & 3 & 3.8 & 3 & 590 & 2750 \\
\hline 4 (morning) & 4 & 4.1 & 4 & 500 & 2000 \\
\hline 4 (morning) & 5 & 4.3 & 2 & 470 & 3550 \\
\hline 4 (morning) & 6 & 5.6 & 4 & 420 & 2950 \\
\hline
\end{tabular}

Table A-10: Nitrogen species Concentration in 1-day SRT

\begin{tabular}{|c|c|c|c|c|c|}
\hline Day & $\begin{array}{c}\text { Reactor } \\
\text { Number }\end{array}$ & $\begin{array}{c}\text { Nitrite } \\
(\mathbf{m g} / \mathbf{L})\end{array}$ & $\begin{array}{c}\text { Nitrate } \\
(\mathbf{m g} / \mathbf{L})\end{array}$ & $\begin{array}{c}\text { Total Soluble } \\
\text { Nitrogen }(\mathbf{m g} / \mathbf{L})\end{array}$ & $\begin{array}{c}\text { Total Nitrogen } \\
(\mathbf{m g} / \mathbf{L})\end{array}$ \\
\hline 3 & 1 & 2.5 & 1 & 810 & 2450 \\
\hline 3 & 2 & 2.5 & 1 & 870 & 2800 \\
\hline 3 & 3 & 2.6 & 6 & 840 & 2500 \\
\hline 3 & 4 & 3.5 & 2 & 640 & 2050 \\
\hline 3 & 5 & 3.7 & 4 & 860 & 2100 \\
\hline 3 & 6 & 2.9 & 5 & 440 & 2150 \\
\hline 6 & 1 & 2.4 & 4 & 550 & 2350 \\
\hline 6 & 2 & 3.7 & 2 & 610 & 2150 \\
\hline 6 & 3 & 3.7 & 3 & 470 & 1950 \\
\hline 6 & 4 & 3.0 & 3 & 490 & 1750 \\
\hline 6 & 5 & 3.0 & 4 & 410 & 2350 \\
\hline 6 & 6 & 2.9 & 3 & 400 & \\
\hline
\end{tabular}

Table A-11: Nitrogen species Concentration in 2-day SRT 


\section{Nitrogen Solubilization}

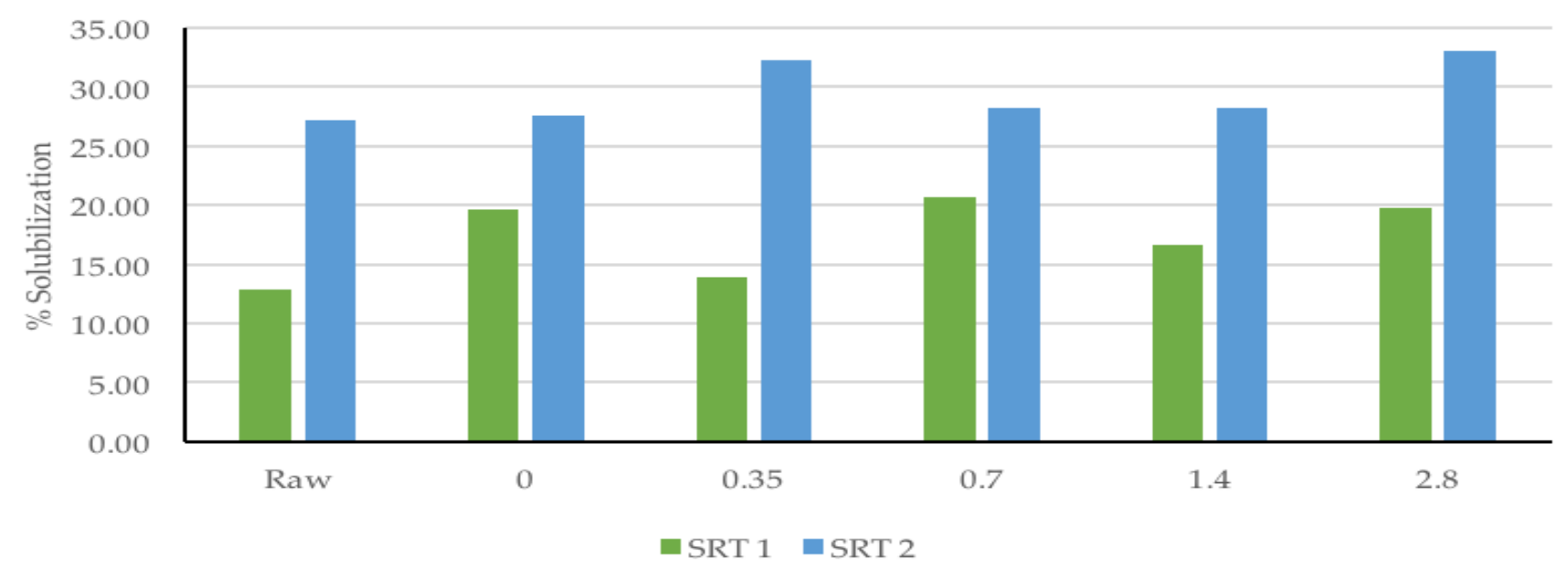

Figure A-3: Nitrogen solubilization with varying pre-treatment conditions and varying SRT SRT 1

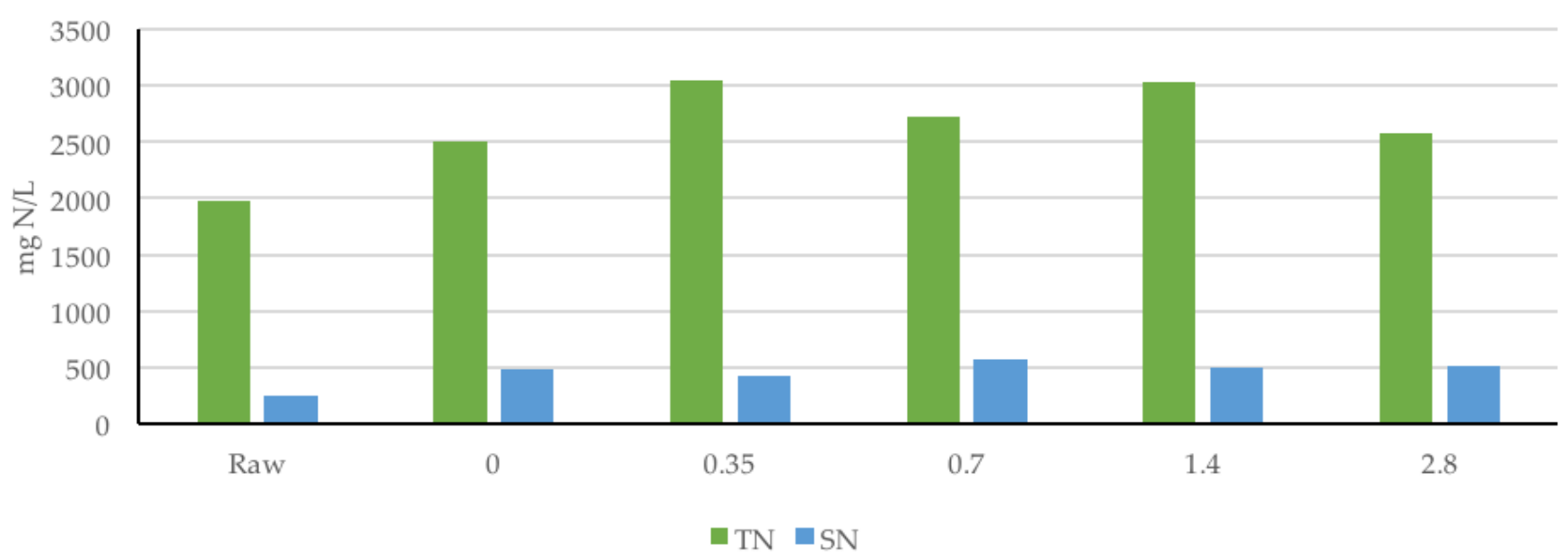

Figure A-4: Total vs Soluble Nitrogen content (SRT 1 day)

SRT 2

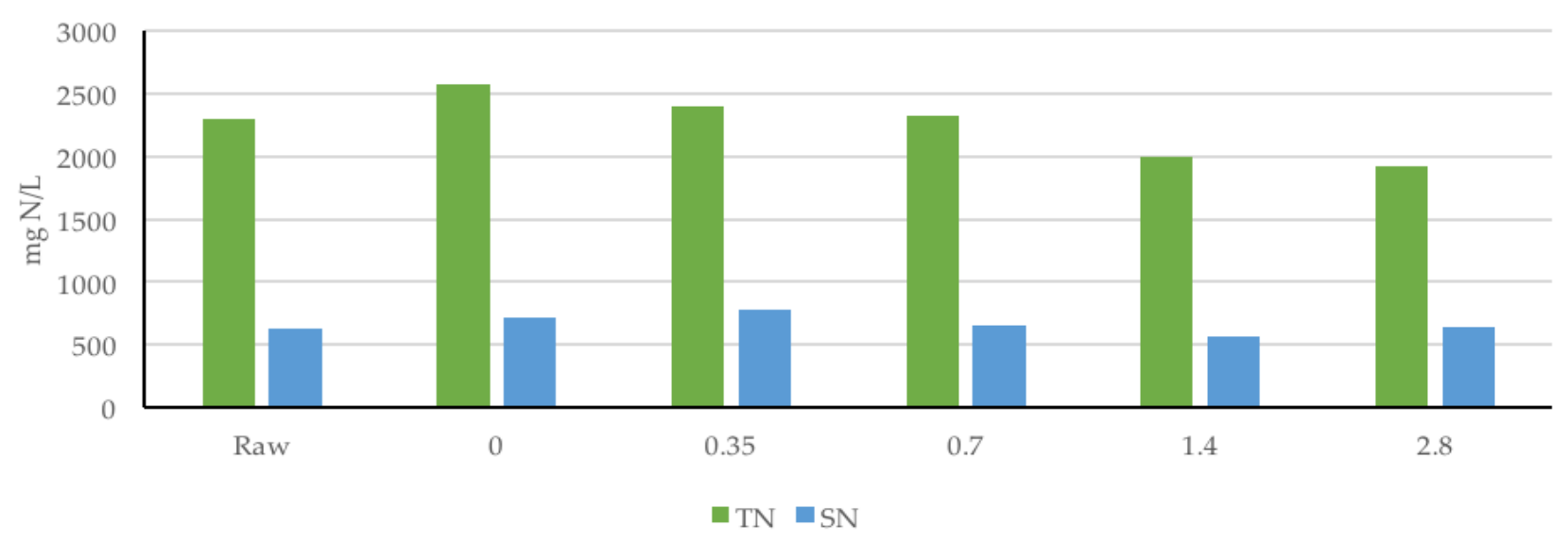

Figure A-5: Total vs Soluble Nitrogen content (SRT 2 day) 


\begin{tabular}{|c|c|c|}
\hline $\begin{array}{c}\text { FNA Concentration } \\
(\mathbf{m g} \text { N/L) }\end{array}$ & $\begin{array}{c}\text { SRT 1 } \\
(\mathbf{m g} / \mathbf{L})\end{array}$ & $\begin{array}{c}\text { SRT 2 } \\
(\mathbf{m g} / \mathbf{L})\end{array}$ \\
\hline Raw & 553 & 940 \\
\hline $\mathbf{0}$ & 708 & 880 \\
\hline $\mathbf{0 . 3 5}$ & 725 & 875 \\
\hline $\mathbf{0 . 7}$ & 730 & 948 \\
\hline $\mathbf{1 . 4}$ & 930 & 830 \\
\hline $\mathbf{2 . 8}$ & 698 & 848 \\
\hline
\end{tabular}

Table A-12: Ammonia Concentrations in 1-day and 2-day SRT

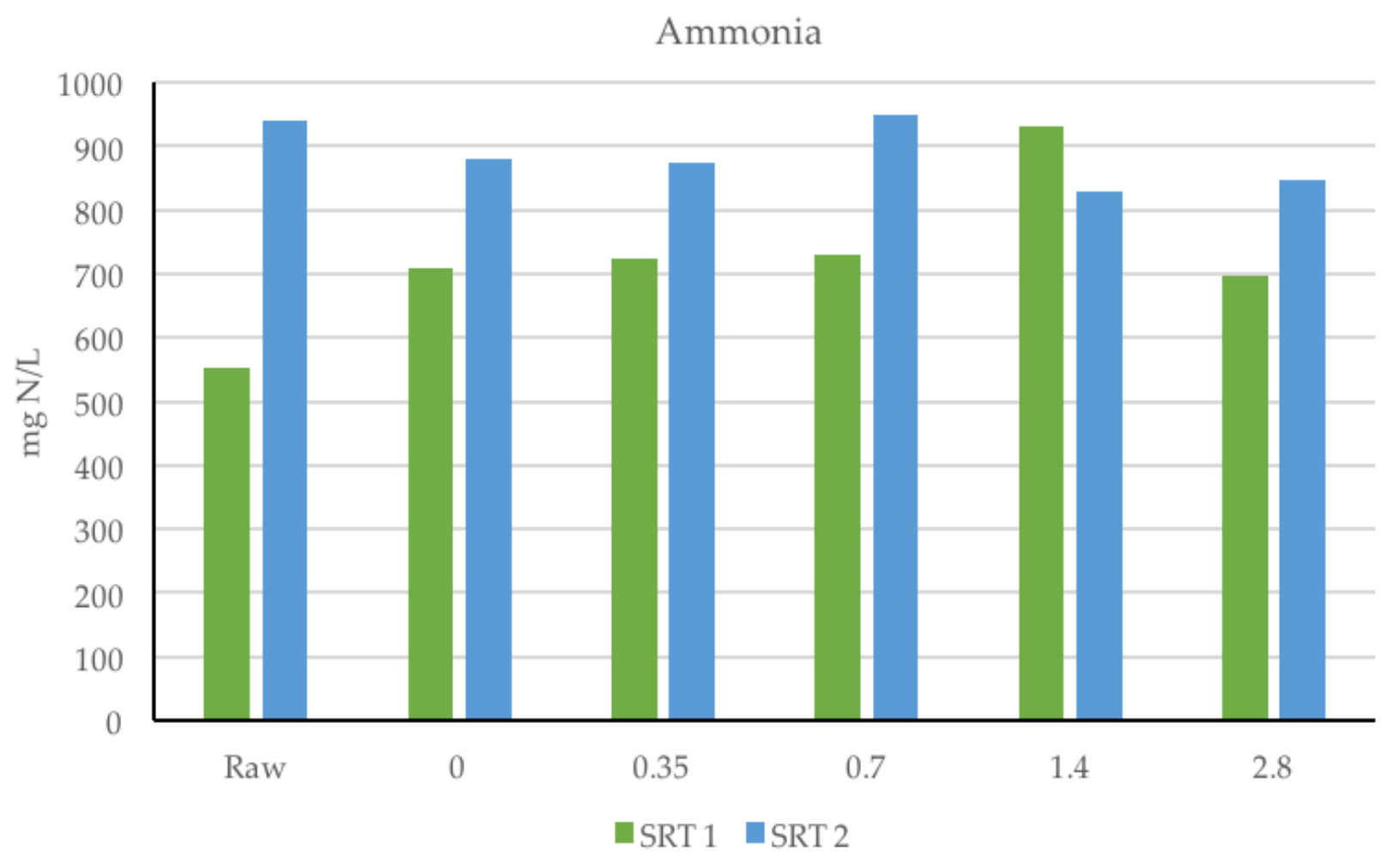

Figure A-6: Ammonia Concentrations in 1-day and 2-day SRT 


\begin{tabular}{|c|c|c|}
\hline $\begin{array}{c}\text { FNA Concentration } \\
(\mathbf{m g} \text { N/L) }\end{array}$ & $\begin{array}{c}\text { SRT 1 } \\
(\mathbf{m g} / \mathbf{L})\end{array}$ & $\begin{array}{c}\text { SRT 2 } \\
(\mathbf{m g} / \mathbf{L})\end{array}$ \\
\hline Raw & 2285 & 1710 \\
\hline $\mathbf{0}$ & 1885 & 2050 \\
\hline $\mathbf{0 . 3 5}$ & 2440 & 2345 \\
\hline $\mathbf{0 . 7}$ & 2815 & 2265 \\
\hline $\mathbf{1 . 4}$ & 3130 & 2525 \\
\hline $\mathbf{2 . 8}$ & 2440 & 1970 \\
\hline
\end{tabular}

Table A-13: Alkalinity Concentrations in 1-day and 2-day SRT

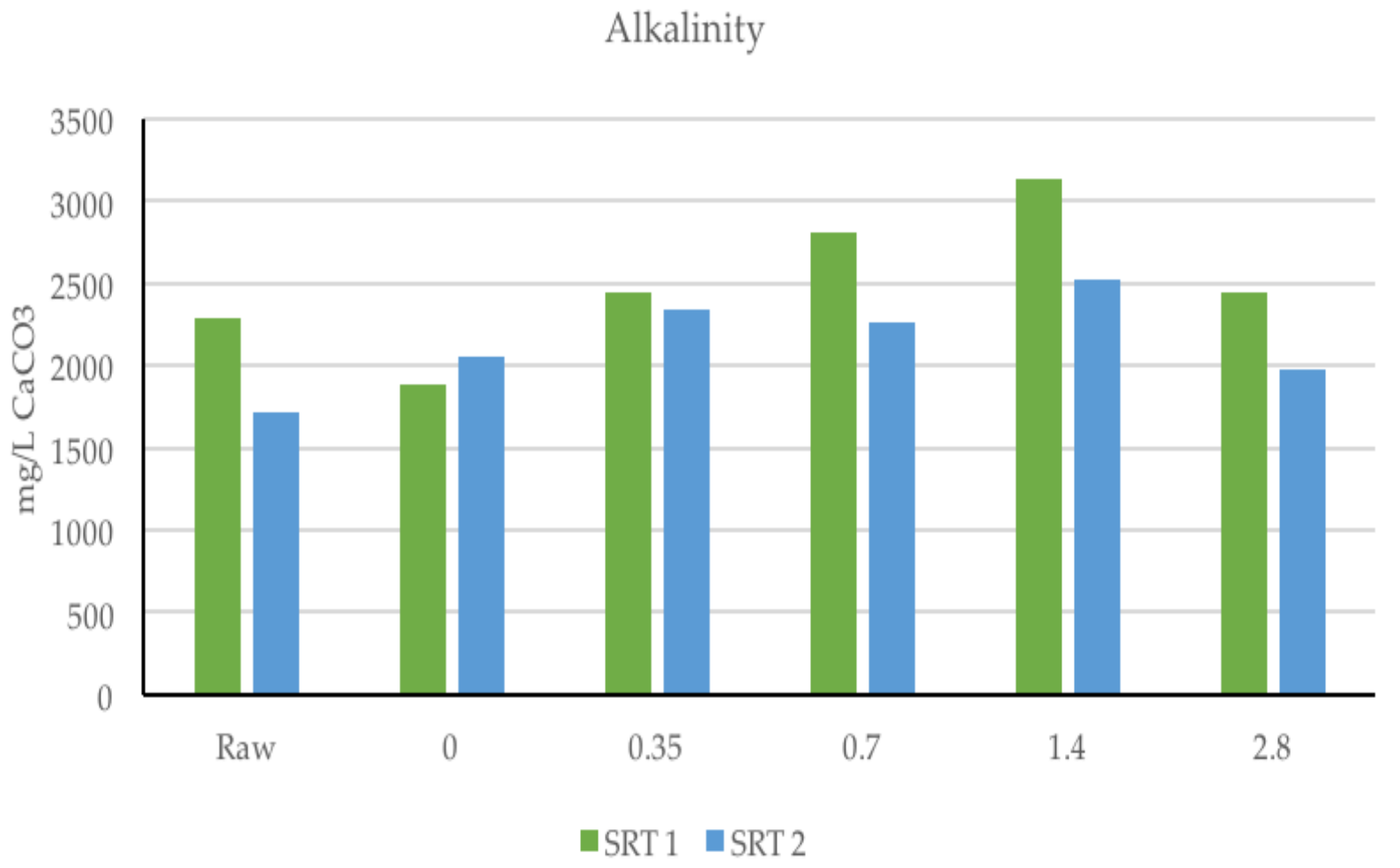

Figure A-7: Alkalinity Concentrations in 1-day and 2-day SRT 


\begin{tabular}{|c|c|c|}
\hline $\begin{array}{c}\text { FNA Concentration } \\
(\mathbf{m g} \text { N/L) }\end{array}$ & $\begin{array}{c}\text { SRT 1 } \\
(\mathbf{m g} / \mathbf{L})\end{array}$ & $\begin{array}{c}\text { SRT 2 } \\
(\mathbf{m g} / \mathbf{L})\end{array}$ \\
\hline Raw & 48950 & 45675 \\
\hline $\mathbf{0}$ & 50725 & 45925 \\
\hline $\mathbf{0 . 3 5}$ & 46275 & 46450 \\
\hline $\mathbf{0 . 7}$ & 50775 & 49700 \\
\hline $\mathbf{1 . 4}$ & 49525 & 40775 \\
\hline $\mathbf{2 . 8}$ & 41475 & 33500 \\
\hline
\end{tabular}

Table A-14: Total COD Concentrations in 1-day and 2-day SRT

\section{Total COD}

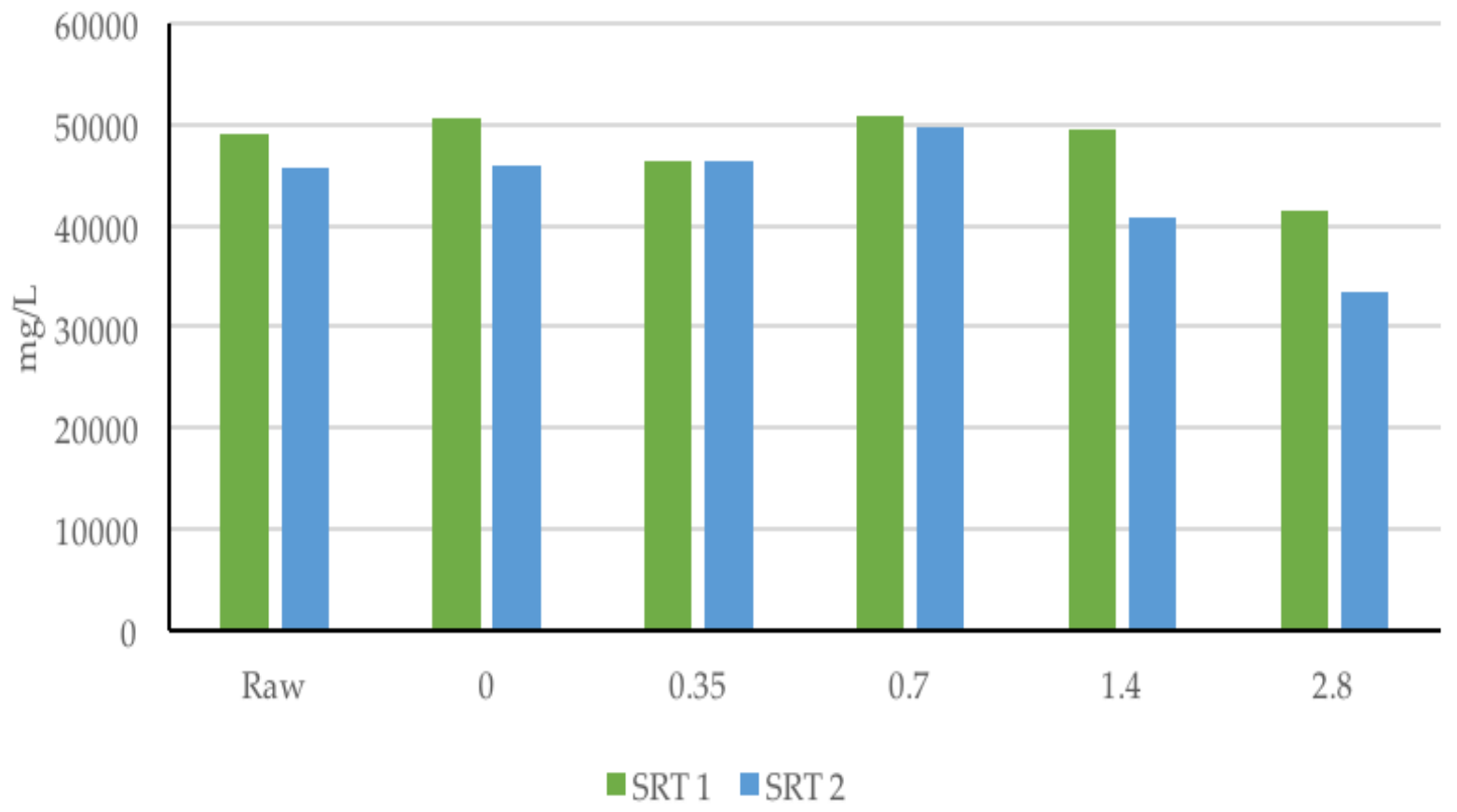

rlgure A-ð: Iotal CUU Concentratıons in I-aay ana L-aay دKI 


\begin{tabular}{|c|c|c|}
\hline $\begin{array}{c}\text { FNA Concentration } \\
(\mathbf{m g} \text { N/L) }\end{array}$ & $\begin{array}{c}\text { SRT 1 } \\
(\mathbf{m g} / \mathbf{L})\end{array}$ & $\begin{array}{c}\text { SRT 2 } \\
(\mathbf{m g} / \mathbf{L})\end{array}$ \\
\hline Raw & 1485 & 5600 \\
\hline $\mathbf{0}$ & 2300 & 5525 \\
\hline $\mathbf{0 . 3 5}$ & 2575 & 5470 \\
\hline $\mathbf{0 . 7}$ & 3085 & 5130 \\
\hline $\mathbf{1 . 4}$ & 3245 & 4945 \\
\hline $\mathbf{2 . 8}$ & 5025 & 4160 \\
\hline
\end{tabular}

Table A-15: Soluble COD Concentrations in 1-day and 2-day SRT

\section{Soluble COD}

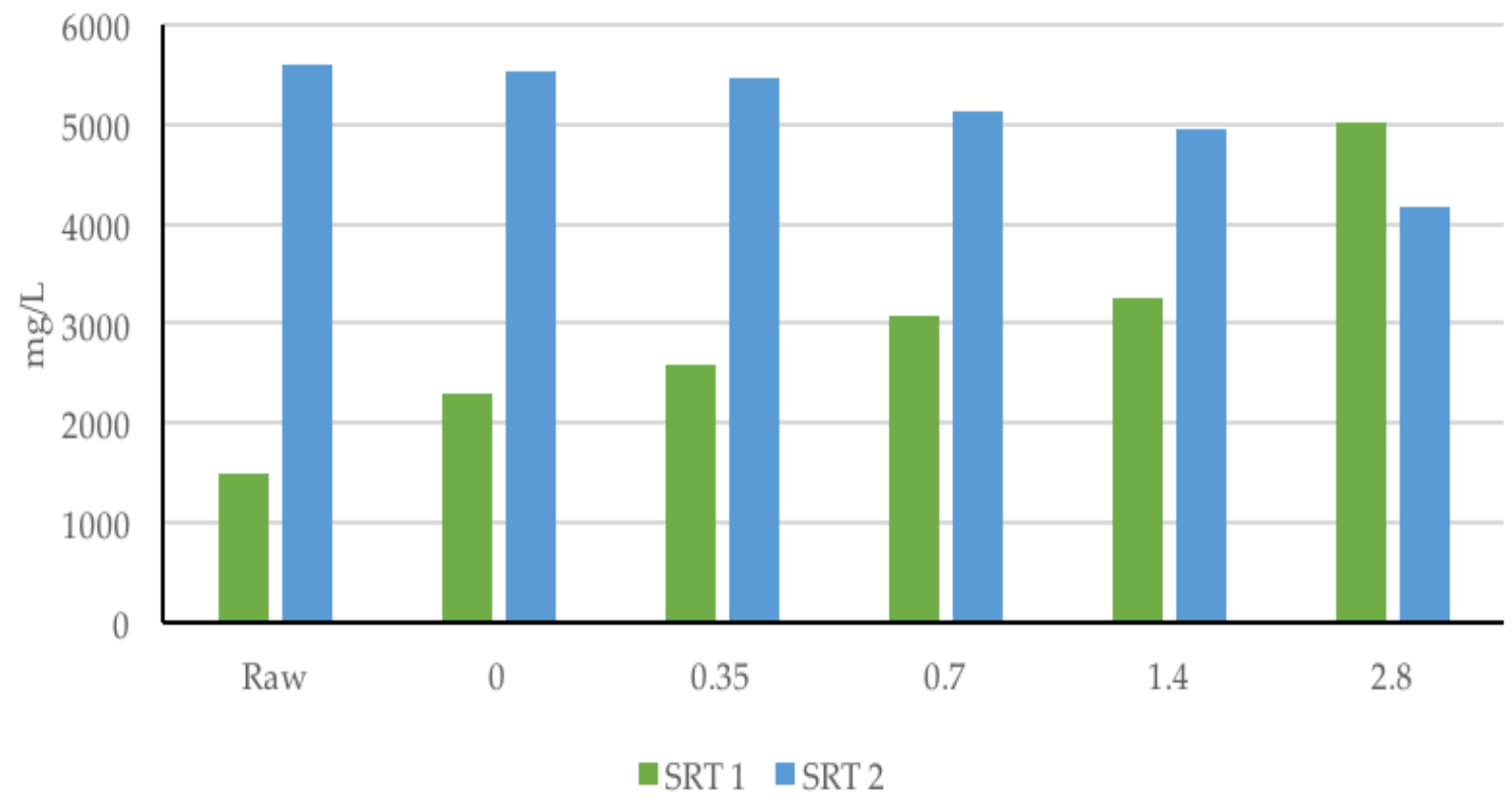




\begin{tabular}{|c|c|c|}
\hline $\begin{array}{c}\text { FNA Concentration } \\
(\mathbf{m g ~ N} / \mathbf{L})\end{array}$ & $\begin{array}{c}\text { SRT 1 } \\
(\mathbf{m g} / \mathbf{L})\end{array}$ & $\begin{array}{c}\text { SRT 2 } \\
(\mathbf{m g} / \mathbf{L})\end{array}$ \\
\hline Raw & 3 & 12 \\
\hline $\mathbf{0}$ & 5 & 12 \\
\hline $\mathbf{0 . 3 5}$ & 6 & 12 \\
\hline $\mathbf{0 . 7}$ & 6 & 10 \\
\hline $\mathbf{1 . 4}$ & 7 & 12 \\
\hline $\mathbf{2 . 8}$ & 12 & 12 \\
\hline
\end{tabular}

Table A-16: Percentage Solubilization in 1-day and 2-day SRT

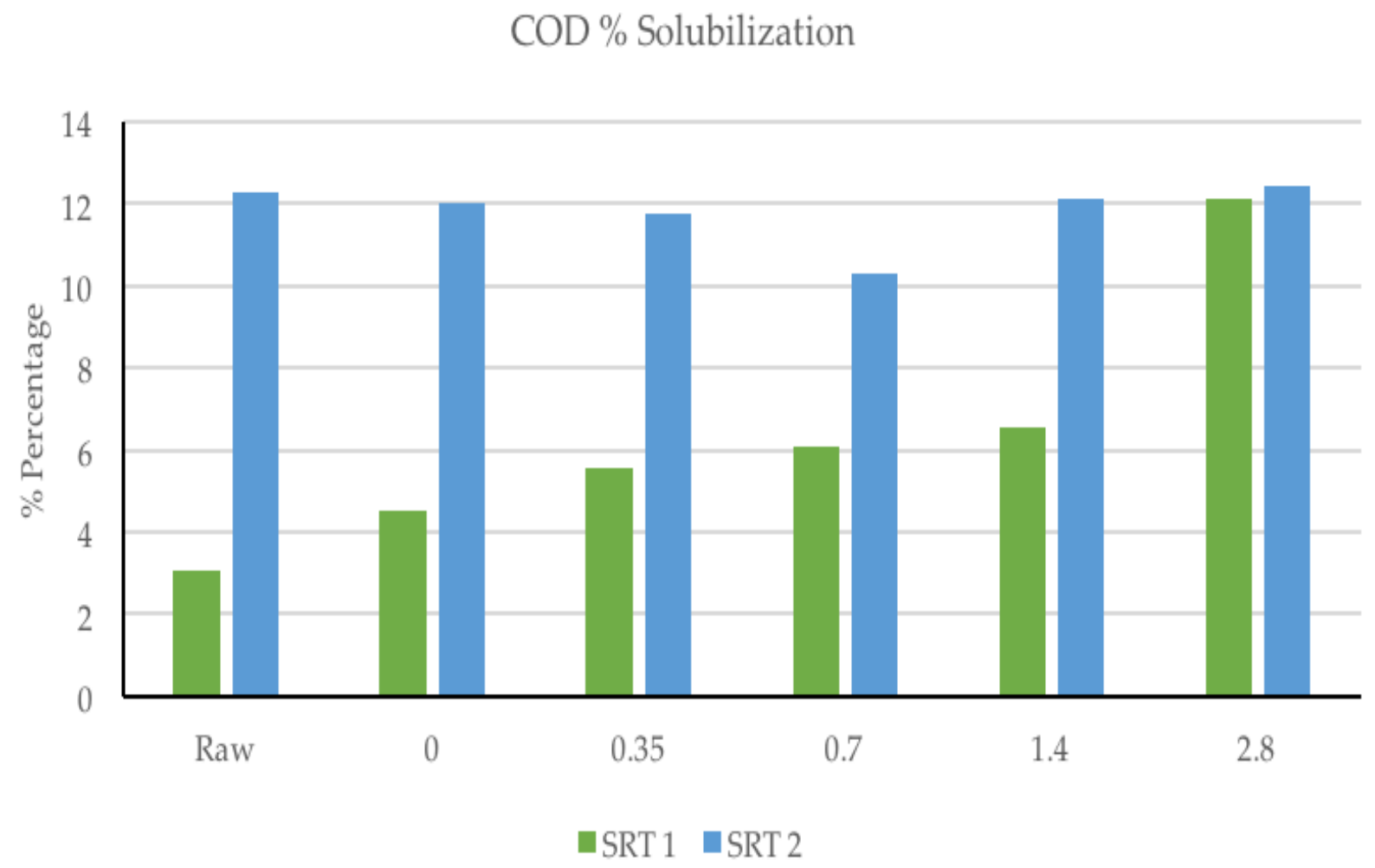

Figure A-10: Percentage Solubilization in 1-day and 2-day SRT 


\begin{tabular}{|c|c|c|}
\hline $\begin{array}{c}\text { FNA Concentration } \\
(\mathbf{m g ~ N} / \mathbf{L})\end{array}$ & $\begin{array}{c}\text { SRT 1 } \\
(\mathbf{m g} / \mathbf{L})\end{array}$ & $\begin{array}{c}\text { SRT 2 } \\
(\mathbf{m g} / \mathbf{L})\end{array}$ \\
\hline Raw & 2.12 & 2.32 \\
\hline $\mathbf{0}$ & 2.05 & 2.47 \\
\hline $\mathbf{0 . 3 5}$ & 2.07 & 2.22 \\
\hline $\mathbf{0 . 7}$ & 2.08 & 2.33 \\
\hline $\mathbf{1 . 4}$ & 2.22 & 2.12 \\
\hline $\mathbf{2 . 8}$ & 2.14 & 1.75 \\
\hline
\end{tabular}

Table A-17: Total Solids in 1-day and 2-day SRT

Total Solids

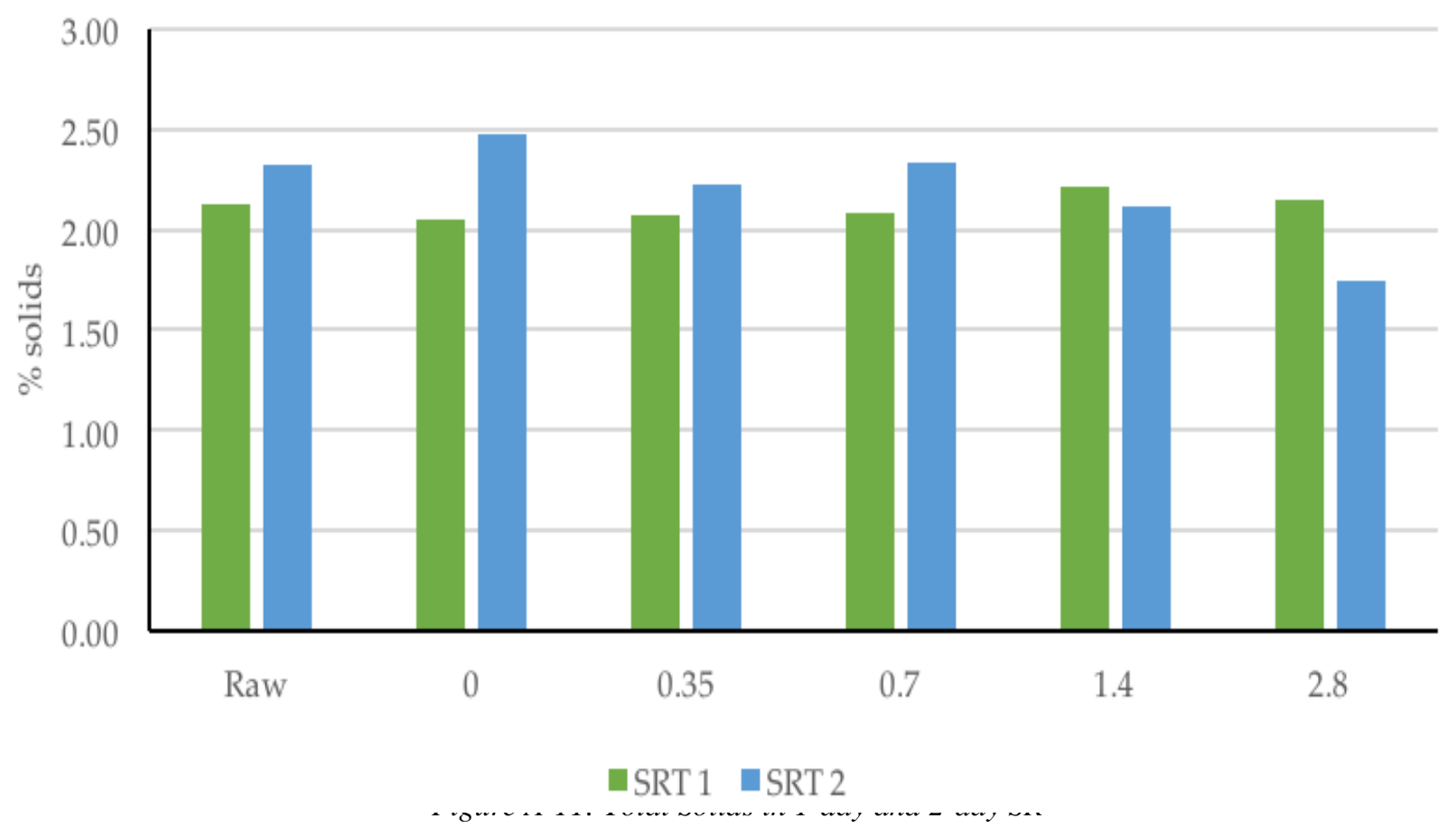




\begin{tabular}{|c|c|c|}
\hline $\begin{array}{c}\text { FNA Concentration } \\
(\mathbf{m g ~ N / L )}\end{array}$ & $\begin{array}{c}\text { SRT 1 } \\
(\mathbf{m g} / \mathbf{L})\end{array}$ & $\begin{array}{c}\text { SRT 2 } \\
(\mathbf{m g} / \mathbf{L})\end{array}$ \\
\hline Raw & 58.38 & 65.97 \\
\hline $\mathbf{0}$ & 59.22 & 66.92 \\
\hline $\mathbf{0 . 3 5}$ & 58.18 & 63.57 \\
\hline $\mathbf{0 . 7}$ & 57.73 & 65.10 \\
\hline $\mathbf{1 . 4}$ & 58.77 & 60.63 \\
\hline $\mathbf{2 . 8}$ & 56.84 & 50.24 \\
\hline
\end{tabular}

Table A-18: Volatile Solids in 1-day and 2-day SRT

\section{Volatile Solids}

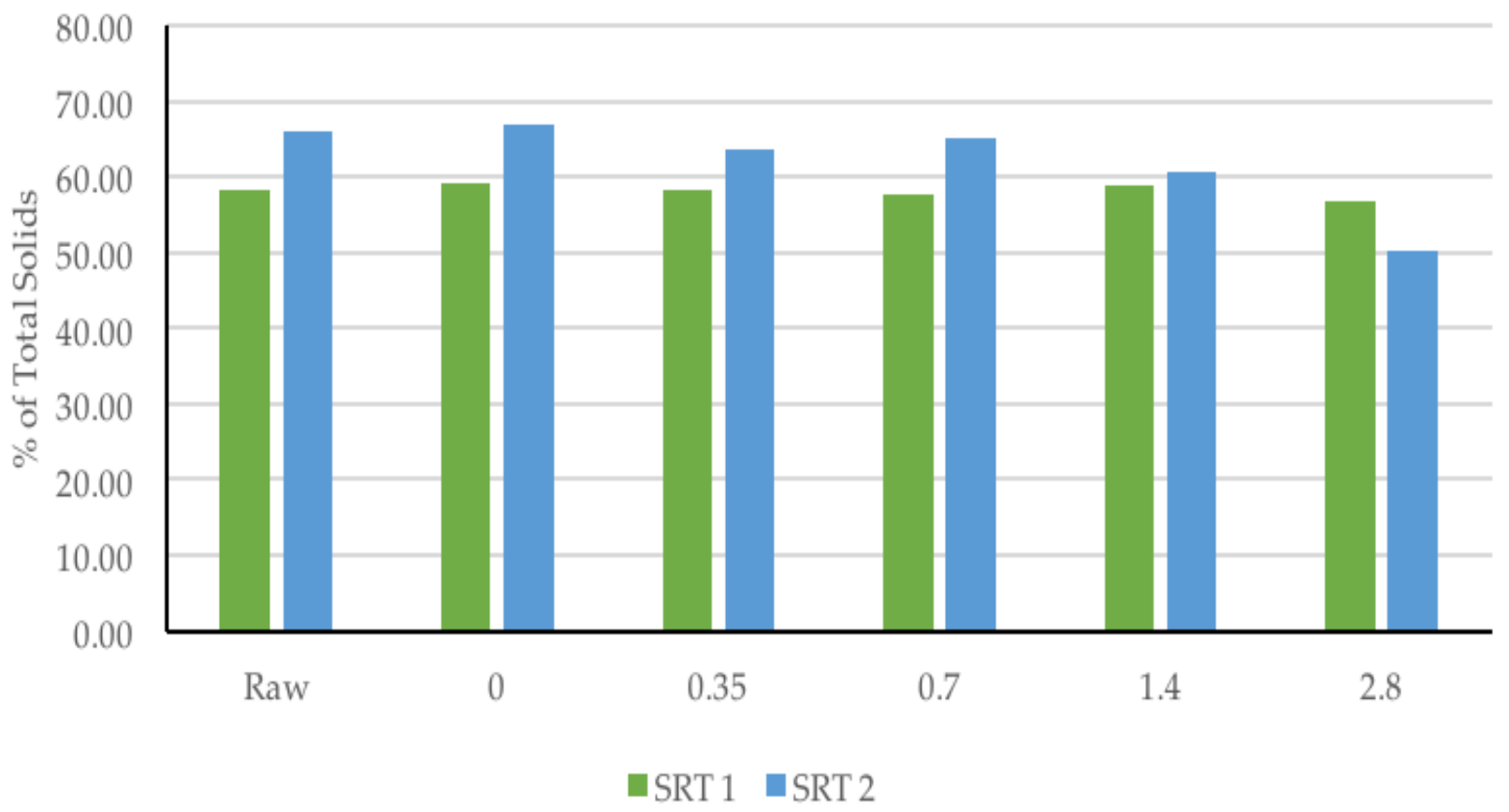

Figure A-12: Volatile Solids in 1-day and 2-day SRT 


\begin{tabular}{|c|c|c|}
\hline $\begin{array}{c}\text { FNA Concentration } \\
(\mathbf{m g ~ N} / \mathbf{L})\end{array}$ & $\begin{array}{c}\text { SRT 1 } \\
(\mathbf{m g} / \mathbf{L})\end{array}$ & $\begin{array}{c}\text { SRT 2 } \\
(\mathbf{m g} / \mathbf{L})\end{array}$ \\
\hline Raw & 4260.00 & 3460.00 \\
\hline $\mathbf{0}$ & 4600.00 & 3510.00 \\
\hline $\mathbf{0 . 3 5}$ & 4310.00 & 3670.00 \\
\hline $\mathbf{0 . 7}$ & 4805.00 & 3510.00 \\
\hline $\mathbf{1 . 4}$ & 4220.00 & 3430.00 \\
\hline $\mathbf{2 . 8}$ & 4310.00 & 3145.00 \\
\hline
\end{tabular}

Table A-19: Total Phosphorus Concentrations in 1-day and 2-day SRT

Total Phosphorus

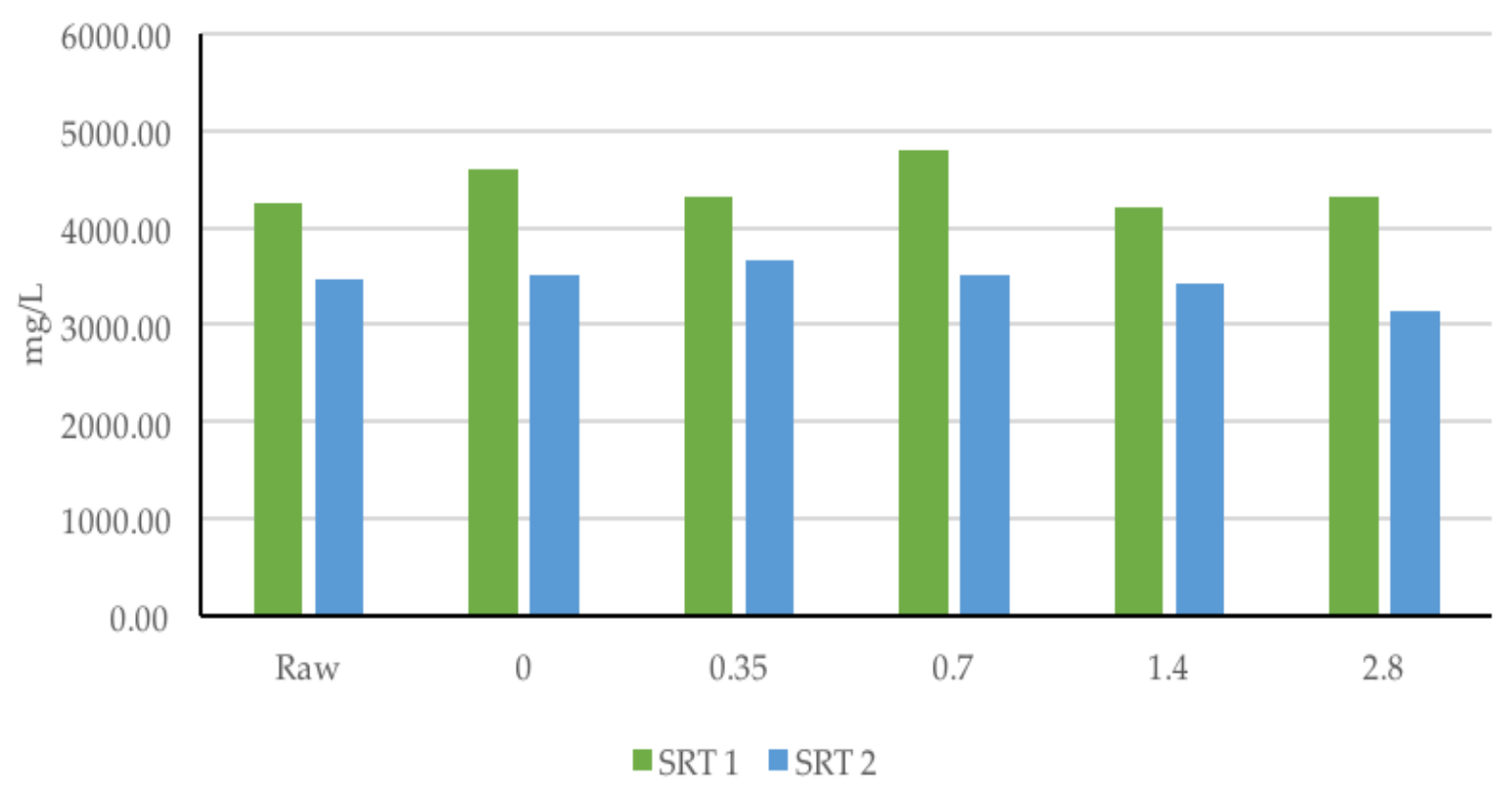

Figure A-13: Total Phosphorus Concentrations in 1-day and 2-day SRT 


\section{References}

Albuquerque, M. G., Eiroa, M., Torres, C., Nunes, B. R., \& Reis, M. A. (2007, July 15). Strategies for the development of a side stream process for polyhydroxyalkanoate (PHA) production from sugar cane molasses. Journal of Biotechnology, 130(4), 411421.

Álvarez-Gallego, C. J., Fdez-Güelfo, L. A., Romero Aguilar, M., \& Romero García, L. I. (2015, February 9). Thermochemical pretreatments of organic fraction of municipal solid waste from a mechanical-biological treatment plant. (J. H. Clark, Ed.) International Journal of Molecular Sciences, 3769 - 3782.

American Public Health Association. (1992). APHA Method 9215: Standard Methods for the Examination of Water and Wastewater. United States of America: American Public Health Association, American Water Works Association, Water Environment Federation.

Appels, L., Baeyens, J., Degrève, J., \& Dewil, R. (2008). Principles and potential of the anaerobic digestion of waste-activated sludge. Prog. Energy Combust. Sci., 34(6), 755781.

Ariunbaatar, J., Panico, A., Esposito, G., Pirozzi, F., \& Lens, P. N. (2014). Pretreatment methods to enhance anaerobic digestion of organic solid. Applied Energy, 123, 146 $-156$.

Ariunbaatar, J., Panico, A., Esposito, G., Pirozzi, F., \& Lens, P. N. (2014). Pretreatment methods to enhance anaerobic digestion of organic solid waste. Appl. Evergy, 123, 143156.

Atherton, H. (1995). Primary Sludge Fermentation Using a Pilot-Scale Mainstream Fermenter to Enhance Biological Phosphorus Removal. Master Thesis, University of British Columbia, Department of Civil Engineering.

Banerjee, A. K. (1997). The Effect of Hydraulic Retention Time (HRT). UMI.

Bengtsson, S., Hallquist, J., Werker, A., \& Welander, T. (2008, July). Acidogenic Fermentation of Industrial Wastewaters: Effects of Chemostat Retention Time and $\mathrm{pH}$ on Volatile Fatty Acids Production. Biochemical Engieering Journal, 40(3), 492-499.

Boardman, G. D. (2003). Anaerobic Digestion (Vol. 3rd Edition Volume 1). (M. Bortman, P. Brimblecombe, \& M. Cunningham, Eds.) Detroit: 
Environmental Encyclopedia.

Boucher, P. S., \& Van Eeden, J. J. (n.d.). Investigation of Inorganic Material Derived from Water Purification Processes for Ceramic Applications. Water Research Commission Report, Pretoria.

Çalli, B. (2009). Anaerobic Fermentation of Organic Wastes for Production of Soluble Compounds. Presentation, Marmara University, Department of Environmental Engineering, Instanbul.

Chi, Z., Zheng, Y., Ma, J., \& Chen, S. (2011, August). Oleaginous yeast Cryptococcus curvatus Culture with dark Fermentation Hydrogen Production Effluent as Feedstock for microbial Lipid production. International Journal of Hydrogen Energy, 36(16), 9542-9550.

Chisti, Y. (1999). Fermentation (Industrial): Basic Considerations. Encyclopedia of Food Microbiology, 663-674.

City of Toronto. (2016). Ashbridges Bay Wastewater Treatment Plant 2015 Annual Report. Toronto.

De Falco, M., \& Basile, A. (Eds.). (2015). Enriched Methane: The First Step Towards the Hydrogen Economy. Springer International Publishing.

Elbeshbishy, E. (2016). Wastewater Treatment Process. Lecture Notes.

Elefsiniotis, P., \& Oldham, W. K. (1993). Anaerobic Acidogenesis of Primary Sludge: The Role of Solids Retention Time. The University of British Columbia, Department of Civil Engineering, Vancouver.

Environmental Protection Agency. (2009). Municipal Solid Waste - Pre-treatment \& Residuals Management. An EPA Technical Guidance Document.

Erden, G., \& Filibeli, A. (2011). Effects of fenton pre-treatment on waste activated sludge properties. Clean - Soil, Air, Water, 39(7), 626-632.

Evans, G. (2001). Biowaste and Biological Waste Treatment. London: James \& James (Science Publisher) Ltd.

Fei, Q., Shang, L., Choi, J.-d.-r., Chang, H. N., Kim, N., \& Kang, J. (2011, February). The Effect of Volatile Fatty Acids as a Sole Carbon Source on Lipid Accumulation by Cryptococcus albidus for Biodiesel Production. Bioresource Technology, 102(3), 26952701. 
Fuzhou, T. (2008). Anaerobic degradation and pretreatment of municipal sludge. The University of Western Ontario, Department of Chemical and Biochemical Engineering. London: ProQuest Dissertations Publishing.

Gottschalk, G. (1986). Bacteria Metabolism.

Grady, Jr., C., Daigger, G. T., Love, N. G., \& Filipe, C. D. (2011). Biological Wastewater Treatment (3rd Edition ed.). CRC Press.

Gujer, W., \& Zehnder, A. J. (1983). Conversion Processes in Anaerobic Digestion. Water Science and Technology, 18(8/9), 127-167.

Gupta, A. K. (2016). Design of Wastewater Treatment Plant and Nutrients Recovery. MEng Project, Ryerson University, Civil Enigneering, Toronto.

Hendriks, A., \& Zeeman, G. (2009, January). Pretreatments to enhance the digestibility of lignocellulosic biomass. Biosource Technology, 100(1), 10 - 18.

Henze, M., Van Loosdrecht, M. C., Brdjanovic, D., Amy, G., Comeau, Y., Ekama, G. A., Zeeman, G. (2008). Biological Wastewater Treatment. (M. Henze, M. Van Loosdrecht, G. Ekama, \& D. Brdjanovic, Eds.) IWA Publishing.

Hidalgo, D., Sastre, E., Gómez, M., \& Nieto, P. (2012). Evaluation of pretreatment process for increasing biodegradablility of agro-food wastes. Environ. Technology, 33(13), 14971503.

Highland Creek Wastewater Treatment Plant. (2017). Highland Creek Wastewater Treatment Plant: 2016 Annual Report. Annual Report, Toronto Water, Toronto.

Holems, P. A. (1985). Applications of PHB - A Microbially Produced Biodegradable Thermoplastic. Physics in Technology, 16(1), 32. Retrieved 2017

Holmes, P. A. (n.d.). Applications of PHB - A Microbially produced Biodegradable Thermoplastic. Physics in T.

House, J. E., \& House, K. A. (2011). Nitrogen. Descr. Inorgarnic Chemistry, 277-299.

Huang, Y. L., Wu, Z., Zhang, L., Cheung, C. M., \& Yang, S.-T. (2002, March). Production of Carboxylic Acids from Hydrolyzed Corn Meal by Immobilized Cell Fermentation in a Fibrous-Bed Bioreactor. Biosource Technology, 82(1), 51-59.

IWA Task Group for Mathematical Modelling of Anaerobic Digestion Processes. (2002). Anaerobic Digestion Model No.1 (ADM1). IWA Publishing. 
Jiang, G., Gutierrez, O., \& Yuan, Z. (2011). The strong biocidal effect of free nitrous acid on anaerobic sewer biofilms. Water Resources, 45(12), 3735-3743.

Jiang, S., Chen, Y., \& Zhou, Q. (2007). Effect of Sodium Dodecyl Sulfate on Waste Activated Sludge Hydrolysis and Acidification. Chemical Engineering Journal, 132, 311-317.

Jiang, S., Chen, Y., \& Zhou, Q. (2007). Influence of Alkyl Sulfates on Waste Activated Sludge Fermentation at Ambient Temperature. Journal of Hazardous Materials, 110-115.

Jiang, S., Chen, Y., Zhou, Q., \& Gu, G. (2007, July). Biological Short-Chain Fatty Acids (SCFAs) Production from Waste-Activated Sludge Affected by Surfactant. Water Research, 41(14), 3112-3120.

Kurniawan, A., Kwon, S. Y., Shin, J.-H., Hur, J., \& Cho, J. (2016, March 24). Acid Fermentation Process Combined with Post Denitrification for the Treatment of Primary Sludge and Wastewater with High Strength Nitrate. (Y.-T. Hung, Ed.) MDPI.

Law, Y., Ye, L., Wang, Q., Hu, S., Pijuan, M., \& Yuan, Z. (2015). Producing free nitrous acid - A green and renewable biocidal agent - From anaerobic digester liquor. Chemical Engineering Journal, 259, 62-69.

Lee, W. S., Chua, A. S., Teoh, H. K., \& Ngoh, G. C. (2014). A Review of the Production and Applications of Waste-Derived Volatile Fatty Acids. Chemical Engineering Journal, 235, 83-99.

Lei, L., Rabinowitz, B., Leaf, B., Bishop, R., \& Kresge, B. (2009). Primary Sludge Fermentation for Reliable Biological Phosphorus Removal. CH2MHILL.

Li, H., Li, C., Liu, W., \& Zou, S. (2012, November). Optimized alkaline pretreatment of sludge before anaerobic digestion. Biosource Technology, 123, 189-194.

Liu, H., Wang, J., Liu, X., Fu, B., Chen, J., \& Yu, H.-Q. (2012, March). Acidogenic Fermentation of Proteinaceous Sewage Sludge: Effect of pH. Water Research, 46(1), 799-807.

Long, H. (2010). Retrieved July 19, 2017, from http://water.me.vccs.edu/courses/ENV149/lesson4b.htm

Metcalf, \& Eddy. (2002). Wastewater Engineering: Treatment \& Reuse (4th Edition ed.). McGraw-Hill.

Miah, M. S., Tada, C., Yang, Y., \& Sawayama, S. (2005). Aerobic thermophilic bacteria enhance biogas production. J. Mater. Cycles Waste Manag., 7, 48-54. 
Morgan-Sagastume, F., Pratt, S., Karlsson, A., Cirne, D., Lant, P., \& Werker, A. (2011). Production of Volatile Fatty Acids by Fermentation of Waste Activated Sludge PreTreated in Full-Scale Thermal Hydrolysis Plants. Bioresource Technology, 102, 30893097.

Nebot, E., Romero, L. I., Quiroga, J. M., \& Sales, D. (1995). Effect of the Feed Frequency on the Performance of Anaerobic Filters.

Oktem, Y. A., Ince, O., Sallis, P., \& Ince, B. K. (2006, November). Determination of Optimum Operating Conditions of an Acidification Reactor Treating a Chemical Synthesis-Based Pharmaceutical Wastewater. Process Biochemistry, 41(11), 2258- 2263.

Peng, Z., Chen, Y., \& Zhou, Q. (2009, August). Waste activated sludge hydrolysis and shortchain fatty acids accumulation under mesophilic and thermophilic conditions: Effect of pH. ScienceDirect, 43(15), 3735-3742.

Pijuan, M., Wang, Q., Ye, L., \& Yuan, Z. (2012). Improving secondary sludge biodegradability using free nitrous acid treatment. Bioresour Technol, 116, 92-98.

Pijuan, M., Ye, L., \& Yuan, Z. (2010). Free nitrous acid inhibition on the anerobic metabolisn of poly-phosphate accumulation organisms. Water Research, 44(20), 6063 - 6072.

Ravindra, P. (Ed.). (2015). Advances in Bioprocess Technology. Switzerland: Springer Inthernational Publishing.

Reeta Rani Singhania, Anil Kumar Patel, Gwendoline Christophe, Pierre Fontanille, \& Christian Larroche. (2013). Biological Upgrading of Volatile Fatty Acids, Key Intermediates for the Valorization of Biowaste through Dark Anaerobic Fermentation. Bioresource Technology, 145, 166-174.

Salehizadeh, H., \& Van Loosdrecht, M. M. (2004). Production of Polyhydroxyalkanoates by Mixed Culture: Recent Trends and Biotechnological Importance. Biotechnology Advances, 22(3), 261-279.

Stanbury, P. F., Whitaker, A., \& Hall, S. J. (1995). Principles of Fermentation Technology

(Vol. III). New York: Butter-Worth-Heinemann.

Statistics Canada. (2016). Estimates of population by census metropolitan area, sex and age group for July 1, based on the Standard Geographical Classification (SGC) 2011.

Tchobanoglous, G., Burton, F. L., Stensel, H. D., \& Metcalf \& Eddy. (2002). Wastewater Engineering: Treatment and Reuse (4th Edition ed.). Toronto: Dubuque IA: McGraw- 
Hill.

Toreci, I., Kennedy, K. J., \& Droste, R. L. (2009, March 5). Evaluation of continuous mesophilic anaerobic sludge digestion after high temperature microwave pretreatment. Water Research, 43(5), 1273-1284.

Turovskiy, I. S., \& Mathai, P. K. (2006). Wastewater Sludge Processing. 31-45.

Valo, A., Carrere, H., \& Delgenes, J. P. (2004). Thermal, chemical and thermo-chemical pretreatment of waste activated sludge for anaerobic digestion. $j$. Chem. Technol. Biotechnol., 79(11), 1197-1203.

Wang, L., Mattson, M., Rundstedt, J., \& Karlsson, N. (2011). Different pre-treatments to enhance biogas production. Master of Sciennce Theisis, Halmstad University.

Wang, Q., Jiang, L., \& Yuan, Z. (2014). Enhancing methane production from waste activiated sludge using combined free nitrous acid and heat pre-treatment. Water Resources, 63, 71-80.

Wang, Q., Ye, L., Jiang, G., Jensen, P. D., Bastone, D. J., \& Yuan, Z. (2013, September 17). Free Nitrious Acid (FNA)-based pretreatment enhannces methane production from waste activated sludge. Environmental Science \& Technology, 11897 - 11904.

Weiland, P. (2010). Biogas Production: Current State and Perspectives. 849-860.

Wu, H., Yang, D., Zhou, Q., \& Song, Z. (2009, December 15). The Effect of pH on Anaerobic Fermentation of Primary Sludge at Room Temperature. ScienceDirect, 172(1), 196201.

Xu, G., Chen, S., Shi, J., Wang, S., \& Zhu, G. (2010). Combination treatment of ultrasound and ozone for improving solubilization and anerobic biodegradablility of waste activated sludge. J. Hazard Mater, 180(1-3), 340-346.

Xu, J., Yuan, H., Lin, J., \& Yuan, W. (2014). Evaluation of thermal, thermal-alkaline, alkaline and electrochemical pretreatment on sludge to enhance anaerobic biogas production. $J$. Taiwan Inst. Chem. Eng, 45(5), 2531-2536.

Yi, H., Han, Y., \& Zhuo, Y. (2013). Effect of combined pretreatment of waste activated sludge for anaerobic digestion process. Procedia Environ. Sci, 18, 716-721.

Yuan, Q., Sparling, R., \& Oleszkiewicz, J. A. (2011). VFA Generation from Waste Activated Sludge: Effect of Temperature and Mixing. Chemosphere (82), 603-607. 
Zhang, P., Chen, Y., \& Zhou, Q. (2009, August). Waste Activated Sludge Hydrolysis and Short-Chain Fatty Acids Accumulation under Mesophilic and Thermophilic Conditions: Effect of pH. Water Research, 43(15), 3735-3742.

Zigová, J., Vandák, D., Schlosser, Š., \& Šturdík, E. (1999, October). Butyric Acid Production by Clostridium butyricum with Integrated Extraction and Pertraction. Process Biochemistry, 34(8), 835-84 